\title{
VOICES OF YOUNG ENVIRONMENTALISTS: \\ A GENERATIONAL PERSPECTIVE ON ENVIRONMENTALISM
}

\author{
by
}

\section{PETER ROBINSON}

A Dissertation Submitted to the Faculty of Social and Applied Sciences in Partial Fulfilment of the Requirements for the Degree of

DOCTOR OF SOCIAL SCIENCES

Royal Roads University

Victoria, British Columbia, Canada

Supervisor: Dr. GORDON SMITH

SUMMER, 2014

(C) Copyright PETER ROBINSON, 2014 


\section{COMMITTEE APPROVAL}

The members of PETER ROBINSON's Dissertation Committee certify that they have read the dissertation titled VOICES OF YOUNG ENVIRONMENTALISTS: A GENERATIONAL PERSPECTIVE ON ENVIRONMENTALISM and recommend that it be accepted as fulfilling the dissertation requirements for the Degree of Doctor of Social Sciences:

Dr.Gordon Smith [signature on file]

Dr. Brian Belcher [signature on file]

Dr. Alex Himelfarb [signature on file]

Dr. Tina Loo [signature on file]

Final approval and acceptance of this dissertation is contingent upon the candidate's submission of the final copy of the dissertation to Royal Roads University. The dissertation supervisor confirms to have read this dissertation and recommends that it be accepted as fulfilling the dissertation requirements:

Dr. GORDON SMITH [signature on file] 
(CC) (cc) (i) (c) (-)

This work is licensed under the Creative Commons Attribution-NonCommercialShareAlike 2.5 Canada Licence.

You are free:

- To share: to copy, distribute, and transmit the work

- To Remix: to adapt the work

Under the following conditions:

- Attribution: You must attribute this work in the manner specified by the author or licensor (but not in any way that suggests that they endorse you or your use of the work).

- Non-commercial: You may not use this work for commercial purposes.

- Share Alike: If you alter, transform, or build upon this work, you may distribute the resulting work only under the same or similar licence to this one.

With the understanding that:

- Waiver: Any of these conditions can be waived with the permission from the copyright holder.

- Public Domain: Where the work or any of its elements is in the public domain under applicable law, that status is in no way affected by the licence.

- Other Rights - In no way are any of the following rights affected by the licence:

○ Your fair dealing or fair use rights, or other applicable copyright exceptions and limitations;

○ The author's moral rights;

- Rights other persons may have either in the work itself or in how the work is used, such as publicity or privacy rights.

Some material in this work is not being made available under the terms of this licence:

- Third-Party material that is being used under fair dealing or with permission.

- Any photographs where individuals are easily identifiable. 


\begin{abstract}
Modern environmentalism, a conceptual lens through which to view the human relationship with the natural world, has deep roots in the period of social movement building that swept Western nations during the late 1960s and early 1970s. Over the past half century it has evolved to include new perspectives and face new environmental challenges. More recently, it has been less effective in tackling significant global environmental problems. Fifty years on, a younger generation of environmentalists is now addressing contemporary environmental issues, and developing its own interpretation of how environmentalism can be a force for social change. Through a phenomenological study of 20 young adults from British Columbia who care about the environment, the research focuses on how the group views modern environmentalism. The findings indicate that the participants believe environmentalism is in transition, and they are optimistic about their role in the changes that are under way. The emerging interpretation retains strong continuity with the past, but notably emphasizes people, a deeply personal view of how one lives a sustainable life, a new localism, a focus on community organizing grounded in social media, and a hopeful narrative predicated on solutions. The results suggest that with the entry of a new generation of environmentalists, environmentalism will continue to evolve as a durable and relevant worldview.
\end{abstract}




\section{Table of Contents}

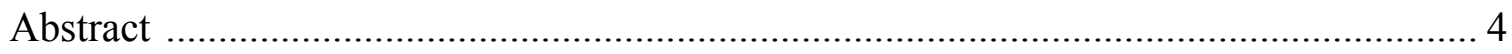

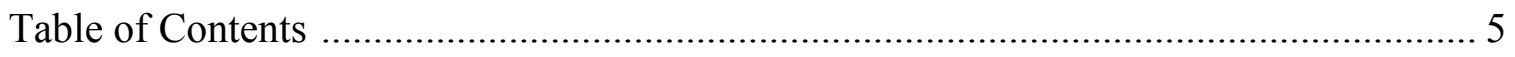

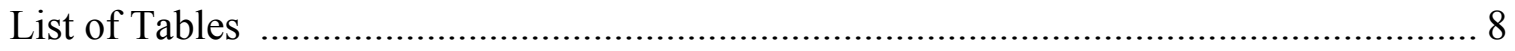

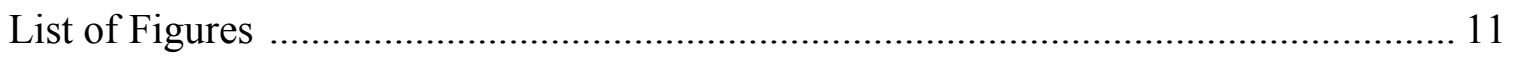

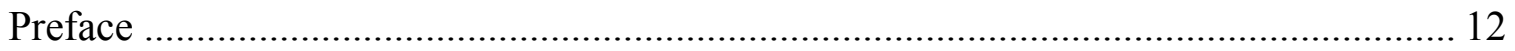

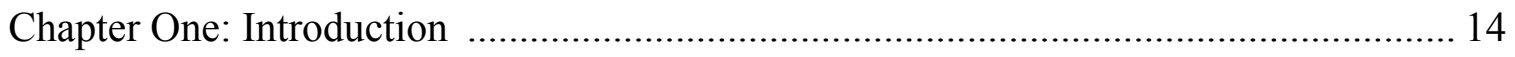

Research Purpose and Questions ...................................................................... 16

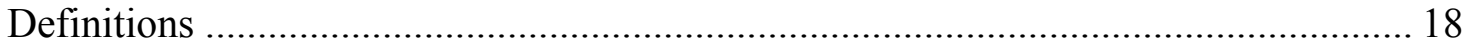

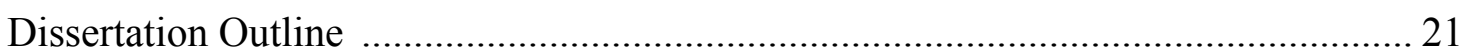

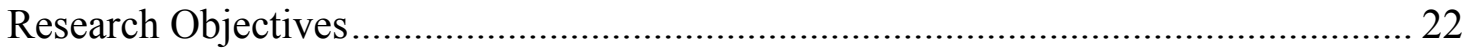

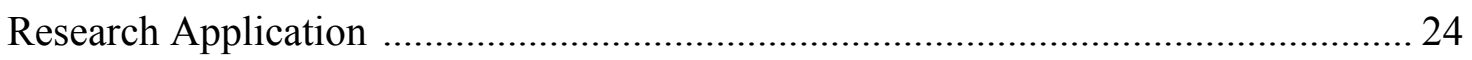

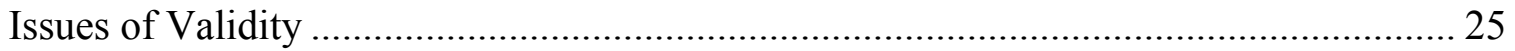

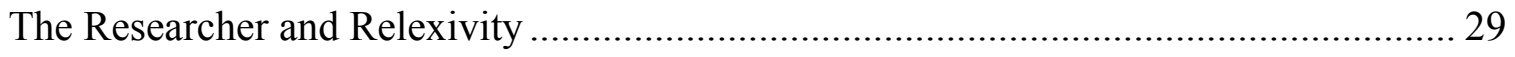

Chapter Two: Literature Review ........................................................................ 32

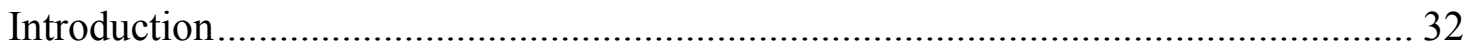

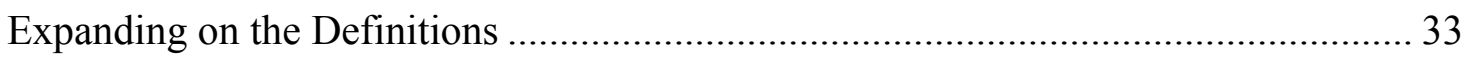

The Historical Context of Modern Environmentalism .......................................... 48

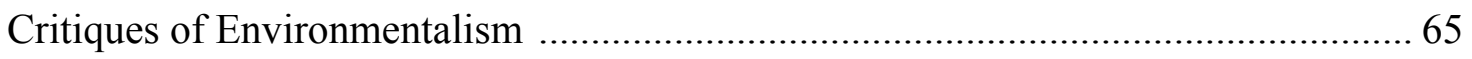

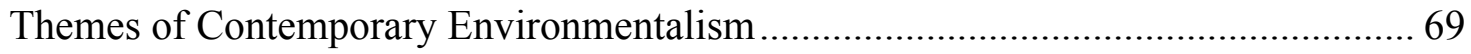

Future Visions of Environmentalism ............................................................... 72

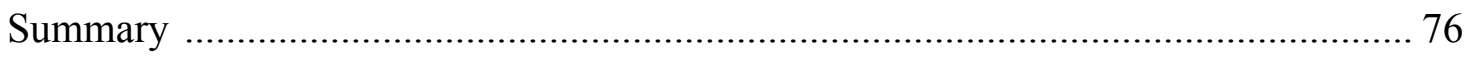




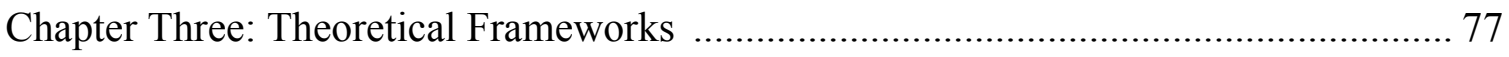

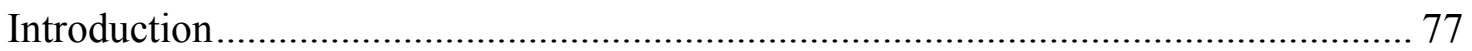

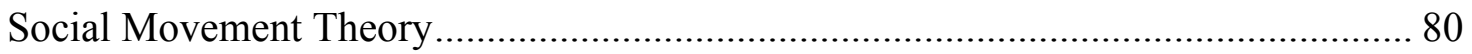

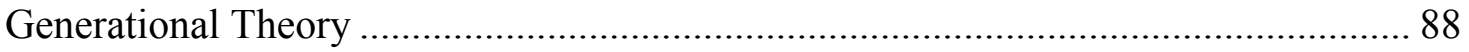

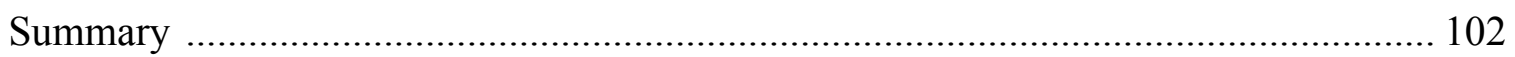

Chapter Four: Research Design .......................................................................... 104

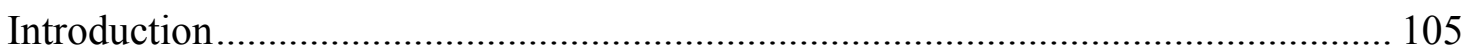

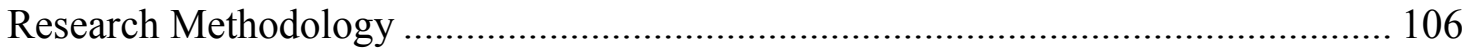

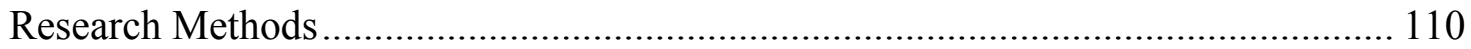

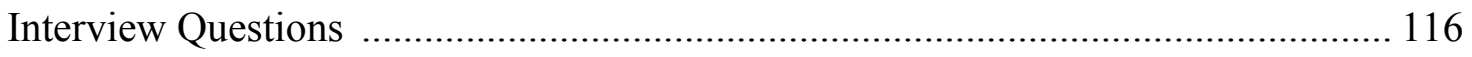

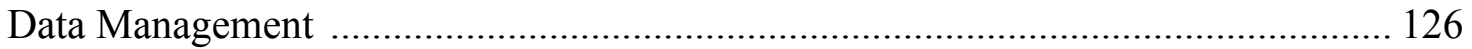

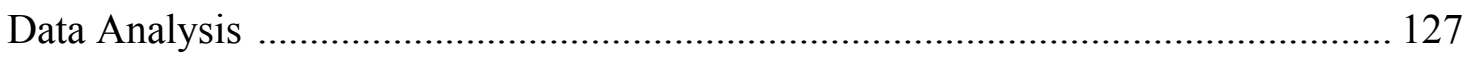

Data Reliability - Trustworthiness and Rigour .................................................. 129

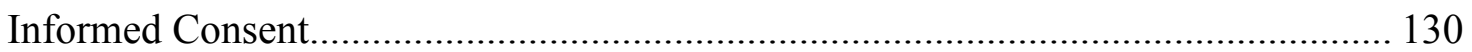

Integrating the Literature, Theoretical Frameworks, and the Interviews ................. 131

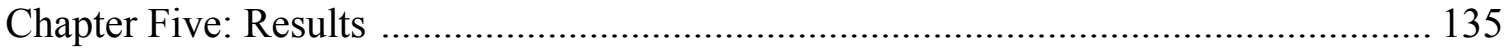

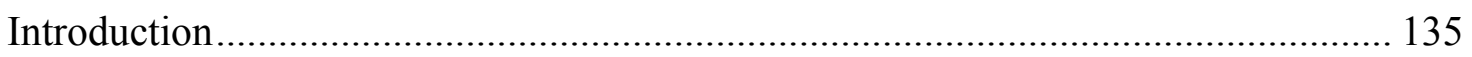

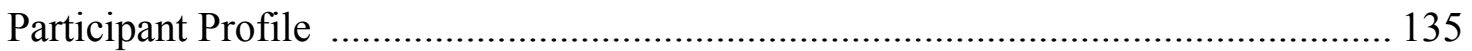

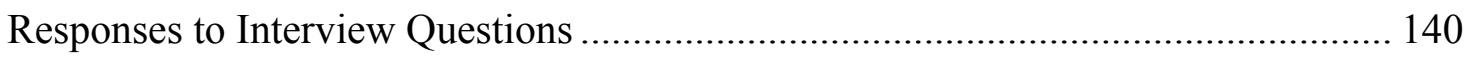

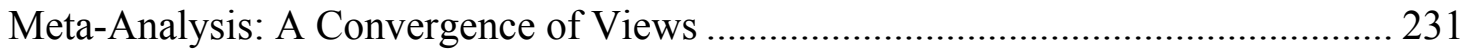

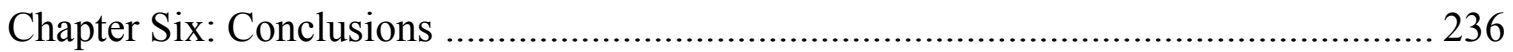

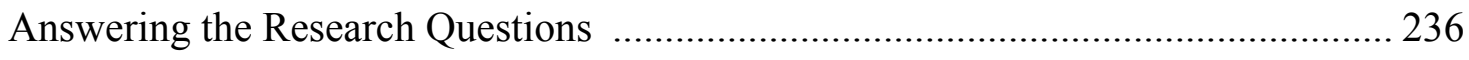

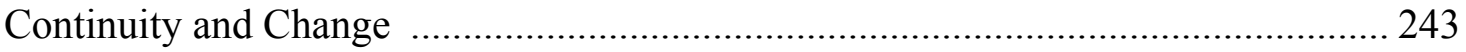




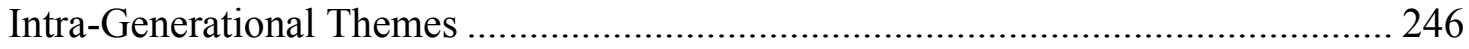

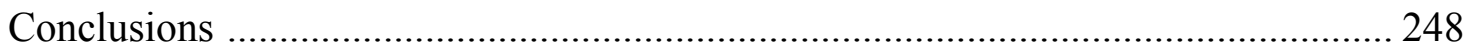

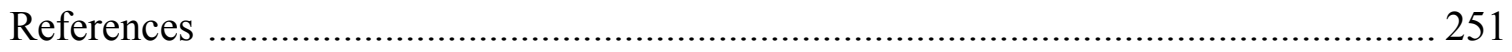

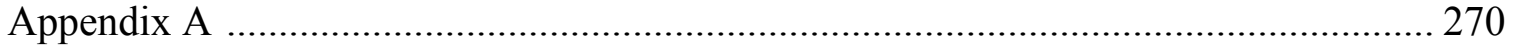

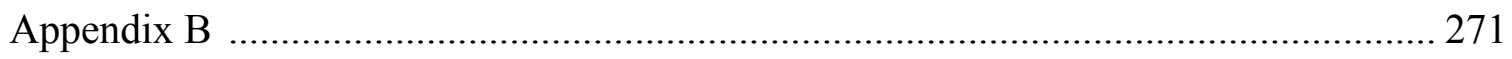




\section{List of Tables}

Table 1. Clusters of Environmentalism Recognized by Martinez-Alier (2000) .............. 82

Table 2. Characteristics of Social Movements ........................................................... 82

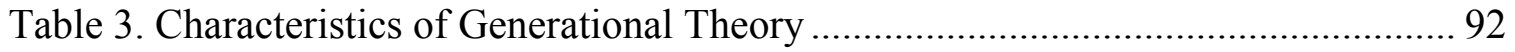

Table 4. Participant Profile by Age, Gender, Ethnicity, and Education ........................ 137

Table 5. Participant Environmental Clusters, Adapted from Martinez-Alier................. 138

Table 6. Participant Profile Adjusted for Environmental Interest ............................... 139

Table 7. Sample Comments: Playing Outdoors .................................................... 143

Table 8. Sample Comments: The Outdoor Experience ............................................ 144

Table 9. Participant Comments: Call to Action ....................................................... 146

Table 10a. Participant Comments: Environmentalism Is in Transition........................ 151

Table 10b. Subgroups: Environmentalism Is in Transition ...................................... 152

Table 11a. Participant Comments: Environmentalism Is Deeply Personal ................... 153

Table 11b. Subgroups: Environmentalism Is Deeply Personal .................................. 154

Table 12a. Participant Comments: Stewardship and Sustainability ............................ 155

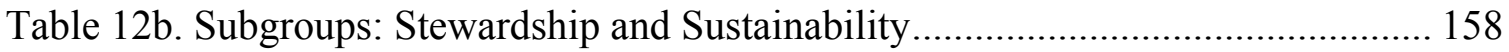

Table 13a. Participant Comments: Sustainability Is Personal Awareness..................... 160

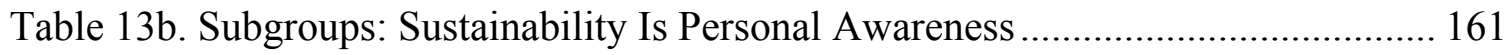

Table 14a. Participant Comments: Personal - How I Live My Life ............................ 165

Table 14b. Subgroups: Personal - How I Live My Life.......................................... 165

Table 15a. Participant Comments: Networks - Family, Friends, and Community ........ 167

Table 15b. Subgroups: Networks - Family, Friends, and Community ........................ 168

Table 16a. Participant Comments: Interdependence and Interconnection..................... 169 
Table 16b. Subgroups: Interdependence and Interconnection .................................. 170

Table 17a. Participant Comments: Societal Norms and Systems ................................ 172

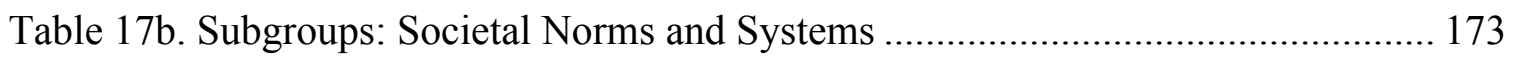

Table 18a. Participant Comments: Personal Barriers ............................................ 174

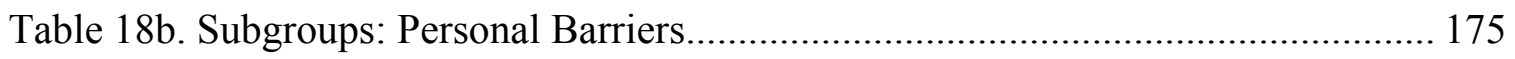

Table 19. Participant Comments: Environmental Health Is Poor................................. 179

Table 20a. Participant Comments: Environmental Health Is Better Locally................. 180

Table 20b. Subgroups: Environmental Health Is Better Locally ................................ 181

Table 21a. Participant Comments: Motivation and Opportunity ................................. 185

Table 21b. Subgroups: Motivation and Opportunity .............................................. 186

Table 22a. Participant Comments: Sadness and Despair.......................................... 186

Table 22b. Subgroups: Sadness and Despair ........................................................ 187

Table 23. Subgroups: Environmental Challenges Could Have Been Avoided .............. 189

Table 24a. Participant Comments: No Blame Can Be Ascribed ................................. 190

Table 24b. Subgroups: No Blame Can Be Ascribed.................................................. 190

Table 25a. Participant Comments: A Diverse Mass of People..................................... 194

Table 25b. Subgroups: A Diverse Mass of People ..................................................... 195

Table 26a. Participant Comments: The Movement Is in Transition ............................. 196

Table 26b. Subgroups: The Movement Is in Transition ............................................ 197

Table 27a. Participant Comments: A Concern for People ......................................... 206

Table 27b. Subgroups: A Concern for People ...................................................... 207

Table 28a. Participant Comments: A New Story of Environmentalism ....................... 209

Table 28b. Subgroups: A New Story of Environmentalism .................................... 210 
Table 29a. Participant Comments: Community Engagement..................................... 211

Table 29b. Subgroups: Community Engagement ................................................. 212

Table 30. Participant Comments: Are You Pessimistic or Optimistic........................... 213

Table 31a. Participant Comments: Environmentalism Becomes Mainstream............... 218

Table 31b. Subgroups: Environmentalism Becomes Mainstream ............................... 218

Table 32a. Participant Comments: Opportunities to Effect Change Exist...................... 224

Table 32b. Subgroups: Opportunities to Effect Change Exist................................... 225

Table 33a. Participant Comments: Technologically Savvy ........................................ 226

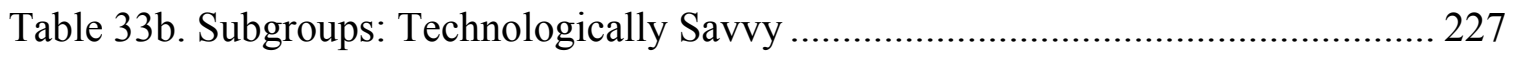

Table 34a. Participant Comments: A Shift Is Happening .......................................... 228

Table 34b. Subgroups: A Shift Is Happening ........................................................ 229

Table 35. Summary of Themes - Younger vs. Older Environmentalist....................... 247 


\section{List of Figures}

Figure 1. Themes - What is environmentalism to you? ............................................. 148

Figure 2. Themes - What does a sustainable life look like for you? .......................... 158

Figure 3. Themes - What beliefs, values, or experiences motivate \& shape you?........ 163

Figure 4. Themes - What stands in the way of you living a sustainable life?............... 171

Figure 5. Themes - How do you perceive the current health of the environment?........ 176

Figure 6. Themes - How do you feel about this? ..................................................... 183

Figure 7. Themes - Could the environmental challenges have been avoided? ............. 188

Figure 8. Themes - How would you describe the environmental movement?.............. 192

Figure 9. Themes - Strengths of the environmental movement ................................ 198

Figure 10. Themes - Weaknesses of the environmental movement ............................ 199

Figure 11. Themes - How could the environmental movement be more effective? ...... 201

Figure 12. Themes - How do you perceive the future of environmentalism?.............. 203

Figure 13. Themes - What would be needed to achieve the future you described?....... 215

Figure 14. Themes - How would you describe your generation? ................................ 220 


\section{Preface}

I grew up in a suburban neighbourhood in North Vancouver, next to a forest that rose up and over the local mountains. Much of my childhood was spent in that forest, and through it I gained an appreciation of the natural world. Early on, I decided I wanted to work in a field that touched on the environment.

I am also part of the generation that came of age in the late 1960s and early 1970s, a remarkable period of cultural change, social protest, and movement building in the Western world. Modern environmentalism is itself a product of that time.

The confluence of my childhood experiences and the emergence of modern environmentalism influenced my choices of education and work. However, in 1971, the year I started my working career, environmental professions as we now understand them (i.e., in the government, business, academic, and the non-profit sectors) did not yet exist. They are themselves an outcome of the circumstances and events that launched environmentalism on its trajectory.

As a result, my first job was in a traditional conservation setting, as a park ranger working throughout British Columbia in what was then called the Department of Recreation and Conservation (the first provincial Department of the Environment did not appear until 1976). Furthermore, my first post-secondary education was a diploma in Fish, Wildlife \& Recreation Management, a program offered by the British Columbia Institute of Technology. These experiences illustrate how much the environmental field has changed, from a focus on conservation to one that now includes sustainability, technology, economics, behavioural sciences, and law. 
My career went on to span a variety of leadership roles in government and business, and eventually I came to head up a Canadian environmental organization - the David Suzuki Foundation. My decision to study environmentalism was primarily motivated by a desire to apply the findings to my work. Over the course of the research, I interacted with a group of bright and passionate young people who care deeply about the environment. Their interpretation of environmentalism and the environmental movement has been both instructive and encouraging. It has led me to alter my perspective about the merits and successes of environmentalism both as a way to conceptualize the human relationship with the natural world and as the foundation for a diverse social movement that seeks to change economic and political systems.

The research has likewise changed the way I regard the mission of the David Suzuki Foundation. I have come to view it as a longer-term project to shift the way people think and act about the environment, rather than the pursuit of short-term, isolated goals. From the perspective of qualitative research, I have undertaken a collaborative inquiry with research participants, improved my personal understanding and practice, and incorporated the results into the field in which I work. This is applied research.

I want to acknowledge the members of my committee for their ongoing support and thoughtful suggestions throughout the research process (Dr. Gordon Smith, Dr. Brian Belcher, Dr. Alex Himelfarb, and Dr. Tina Loo). I also want to recognize Dr. David Suzuki for our ongoing conversations on the subject of environmentalism - his remarkable perspective continues to inspire and challenge me. Most importantly, I want to thank the 20 participants. Through their voices and words, they have given me optimism about the future of environmentalism as a hopeful force for social change. 


\section{Chapter One: Introduction}

In 2004, American environmental policy experts Ted Nordhaus and Michael Shellenberger published an article that sparked a controversial debate within the environmental community. Titled The Death of Environmentalism (Shellenberger \& Nordhaus, 2004), it claimed that "modern environmentalism, with all of its unexamined assumptions, outdated concepts and exhausted strategies, must die so that something new can live" (Shellenberger \& Nordhaus, 2004, p. 3). In late 2013, Maclean's magazine ran an issue with a photo of Canadian scientist and broadcaster David Suzuki on the cover, under the banner "Environmentalism Has Failed." Inside, Suzuki claimed, "We've come to a point where things are getting worse, not better" (Gatehouse, 2013, p. 65). These are but two examples of a sustained critique of environmentalism that extends back to at least the 1980s (Dunlap, 2004). Wissenburg and Levy (2004) drew attention to this tension when they concluded, "Environmentalism as a counter-movement and counter-ideology, as a critique and alternative to capitalism, liberalism, the Enlightenment and anthropocentrism, it would then seem, is at an end. And yet it still exists" (p. 194).

This combination of existential crisis and continued existence is the starting point for my dissertation. The claims for the death of environmentalism occur at the end of a period of remarkable success. Over a half century environmentalism has become deeply embedded in popular discourse, governments across the globe have established environmental agencies and regulatory regimes, schools teach environmental programs, businesses have created environmental and sustainability departments, households practise recycling and energy conservation, and individuals work in fields that have an environmental focus. 
But things do seem stalled. There is mounting scientific evidence that many environmental indicators are moving in the wrong direction. Much of the key legislation designed to protect the environment in Western nations was put in place during the 1970s, and the ability to introduce new policies to address climate change, the transition to clean energy systems, the reduction of toxic pollutants, the degradation of critical ecosystem services, and the loss of biodiversity has proven to be a challenge. The seeming inability to take collective action at the national and supranational level is occurring even as scientific evidence indicates the detrimental ecological impact of many human activities (Millennium Ecosystem Assessment, 2005; IPCC, 2007, 2013). Furthermore, broad public concern for the environment has been repeatedly tested in recent years by a focus on the economy and security.

According to social movement theory, it is at such times that worldviews either adapt to new circumstances in order to continue, or lose their relevance and power to inspire. McAdam and Scott (2005) argue that "no movement ever manages to 'succeed' to fulfill all of the hopes of those who laboured to instigate institutional change. Goals are transformed as they are translated, and today's 'victories' give rise to tomorrow's disappointments, provocations, and - eventually - to new reform efforts” (p. 40).

From this perspective, something different seems to be happening in the environmental movement. Yes, it has adapted over the past few decades. But in this period of stall, what seems to be the major source of change is not so much deliberate adaptation to demanding circumstances, as a generational shift in outlook and approach. Nor do the current challenges seem to be threatening the demise of the movement. It continues even as it is being, potentially at least, transformed by a new generation. 
The theoretical literature generally describes how social movements adapt or fail, how they become institutionalized, and how participants gain or lose steam. The literature focuses on how movements are transformed by external events, by successes and failures, and by the changing interests of their members over their lifespans. What is missing from much of this analysis is an understanding of how movements evolve as a consequence of changes in the membership itself, specifically as a new generation displaces the old leadership. This is likely because many movements, particularly single-issue movements, have short lifespans - they do not last for multiple generations. Environmentalism has been successful if only by being durable, and is now attracting a new generation of participants. An understanding of the evolution of environmentalism, therefore, will require an understanding of who these new participants are, and how they view environmentalism and its future. In theoretical terms, social movement theory can benefit from an infusion of generational theory.

\section{Research Purpose and Questions}

My motivation to study this subject arose out of conversations with young environmentalists I encountered at the David Suzuki Foundation. Through interactions with this group, I became aware that their approach to environmental issues might have a generational dimension. I was curious to know how young people might be interpreting environmentalism, and what experiences might inform their views.

I hypothesized that a new generation of environmentalists might see environmental challenges and solutions differently than the leaders who had built the movement. Generational theory suggests that as the younger group members assume 
leadership of the environmental movement, their views will become increasingly prevalent.

In this context, the purpose of my research is to gain insight into how young people who care about the environment interpret environmentalism, and to apply the findings to the field in which I work. Through a phenomenological study of a group of individuals in their twenties, a review of the literature concerning the emergence and evolution of modern environmentalism, and the use of social movement and generational theory as interpretive frameworks, the research addresses the following questions:

1. How are young people who care about the environment interpreting environmentalism?

2. Does this interpretation differ from the depiction of modern, mainstream environmentalism?

3. How do the personal beliefs, values, and experiences of the research participants contribute to their understanding of environmentalism?

4. Does this suggest a generational shift in thinking, and what are the implications for the future of environmentalism?

These questions are of professional relevance to me. I work in a field where the response to the environmental challenges of climate change and the degradation of critical ecosystem services requires new ways of thinking to achieve the outcomes needed. I also direct an environmental organization that is experiencing a generational shift in the work force. I seek to learn how environmentalism is recognized and being applied by the generation of environmentalists that will lead the movement in the coming decades. The need for young people to be involved in shaping and changing 
environmentalism is echoed by Nordhaus and Shellenberger (2007), who note that "with young and grassroots environmentalists ... there's a new hope that we will soon see the emergence of a more expansive, relevant, and powerful ecological movement" (p. 128).

At stake are many of the challenges that face modern environmentalism. These include whether it can continue as a force for change, and how a younger generation of environmentalists can become more effective in stimulating the kinds of social, political, and economic changes that will be necessary to address future environmental issues. This is particularly relevant given the generational impulses that were inherent in the Occupy Wall Street movement that emerged in late 2011, and the Idle No More movement that arose among Aboriginal people in Canada in 2012.

The timeliness of the research should be apparent. We are about to experience an enormous shift over the coming decades as the members of the generational bubble that defined the last half century retire from their careers and are replaced by an equally large cohort consisting of their children. Lincoln and Denzin (2008) note this pending generational shift as one of the major issues that will characterize the future of qualitative research, but the change extends to all areas of society.

\section{Definitions}

The terms environmentalism, environmental movement, and environmentalist are used throughout this dissertation. Unfortunately, the meanings of these terms are often conflated to include both a conceptualization of environmental thinking and the actions undertaken to address environmental challenges. Such thinking tends to blur environmental activities with the underlying philosophical and intellectual framework. 
Furthermore, the terms environmentalism and environmental movement are contested. There is disagreement among some in the broader environmental community about the correct approach, practice, and outcomes of environmentalism. In this dissertation, I define environmentalism, the environmental movement, and environmentalist as follows (the terms are further elaborated in Chapter Two). They reflect a Western world characterization, as modern environmentalism has its formative roots in the United States and other Western nations (Eder, 1988; Haq \& Paul, 2012; Hays, 1987; MacDowell, 2012; Peterson del Mar, 2006; Rome, 2003, 2013; Taylor, 2010; Worster, 1994).

\section{Environmentalism.}

I define environmentalism as a way to conceptualize the human relationship with the natural world, a critique of the excesses of modern industrial societies, and the foundation for a diverse social movement seeking to change economic and political systems. In this definition, humans are embedded in nature, and the natural world is viewed as something to be celebrated and protected.

The definition is broad enough to accommodate a variety of environmental views and forms (what Martinez-Alier, 2002, calls clusters), while also allowing for the addition of perspectives that has occurred over the past five decades. I acknowledge that environmentalism as I define it is only one way to conceptualize the human relationship with nature. Other worldviews exist based on religious, spiritual, and animistic beliefs. There are also perspectives that portray nature as a resource for humans to extract and use, or that consider the natural world as something to fear and dominate. My definition, 
which I expand on in Chapter Two, reflects how mainstream writers and environmentalists have depicted it.

\section{Environmental movement.}

I define the environmental movement as the manifestation of environmentalism. It includes the pioneer thinkers who articulated the philosophical and intellectual foundation for the movement through a range of views, from nature as sublime to nature as incompatible with modern industrial society. It is a social movement made up of the early leaders who encouraged collective action; the mass of individuals who came together to celebrate the beauty and wonder of the natural world, and to protest what they saw as its degradation and destruction; and the organizations that have emerged to research into, organize for, and advocate around environmental issues.

This definition has a temporal dimension. It implies both the present form of the environmental movement and a connection to its history. I believe it is necessary for those involved in a social movement that extends over decades to know its origins and its subsequent trajectory in order to envision how the movement can learn and adapt. Dunlap (2004) echoes this sentiment, noting "only if we understand where it [environmentalism] comes from can we understand what it is and think effectively about where it might go" (p. 11).

\section{Environmentalist.}

I define an environmentalist as an individual who undertakes purposeful actions in support of their environmental beliefs and concerns - whether they self-identify as an environmentalist or not. This definition reflects that there is not another generally recognized label for someone who acts on his or her environmental beliefs (interestingly, 
only 8 of the 20 the participants in my research self-identified themselves as environmentalists - even though they all deeply care about environmental issues).

The term environmentalist has increasingly become synonymous with the term activist, which has repercussions both for environmentalism as a worldview and for a movement that seeks to reach a broader constituency. I expand on this challenge in Chapter Two.

\section{Dissertation Outline}

Chapter One provides the context for the dissertation. It sets out the research purpose and questions, as well as definitions for key terms that are referred to throughout the study. I raise possible validity issues inherent in the research, and suggest how they can be viewed and addressed. I conclude the chapter with a reference to objectivity, as it is important to acknowledge that I am both researching the evolution of environmentalism and leading an environmental organization. Addressing the perception of bias and objectivity at the outset is therefore an important consideration.

In Chapter Two, I review the literature on environmentalism. This review includes an elaboration of the definitions of environmentalism, environmental movement, and environmentalist introduced in Chapter One, together with an historical context for the evolution of environmental thinking over the past century. I also present a portrait of contemporary environmentalism and the various critiques that have emerged, as well as how a number of writers envision the future. Later in the dissertation, I will contrast how the research participants understand environmentalism with how it is portrayed by academics and environmentalists. 
In Chapter Three, I outline two theoretical frameworks that have guided my research - social movement theory and generational theory. Social movement theory describes how issues grow from small groups of people, to larger collective actions. It also provides a reference for how movements reframe issues and adapt to new circumstances in order to remain relevant. Generational theory explains how generational cohorts from distinct time periods define themselves and the world around them. An understanding of how social movements emerge and evolve, and how social change can be viewed as a consequence of generational replacement, can be applied to my research.

Chapter Four outlines the research design, focusing on phenomenology as the research methodology and participant interviews as the method used. I outline how participants were recruited, and the process of phenomenological reduction, data coding, and analysis. The rationale for the 14 questions asked is provided, together with a reference to data reliability.

Chapter Five presents the research results, including a profile of the group based on the members' attributes and environmental perspectives, and a summary of the dominant themes that emerged from the interviews. In Chapter Six, I conclude with the findings of the dissertation, together with several implications for the future.

\section{Research Objectives}

There were two research objectives that contributed to answering the research questions.

1. The first was to build a profile of young adults (i.e., those born after 1981) who are currently involved with, and care about, environmental issues. The resulting profile is from a Canadian (British Columbia) perspective, and was achieved through a 
combination of participant demographic data, and a phenomenological approach in which the individuals responded to open-ended research questions. This particular approach allows the researcher to summarize the subjective viewpoint of a participant's experience, and results in descriptions from which meanings can be ascribed. I analyzed the meanings that emerged through the participant's stories and descriptions to derive a number of primary themes. The outcome was a set of views representative of the group studied, regardless of the individual's personal circumstances or environmental interests. I cannot claim that these views represent all environmentalists in this age cohort, but they do offer a glimpse that is helpful to understanding a younger perspective.

2. A second objective was to review the literature concerning the evolution of environmentalism and the environmental movement over the past five decades in order to arrive at a context against which the views of the participants can be compared. The literature shows that environmentalism and the environmental movement have largely evolved through accretion instead of substitution, and that contemporary environmentalism is therefore an aggregation of views and goals. I contrast the literature with the primary themes of the research participants to determine if they represent new views, or whether they might indicate environmentalism is being more narrowly interpreted and focused. Generational theory would predict that if such views represent a strong consensus among young people who care about and are active on environmental issues, then generational replacement will help the emerging perspective become increasingly prevalent in the environmental community over time. 


\section{Research Application}

The Royal Roads University Doctor of Social Sciences program is described as “Canada's first applied research doctorate designed exclusively for working professionals. It responds to the growing demand nationally and internationally for scholar-practitioners who can provide intellectual leadership in the workplace and help build sustainable organizations, communities, and societies in an age of global interdependence" (Royal Roads University, 2014). My approach to the research was guided by the program design, as my intent was to apply the findings to the field in which I work - something I have done concurrently with the research project. In reviewing the literature, I could not discern a body of research that looked in depth at how a younger generation of people who care about the environment interpret and apply their understanding of environmentalism. The research therefore represents an important step toward understanding how environmentalism is evolving, and how such change is apparent among younger individuals.

In this context, the research can support a number of applications. The first relates to my role with the David Suzuki Foundation. The organization's work is primarily concerned with promoting the creation of a more sustainable society within a generational time frame. As individuals currently in their twenties will be leading the institutions that form the basis of our economic, political, and educational systems in the coming decades, it is helpful to understand how those who will shape the environmental community in the future have begun to conceptualize their own environmental perspective. Many of the research findings have helped inform organizational decisions I 
have made over the past four years. These include choices about work, structure, partnerships, social media outreach, and employee recruitment practices.

A related application has to do with the work of the David Suzuki Foundation within the broader community. The organization's projects and programs have the ability to integrate a generational dimension in their outcomes. As the intent is to achieve a shift in environmental attitudes and actions within a generation, then specifically engaging a younger generation will be critical to success. In this context, understanding how young environmentalists might conceptualize their place in the natural world can contribute to the organization's longer-term goals.

A third application is to seed further research with respect to generational shifts in awareness and attitude - not just for environmental issues, but social and economic ones as well. We have witnessed a number of nascent societal conflicts in Canada in recent years that have an inherent generational dimension (e.g., Occupy, student protests in Quebec, and Idle No More). Such tensions raise the spectre that other conflicts may arise in the near future, as a large generational cohort (i.e., the Baby Boomers) retires, and an equally large cohort (i.e., the children of Baby Boomers) enters adulthood. Further research about the possibility of intergenerational conflict will be of importance to those who study such phenomena.

\section{Issues of Validity}

There are a number of validity issues that need to be identified at the start. I address them here, as they are relevant to findings that emerge through the dissertation. 


\section{Sample.}

First, the participants do not represent the ideas and beliefs of all young people in their twenties (sometimes referred to as the Millennials, or Generation Y), nor was this the intent. As I note in Chapter Three, no generational cohort has a single worldview that can be applied across all geographies and personal circumstances. Rather, I focused on individuals who are already interested in, indeed passionate about, environmental issues. The research addresses what we might learn from this group of people, and how this can contribute to understanding how environmentalism might change in the future.

Second, a question may arise about the choice of participants, specifically that the sample may be biased or selective. The limitation would be that in asking community leaders and academics to suggest individuals who care deeply about environmental issues, the resulting suggestions will reflect the values and views of those who made the recommendations. Furthermore, the selection might omit young adults who represent views not represented by the study group. I attempted to mitigate this by approaching a wide variety of leaders who represent different perspectives. I did not ask for the names of prominent environmentalists, as I felt that might lead to a selection bias. Instead, I asked for the names of young people who care about, and are active on, environmental issues more broadly. The group that is profiled in Chapter Five indicates the variety of those who were interviewed. The participants include young adults who have a conservation background, and others who desire to solve environmental problems through policy and technological innovation, as well as individuals who have been active in the anti-globalization and the Occupy and Idle No More movements. The resulting diversity is not exhaustive of the possible viewpoints, but it does reflect a wide-ranging 
representation of ideas and interests. The intent of the research was to see if, among this group, there were common views, opinions, and beliefs shared by the participants.

\section{Extrapolation and replication.}

Following from the first limitation is the question of extrapolating the findings more broadly. The sample is from a specific geography, British Columbia, which has its own environmental history and challenges. I cannot claim that the results represent the views and beliefs of similarly aged cohorts in other locations. However, I note in Chapter Five a prominent finding that the participants are connected through a variety of networks, and are actively engaged in the exchange of ideas and actions. As a result of such networks among similarly minded individuals, it is plausible that the thinking reflected in the study has resonance in other geographic areas.

\section{Methodology.}

The intent of the research is to explore differences in worldviews, the deep meanings between two generations of environmentalists. There currently exists no literature, no empirical base, and therefore no framework from which a quantitative comparison can be drawn - or even hypotheses developed to be tested. Thus this thesis intends to pull out the main axes of differentiation that would enable immediate understanding and future quantitative research. Given this intent, a qualitative approach was adopted that allowed me to draw on my experience and networks in the environmental movement and on the extensive literature that my generation has produced. The challenge, however, was to get at the views of the new generation of environmentalists who have published relatively little, who often express their 
environmental commitments in more private ways than in the past, and who are less likely to join large organizations such as the one of which I am part.

To address this element of the research design, I adopted a phenomenological approach. Phenomenology is a methodology to describe and analyze how individuals conceptualize and understand various experiences. The researcher seeks to ascribe meaning(s) to a participant's responses, which are obtained through face-to-face interviews. I also include a synthesis of the primary themes (i.e., where over half the participants indicated a consistent interpretation or viewpoint) that emerged from the 14 questions asked.

The validity issue is that while I have created a profile of a younger generation, including how they make sense of environmentalism, I have not done the same for the older generation of environmentalists. Instead, I have contrasted the phenomenological experience of the participants against what the literature says about those who came before them - complemented by my personal experience in this field.

In effect, I am representative of the older group. I can draw on my experience over four decades, much of it in the environmental movement. I interact with others of my generation who are involved in environmental issues constantly; it's part of my job. My subjective experience is rich and long term, and much of it is professionally reflected. But to defend against the limitation that my views are subjective, I verified my views against what the literature of my contemporaries says. I also tested broad themes in informal conversations with colleagues. Such data were not available to yield an understanding of the new generation of environmentalists, and that required a much more intensive and specific approach. 


\section{Comparison to modern environmentalism.}

A critical element of the research is to contrast how 20-year-olds perceive environmentalism, against the context of modern environmentalism. The challenge here is in establishing a viable portrayal of what currently exists. In Chapter Two, I note that environmentalism is heterogeneous and diverse, and has tended to accommodate new outlooks, outcomes, and approaches - rather than reject them. It includes the worldviews and perceptions of Baby Boomers, but also those born before and after this cohort. The result is that forms focusing on wilderness preservation coexist with interpretations that emphasize environmental rights and justice. The comparison is therefore between the primary themes that emerged from the study group and the broader themes that characterize modern environmentalism. In addressing this limitation, I suggest that the evidence of a narrower focus might itself be an indication that environmentalism is evolving (i.e., the more focussed views held by a younger cohort contrast with the diverse perspective held by the broader environmental community). Furthermore, I would expect to see generational differences as they relate to the use of language, the application of technology, the presence of connected networks of like-minded individuals, and the approach to environmental challenges that can no longer be avoided (e.g., climate change). Such differences did emerge through the research, but so did unexpected themes of the deeply personal nature of environmentalism and a strong sense of optimism.

\section{The Researcher and Reflexivity}

I conclude this chapter with a word about researcher impartiality. Ahern (1999) notes that "Despite the realization that total objectivity is neither achievable nor necessarily desirable in qualitative research, researchers are required to put aside 
assumptions so that the true experiences of respondents are reflected in the analysis and reporting of research.” (p. 407). There were several dimensions to remaining neutral through the process - including the applied nature of the research (I work for an environmental organization), my position (I am the head of an environmental organization), and any bias or preconceptions I might bring to the research based on personal attributes (I am an older, white, middle-class male).

Theoretical practitioners of phenomenology note that researchers must take stock of their own involvement, interest, commitment, and bias with respect to the research, and that researchers will have their own conclusions about the material being analyzed (Groenewald, 2004; Moran, 2000; Moustakas, 1994). The active suppression - or what is termed bracketing - of a researcher's attitude is therefore an essential element of phenomenology (Ahern, 1999; Moran, 2000; Sokolowski, 2000; Tufford \& Newman, 2012).

With respect to the applied nature of the work and my position, there are a number of issues that arise from the proposed research. No matter how hard I strive to practise a neutral stance, I will bring my perceptions to the research. After all, I will be synthesizing the described experiences of the participants into a narrative in my own words, on an issue that reflects my professional involvement. To address this, I tried to maintain a conscious reflexive stance through active and regular journal entries that reflected my thoughts and impressions throughout the research. Tufford and Newman (2012) note that the "maintenance of a journal can enhance researchers' ability to sustain a reflexive stance" (p. 86). 
There is also the matter of the position I hold as the leader of the David Suzuki Foundation, which is an established environmental organization in Canada. My choice of methodology required that I interact with individuals with respect to their views on environmentalism, and this poses a challenge. To paraphrase Foucault et al., I am part of the power relation - and as a consequence I needed to be transparent about what I was doing, how I hoped to engage individuals, and what I intended to do with the resulting materials. I also needed to be aware of how my position did or did not create bias in the responses of those I interact with.

Finally, with respect to my age, gender, and ethnicity - I was aware of this throughout the research process, and practised considerable reflection to take account of my perspective on the interpretation of the research data. Ultimately, however, personal bias and perceptions will be present. As Ahern (1999) notes, "researchers are part of the social world they study" (p. 408). 


\section{Chapter Two: Literature Review}

\section{Introduction}

In this chapter, I draw on the extensive literature concerning environmentalism to integrate terminology, historical context, critiques, and future visions. I begin by developing the definitions of environmentalism, environmental movement, and environmentalist introduced in Chapter One. I then outline a context for modern environmentalism and the environmental movement in the Western world (with a focus on the United States and Canada), using the late 1960s and early 1970s as a key landmark. Both modern environmentalism and the environmental movement witnessed substantial increases in public awareness and participation during this period. This was a result of several factors, including postwar economic growth and affluence, the emerging scientific awareness of the impacts of industrial activity, and the appearance of a large and active generation of young people involved in social and cultural change.

I review some of the early ideas and perspectives that preceded the emergence of modern environmentalism in the late 1960s and early 1970s, its evolution over the past five decades, and conclude with a brief description of its status circa the late 2000 s and early 2010s. Finally, I outline the major critiques, as well as some of the visions for the future of environmentalism articulated by contemporary scholars.

It is important to stress that environmentalism is composed of multiple strands of thinking and interpretation that have historical connections that go back centuries. Furthermore, the changes over time are not linear, but are more accurately described as intertwined. Environmentalism is complex, what Taylor (2010) refers to as "an eclectic bricolage ... an amalgamation of bits and pieces of a wide array of ideas and practices, 
drawn from diverse cultural systems, religious traditions, and political ideologies" (p. 14). This dissertation is not intended to provide a definitive outline or history - only a context against which to contrast the views of the research participants.

\section{Expanding on the Definitions}

In Chapter One, I introduced my interpretation of environmentalism, the environmental movement, and environmentalist. Providing further clarity on these terms is important. Taylor (2010), in framing his explanation of environmentalism in the language of religion, writes "terminology matters. It shapes methods and focuses attention in illuminating ways" (p. 1). In this context, elaborating on the definitions provides a foundation for the context of modern environmentalism outlined later in this chapter.

\section{Environmentalism.}

I noted in Chapter One that environmentalism is a contested term. It has been variously referred to as a philosophy (Young, 1990), a belief system (Eder, 1988), a religious tradition (Dunlap, 2004), an ideology (Haq \& Paul, 2012), a counter-ideology (Wissenburg \& Levy, 2004), a public discourse (Eder, 1988), a cultural critique (Sandler \& Pezzullo, 2007), a new social movement (Clayton \& Opotow, 2003), a political movement (Dunlap, 2004), a regime of social regulation (Park, Conca, \& Finger, 2008), a home for moderates (Peterson del Mar, 2006), a home for activists (Sandler \& Pezzullo, 2007), a nostalgic narrative (Nordhaus \& Shellenberger, 2007), and an unfinished story (Forkey, 2012).

I define modern environmentalism as a way to conceptualize the human relationship with the natural world, a critique of the excesses of modern industrial 
societies, and the foundation for a diverse social movement seeking to change economic and political systems. I expand on these three dimensions in the following sections.

\section{As a conceptualization and a worldview.}

A worldview is a shared understanding that provides a frame of reference and a sense of direction for how people find their way in the world (Aerts et al., 1994). From this perspective, a number of writers describe environmentalism as a way to view humanity's relation with the natural world. This includes the ecological dimensions of interconnectedness and biological limits - but also spiritual perspectives and belief systems.

Forkey (2012) believes that environmentalism is fundamentally concerned with "re-evaluating humanity's place amongst other living things in the world" (p. 86). In a similar vein, Worster (1994) claims that human beings "were not passive victims of their surroundings - they were embedded in them, they interacted with them, and they could have an effect" (p. 350). These writers share an understanding that people and societies are a part of the natural world, and environmentalism is a way to conceive that relationship.

Another group of scholars writes about the social and cultural dimensions of environmentalism. Eder (1988) argues that environmentalism should be viewed as a coherent cultural "response to specific social conditions" (p. 163), one that should replace industrialism as the basis for the relationship between humans and nature. He further contends that environmentalism is "the search for a human being's place in nature" (Eder, 1988, p. 186). Wissenburg and Levy (2004) claim "Environmentalism is traditionally not only concerned with the capability of existing political arrangements and institutions to 
successfully address the environmental challenge. It also entails or suggests a different conception of the good society ... goals like the preservation of a self-sustaining nature or natural biodiversity" (p. 4). Haq and Paul (2012) argue that modern environmentalism is concerned with how society operates within ecological systems, and has "evolved in complex and sometimes contradictory ways to span conservative, reformist and radical ideas about what the world should look like, as well as how change should be brought about" (p. 2).

Finally, there are a number of writers who describe environmentalism from a religious or spiritual perspective. Taylor (2010) believes that this perspective "considers nature to be sacred, imbued with intrinsic value, and worthy of reverent care" (p. ix), and Dunlap (2004) sees environmentalism “as an emerging religious tradition” (p. xiv). Both of these scholars believe that the natural world should be revered. Dunlap further notes that what distinguishes environmentalism "has been its success in embracing a materialistic vision consistent with modern science at the same time that it finds deep spiritual meaning” (p. xv).

What perhaps makes these conceptualizations unique among worldviews (i.e., frames of reference for how a person finds their way in the world) is the dialectic between a realist approach to knowledge based on objective, empirical observation, and a phenomenological approach that claims our observations are socially constructed. Environmentalism as a worldview straddles both approaches - environmental science contains elements of a positivist, empirically based perspective that seeks to explain the physical and biological processes associated with natural systems, while the social science perspective acknowledges that environment and nature have socially constructed 
meanings. This dualism is illustrated by Dunlap (2004), who notes that “environmentalism relied on science, but it also embraced the contradictory legacy of Romanticism, which looked to intuition and emotion as guides to a 'deeper' truth, and insisted on searching in the world for ultimate meanings" (p. 11).

As a critique of modernity and modern industrial society.

Notwithstanding perspectives that celebrate nature as sublime and spiritually uplifting, the theme of environmentalism as a critique of modernity is widespread in the literature. A number of scholars (Cronon, 1996; Eder, 1988; Gare, 1995; Glover, 2006; Talshir, 2004) have placed the emergence of environmentalism in the context of postmodernism, even though the formative writings on postmodernism are noticeably silent on the natural world. Instead, postmodernism has been associated with a rejection of modernity's focus on progress, rational science, and technology (Gare, 1995; Harvey, 1990).

Harvey (1990) takes the Enlightenment period that began in the eighteenth century as the reference point for the later emergence of postmodernism as an antimodern movement in the 1960s. In The Condition of Postmodernity (1990), he argues "the first great surge of modernist thinking, took the domination of nature as a necessary condition of human emancipation" (p. 249). He maintains that environmentalism, and other resistances against modernism, "coalesce into social movements with the aim of liberating space and time from their current materializations and constructing an alternative kind of society in which value, time, and money are understood in new and quite different ways" (p. 238). 
Similarly, Peterson del Mar (2006) notes that the Enlightenment was "suffused with a spirit of confidence in the ability of human beings to fathom and manipulate their world" (p. 8). He argues that the origins of environmentalism in the 1960s were part of a broader backlash against modernity and technology. Worster (1994) echoes this position, noting that environmentalists "confronted deeply seated attitudes among traditional economists, business leaders, politicians, and the public about the virtues of economic growth, attitudes underlying the modern economic system and indeed the whole materialistic ethos of modern cultures" (p. 354).

Eder (1988) places environmentalism as a critique of modernity, arguing "contemporary environmentalism is a turning point in the cultural evolution of modernity insofar as it proves a new cultural orientation by substituting ecology for industrialism as the basic cultural model for modernization" (p. 163). Eder goes so far as to argue that environmentalism has evolved from its initial form in the late 1960s, to a new phase that he terms post-environmentalism. Interestingly, Eder's terminology was later echoed by Nordhaus and Shellenberger, who in 2011 wrote a book titled Love Your Monsters: Postenvironmentalism and the Anthropocene. In it, the authors reiterate their comments about the death of environmentalism, and argue that the way forward is to embrace innovation and development. This is counter to Eder's use of the term, which contends that technological development must be thoroughly grounded in ecology and natural limits. Regardless, the term post-environmentalism has not entered the popular discourse as a description of the status of environmentalism after a half century of adaptation and change. The term does, however, reflect the notion that environmentalism is in transition - which is a primary finding of the research noted in Chapter Five. 
Gare (1995) links modernity to the degradation of the environment. He claims that postmodernism is associated "with a loss of faith in modernity, progress and enlightenment rationality, reflects people's awareness that it is just these cultural forms which are propelling humanity to self-destruction. Proponents of postmodernist politics usually endorse ecological resistance" (p. 1). He further contends that the irony of postmodernism's rejection of grand narratives is that we still require a strong narrative to resolve the environmental challenges we face.

Talshir (2004) makes use of an analytical framework to describe environmentalism. Her assessment draws on science, politics, ideology, and theory to conclude that environmentalism is a discourse that has contributed to "challenging some of the dominant approaches to political analysis, facilitated the emergence of a new ideology and extended moral theory beyond humanity’s boundaries" (p. 30). Talshir also situates environmentalism as a critique by concluding that its fundamental nature is "the struggle against economic development as the major criterion for success and progress" (p. 12).

Glover (2006) asserts that anthropogenic climate change is itself an outcome of modernity, and attempts to effectively respond to it are being framed in a traditional, modernistic frame. Like Eder, she believes that postmodernism should be imbued with a “distinctive ecological meaning and implication" (p. 8). She draws on postmodernism to reject a positivist approach to climate change (and other environmental woes), and argues that the appropriate response should be based on social, cultural, and political considerations. Glover does not argue that climate change is socially constructed, only that "postmodernity ... can be used to describe a more fundamental shift in the trajectory 
of human affairs, namely the demise of the ability to know, govern, and manage the global environment according to the dictates of modernity" (p. 254). Her point is that modernity can no longer provide the meaning and social organization necessary for addressing climate change.

Barry (2007) argues that postmodernism is a rejection of modernity. He suggests that "the various problems associated with modernity (including environmental ones) cannot be solved within modernity, but require a postmodern solution" (p. 243). However, he also suggests that postmodernism might be too apolitical and inherently conservative to serve as a platform for achieving the required change.

What these writers share is a contention that environmentalism can be seen as a counter to modernity. They maintain that contemporary environmental problems can be traced back to a belief that humans can dominate and manipulate the natural world to their own ends. From this perspective, environmentalism can be viewed as a critique of the excesses of modern, industrial societies. Later in this chapter I note that this critique has manifested in actions ranging from approaches that generally reject technology to those that attempt to convert and shape it through ecological modernization and sustainable development.

\section{As the foundation for a diverse social movement.}

In Chapter One, I argued that environmentalism provides the emotive and rational foundation, as well as the philosophical and ideological framework, for the environmental movement. I discuss the movement in more detail in the next section, but it is important to note that while social movements form around a contested issue, grievance, or injustice (see Chapter Three), they are also guided by underlying beliefs 
and values. In the case of the civil rights movement, the women's rights movement, and the gay and lesbian rights movement, the foundation was a belief in equality. Similarly, a number of writers contend that the environmental movement has an underlying basis in the way the human relationship with nature is conceived, specifically that humans are a part of the natural world (Dunlap, 2004; Hays, 1987; Taylor, 2010). This is echoed by Cronon (1996), who writes that environmentalism is the basis for "the broad cultural movement in the decades since World War II that has expressed growing concern about protecting nature and the environment against harms caused by human actions" (p. 25).

\section{Environmental movement.}

I indicated earlier that the terms environmentalism and the environmental movement are often conflated. They emerged together in the late 1960s and have evolved in tandem since then. Nevertheless, I maintain there is a distinction between the underlying philosophical and ideological framework, and the actions of individuals and groups.

I define the environmental movement as the manifestation of environmentalism, composed of the pioneer writers who both articulated the incompatibility of modern industrial society with nature and celebrated its beauty and wonder; the early leaders who incited collective action on environmental issues; the mass of individuals who came together to protest what they saw as the degradation and destruction of the natural world; and the organizations that emerged to research into, organize for, and advocate around environmental issues. This definition is not fixed in time but implies a temporal dimension, as suggested by social movement theory. 
There is considerable literature that places the modern environmental movement in the context of social movements that arose in the Western world during the late 1960s. Eder (1988) links the environmental movement to this broader wave of social protest. MacDowell (2012) notes this was a moment of culture change (the counterculture movement), and that the Baby Boom generation "which came of age during this period, found inspiration in the activism of individuals such as Carson and earlier naturalistic writers" (p. 245). Rome (2003) likewise places the rise of the environmental movement in the context of events and protests that occurred in the 1960s.

Haq and Paul (2012) describe this as a time of transformative social and cultural events, fuelled by "a new generation of young people who were openly critical and rebellious" (p. 7). I argue in Chapter Three that the emergence of social movements in the late 1960s, including the environmental movement, can be attributed to the size of the generational cohort that was coming of age (the Baby Boomers), coupled with a sense that existing institutions and systems were incapable of dealing with injustice and inequality, the threat of nuclear war, and the increased awareness of environmental degradation brought about by the writings of scientists.

In this context, the emergence of the environmental movement can be seen as part of a broader cultural shift in the late 1960s, promulgated in part by a new affluence and by the emergence of a large cohort of young people. Many in this group were distrustful of a modern, industrialized, consumer society, and were motivated by the reflections of earlier nature writers (Henry David Thoreau, John Muir, Aldo Leopold) and more recent environmental pioneers (Rachel Carson, Barry Commoner, Paul Ehrlich, Garrett Hardin, Donella Meadows, James Lovelock). These individuals provided inspiration and context 
for a young generation that came to dominate the movement that Wissenburg and Levy (2004) describe as "one of the great New Social Movements of the 1960s-1970s" (p. 2).

A number of writers describe the defining characteristics of the early environmental movement community (Haq \& Paul, 2012; Nordhaus \& Shellenberger, 2007; Peterson del Mar, 2006; Rome, 2003, 2013; Sandler \& Pezzullo, 2007). These characteristics include the aforementioned generational dimension (young people), but also that the group was idealistic, well educated, middle class, white, and predominantly male. Many of these attributes continue to define the movement, although after five decades it is now multi-generational in nature, and the gender balance appears to be shifting toward women (described in Chapter Five).

Eder (1988) claims that the environmental movement has developed from a protest frame to become one of many cultural pressure groups. This process, by which movements become assimilated and normalized into the dominant society, implies that if the environmental movement does not adapt and evolve, it may not survive as a channel for mass mobilization in the future. He argues that when a movement arrives at such a moment "The action repertoire will change fundamentally, and with it the relationship between movements and their constituencies. They will survive as a collective actor" (Eder, 1988, p. 190). Similarly, Nordhaus and Shellenberger (2007) claim that once social movements mature "their agenda shifted from the broadly transformational to the narrowly issue based, they become interest groups" (p. 194).

In Chapter Three, I note that social movement theory predicts movements evolve through a pattern that includes issue identification; leadership from a few individuals who articulate the issue (for the environmental movement, many of the pioneer architects were 
part of the generation that came before the Baby Boomers); consciousness-raising; mobilization (in this case, the Baby Boomers came to dominate the movement); and if the movement endures, the emergence of organizations to coordinate action and acquire resources. Social movement theorists further contend that the disruptive force created by a social movement will tend toward stability, and that if governing institutions appear to channel or satisfy the movement's demands, demobilization and stasis can occur (McAdam \& Scott, 2005). For movements to continue beyond this point, they need to reinterpret and identify the issue or grievance, and adapt to the new circumstances. In Chapter Five, I find that the research participants believe a transition is under way, and that they have adopted further interpretations and tactics to facilitate such change.

I argue this reinterpretation is what has happened to the environmental movement after five decades. In the 1970s, Western governments created environmental laws and agencies that largely addressed the environmental movement's demands, resulting in a subsequent decline in mass action. This is illustrated by the trends in public participation at Earth Day. No Earth Day since 1970 has witnessed the mass participation numbers that occurred at the first event (Rome, 2013).

A core community within the movement continues to be active on environmental issues, hundreds of established environmental organizations now exist, and the public at large routinely polls high for a concern for the environment. What is missing is the broadbased, non-hierarchical, participatory mass of people engaged in environmental issues that was a defining feature of the movement's formative years. I believe that in the future, there will be efforts to rebalance the public dimension that was a hallmark of the early 
movement and to create a new narrative of environment and people, and that young people will be on the forefront of such public organizing, networking, and storytelling.

\section{Environmentalist.}

I define an environmentalist as an individual who undertakes actions in support of their environmental beliefs and concerns. The key aspect of this definition is that the person actively participates, rather than simply holds an idea or view. Such actions can involve an individual's personal behaviour, or concerted efforts to conduct environmental work or collective action.

However, there is an important distinction between being active and being an activist. My definition of an environmentalist contains a wide-ranging representation that is composed of moderates, reformers, and those who self-identify as environmentalists through the way they live their lives - as well as those who conduct acts of protest and civil disobedience. I believe a more inclusive definition is consistent with the broader understanding of environmentalism and those who are involved in the environmental movement.

Kempton and Holland (2003) write that environmental and ecological identities are the basis and the motivation for pro-environmental behaviour. They contend that selfidentification as an environmentalist depends on three aspects of identity development: becoming aware of environmental issues, experiencing oneself as an environmental actor, and developing the personal capacity to undertake action. They further note that this is not a linear model of identity leading to action, but an iterative process involving all three dimensions acting together (pp. 331-339). 
Haq and Paul (2012) argue that environmentalists share a concern about "how society operates within natural systems" and "believe the environment should be championed, looked after and protected" (p. 1). They also note that environmentalists are often "portrayed as radicals driven by unrealistic ideals rather than sound science" (p. 92). Worster (1994) claims that "an environmentalist, consequently, became anyone who was concerned with preservation of ... biophysical surroundings" (p. 350).

Echoing the activist nature, Sandler and Pezzullo (2007) contend that "environmentalists share very little by way of positive images of how humans should relate to nature. Far from visionary, environmentalists are better at opposition and obstruction than at creating and articulating positive views" (p. 87).

Park, Conca and Finger (2008) claim that contemporary environmentalism is fragmented, and that much of its internal tension has to do with how environmentalists view their actions either as participating within existing economic systems or as challenging them. The authors note that many environmentalists tend to be critical of contemporary economic systems and discourse.

Peterson del Mar (2006) discusses the radical and reformist dimensions of environmentalism. He argues that "Environmental activists, like other reformers, have tended to be young, but they have also been well-educated, often prosperous" (p. 199). He contends that the roots of the environmental movement were part of a broader community that was originally reformist in nature - but not radicalized. He believes that the more radical departures from this base that occurred in the 1970s (such as the group Friends of the Earth in the United States and Greenpeace in Canada) were akin to Protestant sects, in which "radical environmental groups tended to become more practical 
and moderate over time, only to be replaced in turn by new, extreme, organizations" (p. 138). He further states that "like all radicals, they often found themselves pulled apart by the incompatible imperatives of ideological purity and political efficacy" (p. 142).

The evolution of environmental activism to include more radical elements is similar to the emergence of blackpower radical and militant elements in the civil rights movement in the 1970s, which McAdam and Scott (2005) presage as the decline of the original logic of civil rights. The fact that the environmental movement has been able to accommodate moderates and radicals is a testament to its endurance.

Many of the writers noted above have tended to depict an environmentalist as an activist. This portrayal of an environmentalist as someone who is willing to take a radical stand has potentially negative consequences for achieving broad-based environmental changes. A recent study has shown that such stereotypes contribute to a perception that "the very individuals who are most actively engaged in promoting social change may inadvertently alienate members of the public" (Bashir, Lockwood, Chasteen, Nadolny, \& Noyes, 2013, p. 625). The authors conclude that the participants involved in their research had:

negative stereotypes of activists (feminists and environmentalists), regardless of the domain of activism, viewing them as eccentric and militant. Furthermore, these stereotypes reduced participants' willingness to affiliate with "typical" activists and, ultimately, to adopt the behaviours that these activists promoted. These results indicate that stereotypes and person perception processes more generally play a key role in creating resistance to social change.

(Bashir et al., 2013, p. 614) 
I raise the distinction between being active and being an activist because I believe it holds an important consideration for the future of environmentalism. If environmentalists become stereotyped as radicals or obstructionists, the implication is that the moderate and reformist elements within the environmental community will have a difficult time promoting their views. Furthermore, interest groups and political parties who disagree with the views of the environmental community can effectively exploit such stereotyping to their advantage. An example is the Conservative government of Canada, who began to portray environmentalists as radicals and terrorists in 2012, as part of an economic agenda to promote natural resource extraction (McCarthy, 2012).

The term environmentalist is a label. Individuals can believe in the principles of environmentalism and undertake actions consistent with their beliefs, but not call themselves environmentalists. Among the 20 participants involved in my research, only eight self-identified themselves as such. This finding is consistent with a 2014 Pew Research survey that found "Millennials are also somewhat less likely than older adults to describe themselves as environmentalists - just 32\% say this describes them very well" (Pew Research Center, 2014, p. 10). Responding to the survey, Samantha Larson (2014) wrote an article titled 'No, We're Not 'Environmentalists.' It's More Complicated Than That," in which she argued that not identifying oneself as an environmentalist is not a rejection of environmentalism. Instead, she suggests that the historical characterization of an environmentalist does not reflect how a Millennial approaches current environmental challenges. I believe that Larson's comment, together with the findings from the Pew survey, illustrate the research findings in Chapter Five that young people are developing new interpretations of environmentalism and what it means to be environmentally active. 
On a final note, a question might arise as to why I have delved at length into the interpretation of the term environmentalist. One of the research findings is that environmentalism is in transition. An indication in support of this argument would be that the language of environmentalism is also changing. I have argued in this section that the term environmentalist has taken on a meaning that may not reflect the thinking of young people who care about the environment - and that as a consequence they might not identity with the term. Larson (2014) alludes to this when she says, in reference to Millennials, "we know solutions that rely on preachiness or dogmatism won't last" (p. 1).

\section{The Historical Context of Modern Environmentalism}

In describing the evolution of modern environmentalism, the interconnection between the underlying intellectual framework provided by environmentalism and the manifestation as a social movement becomes an iterative story. The following section describes the emergence of both as a single narrative.

I noted in Chapter One that my dissertation deals with environmentalism and the environmental movement in the Western world, primarily the United States and Canada. This Western perspective is partially an acknowledgement that modern environmentalism has deep roots in these geographies - but also that my research is concerned with young people in Canada. I recognize that an understanding of modern environmentalism is more complex than I present, involving unique stories, perspectives, resistances, and outcomes from people around the world. However, the history of global environmentalism is beyond the scope of this study. 


\section{Setting the stage - antecedents to modern environmentalism.}

Situating environmentalism in the context of other social movements that emerged in the 1960 s is critical to understanding why it appeared when it did. Conventional wisdom is that modern environmentalism draws its inspiration from Rachel Carson and her publication of Silent Spring in 1962 (Jamison, 1996; Sachsman, 1996; Talshir, 2004; Young, 1990). Nordhaus and Shellenberger (2007) somewhat disparagingly refer to this as the genesis story that is the founding myth of modern environmentalism (p. 22).

Young (1990) extends the importance of Carson's formative work to include other writers, such as Paul Ehrlich's 1968 book The Population Bomb. Sabin (2013) adds to this the 1972 report The Limits to Growth: A Report for the Club of Rome's Project on the Predicament of Mankind, which described "looming threats to humanity from population growth and excessive resource consumption” (p. 81). Common to this interpretation of the roots of environmentalism is that influential thinkers and writers in the 1960 s and early 1970 s were warning that the failure to address issues of pesticide poisoning, pollution, population growth, and resource depletion would lead to environmental catastrophe. This crisis mentality likely resonated with a public already conditioned to think about the apocalyptic outcomes of nuclear war, and although overly pessimistic, a dark environmental vision certainly reached a large audience.

However, notwithstanding the passionate warnings of writers from the time, the origins of modern environmentalism are more complex. There are antecedents to the emergence of modern environmentalism in the late 1960s. 
Two periods in particular stand out. The first is in the eighteenth century, while the second is situated in the Romantic period of the late nineteenth. Worster (1994) notes the emergence of the early naturalist thinkers in the 1700s. He describes two streams of thought from that time, which he refers to as the arcadian tradition and the imperial tradition (p. 2). The former was a pastoral worldview advocating "a simple, humble life for man with the aim of restoring him to a peaceful coexistence with other organisms" (p. 2). Worster argues that the Romantic view of nature, which emerged in the late $1800 \mathrm{~s}$, has continuity with the arcadian tradition.

The imperial tradition, on the other hand, is suffused with Christian beliefs that "made the domination of the earth - often promoted in the name of a purely secular welfare - one of modern man's most important ends" (Worster, 1994, p. 29). According to Worster, the imperial tradition became widespread in the view of nature as serving the needs of man, and later "dovetailed neatly with the needs of the new factory society" (p. 53) which was a hallmark of the industrial revolution.

In this context, the emergence of the Romantic period in the late $1800 \mathrm{~s}$ is both a link to the earlier arcadian tradition and a reaction against a "faith in economic growth and the banal platitudes that equated moral and material progress" (Dunaway, 2005, p. 11). Taylor (2010) believes that during this period "ideas about the sublime and the beautiful in nature - and related political and ethical ideas - were fully in play within the romantic movements ... and were finding expression in philosophy, poetry, visual arts, and music" (p. 47).

The Romantic period marks a unique period in the history of environmental thought. American writers such as Emerson and Thoreau - and later Muir - gave voice to 
the reaction against industrialization. According to Worster (1994), the core of the Romantic view of nature was an ecological perspective, "a search for holistic or integrated perception, an emphasis on interdependence and relatedness in nature" (p. 82). Dunaway (2005) notes that the Romantic view was based on a general unease with how modern life had evolved. This unease "prompted longings for intense experience ... their quest took many forms: from the arts and crafts movement to the back-to-nature movements" (p. 11). Spending time in wilderness settings was part of the effort to reestablish a direct personal relationship with the natural world (Worster, 1994).

This period witnessed a discernible wave of criticism aimed at industrialization and the loss of wild lands to development. The reaction took many forms. In addition to the formation of conservation organizations in North America and Europe (e.g., Sierra Club, the National Audubon Society, and the Royal Society for the Protection of Birds), there were also groups focused on poor urban health conditions (e.g., the first national Red Cross Societies, and organizations such as the Victorian Order of Nurses). The Arts and Crafts movement that was active between 1880 and 1910 was based on a rejection of industrialism. MacDowell (2012) points out that no Canadian conservation groups equivalent to the Sierra Club emerged at this time, but that wildlife preservation became a goal of government policy and legislation.

If there is a commonality to these late nineteenth-century events, it is an early criticism of modernity. Brand (1990) characterizes this era as one of "anti-urbanism and the nostalgic idealization of wilderness and rural life" (p. 36). In effect, these earlier responses to industrialization bear a similarity to the reactions against consumerism and modern society that were characteristic of the 1960s, but without the growing scientific 
evidence of human-induced environmental problems and the existence of a large and active youth cohort. Nevertheless, the early conservation movement that led to the creation of organizations such as the Sierra Club in 1892, and the subsequent establishment of the first national parks by federal governments in the United States and Canada during the late 1800s, illustrates a point I raise in Chapter Three: the dominant establishment attempts to adopt and co-opt the basic tenets of protest discourse in order to channel and satisfy its demands. Governments responded, and much of the fervour subsided. The First World War and the Great Depression subsequently tempered environmental thinking until the end of the Second World War.

\section{Post World War Two to the 1960s.}

A number of writers remark that the period from the end of the Second World War, until the late 1960 s, was critical to the formation of modern environmentalism (Dunaway, 2005; Dunlap, 2004; Hays, 1987; Nordhaus \& Shellenberger, 2007; Worster, 1994). Hays (1987) argues that "World War II is a convenient dividing line between the old and the new values" (p. 3), while Worster notes that the "emerging views in the 1950s gave environmentalism a set of defining ideas" (p. 353). This period is often overlooked, but needs to be reappraised in order to link it to the patterns of social movement formation. There are several aspects of this period that are relevant.

The first has to do with the postwar economic boom. Many environmental scholars have noted the impact of growing affluence in the $1950 \mathrm{~s}$, both as an enabler of the environmental movement (Hays, 1987; Nordhaus \& Shellenberger, 2007) and as the root of the negative impacts of consumer society on the environment (Barry, 2007;

Brand, 1990; Worster, 1994). 
Nordhaus and Shellenberger (2007) posit that there is a "very strong association between prosperity and environmental values" (p. 28). They point out that the connection between affluence and emergence of modern environmentalism "goes a long way toward explaining why environmentalism in the United States emerged in the 1960s and not in the 1930s" (p. 29). Hays (1987) argues that affluence and education were instrumental in the development of new environmental values, noting "these changed markedly after the war. Personal real income grew and the percentage of Americans with college education increased" (p. 3). Dunlap (2004) echoes this position, noting that affluence permitted increased leisure time, which "brought about a boom in outdoor recreation" (p. 70), which he argues led to wilderness becoming a popular cause. In this context, Hays (1987) notes that the "rapid growth in outdoor recreation in the 1950 s, extended into the wider field of the protection of natural environments" (p. 3). Hays contends that the combination of increased prosperity, education, and the leading edge of a demographic change led to an increased appreciation of the aesthetics, health benefits, and long-term value of preserving natural systems - what he refers to as beauty, health, and permanence (pp. 26-27).

What these writers share is a belief that increased prosperity and a higher standard of living created an atmosphere of security and comfort. This in turn led to a higher birth rate (i.e., the Baby Boomers), more leisure time, and the emergence of quality of life concerns which "included things like clean air; clean water; and local, state, and national parks" (Nordhaus \& Shellenberger, 2007, p. 27).

On the other hand, there is a group of scholars that portrays the new affluence in a different light. Brand (1990) argues that the emphasis on material values in the 1950s is 
linked to a condemnation of materialism in the 1960 s from a younger generation concerned with a "life boring, empty, and alienating in a society focused on acquisition and functionality" (p. 31). Young (1990) posits that the new technologies and production processes that were mobilized during the war were later retooled for consumerism. According to Young, there was a delay between the expansion of the postwar consumer economy and the observed negative consequences of industrial pollution and urbanization. In this context, the works of Rachel Carson and Paul Ehrlich were written for a population that was becoming sensitized to the fact that environmental problems were occurring around them.

Jamison (1996) concludes that the period from the end of the war to the mid1960s was a period of education and awareness about the impacts of modern society that was necessary for the movement to emerge in the last half of the 1960s. As an example of this transition, the postwar creation of institutions within the United Nations framework, such as the International Union for the Protection of Nature in 1948 (now the International Union for Conservation of Nature and Natural Resources), elevated the traditional conservation agenda to a global context.

Rome (2003) also argues that the role of middle-class women in the 1950s and 1960s should not be overlooked. He contends that women - housewives and mothers were instrumental in bringing attention to issues of environmental health in the suburban communities where many of them were increasingly living. As evidence, he points to women's magazines from the early 1960s that routinely published articles about the threats of pollution to quality of life (Rome, 2003). 
To summarize to this point, the environmental movement that emerged in the 1960s has a complex history that includes antecedents in the Romantic and conservation movements of the late nineteenth century, the prosperity of the postwar period, a growing awareness of the impacts of industrialization, and a critique of modern society based on questions related to personal values and materialism. Added to this was a generational dimension that included a mass of youth at the front end of the postwar baby boom that was beginning to enter universities and the work force. To this last factor, Adam (1996) acknowledges that to a large extent environmentalism emerged from the counterculture of the 1960s, including the student riots that swept much of the Western world in the latter half of the decade.

Peterson del Mar (2006) notes that the emergence of a large cohort of young people in the late 1960s translated into dramatic increases in university enrolments. He notes that universities became "breeding grounds for alienation and dissent. These children of the growing middle class were accustomed to being heard and taken seriously" (p. 83).

Forkey (2012), in describing the evolution of environmentalism in Canada, notes 'the younger generation was questioning the wisdom of its parents' and grandparents' treatment of the environment. The young generation sought a more benign relationship with nature" (p. 86). Forkey argues this was a period when Baby Boomers began to assert themselves on a variety of issues, including the environment.

\section{The emergence and evolution of modern environmentalism.}

At this point, the emergence of the environmental movement in the context of other social movements of the late 1960 s re-enters the picture. This narrative includes 
growing alarm about the effects of chemical pollution, nuclear power, and resource depletion - accentuated by a number of highly visible environmental accidents. Together with the threat of nuclear war, Worster (1994) argues that "a new moral consciousness called environmentalism began to take form, whose purpose was to use the insights of ecology to restrain the use of modern science-based power over nature" (pp. 343-344).

This new view drew on antecedents from the conservation movement, the emerging field of ecology, and attitudes toward economic growth and materialism. Dunaway (2005) notes that "youthful rebels and wilderness advocates shared a sense of disaffection with postwar America" (p. 188). Dunlap (2004) believes that the growing environmental concerns about pollution "turned vague dissatisfaction into a political movement and a program" (p. 36).

Hays (1987) echoes the importance of the social context. He argues that environmental values flourished because of the presence of a younger, well-educated generation that was involved in the "deep-seated changes in preferences and values associated with the massive social and economic transformation" (p. 13) of the time.

While environmentalism was born with a sense of hope that change was possible, it was also suffused with apocalyptic and pessimistic language (Dunlap, 2004; Taylor, 2010). Nordhaus and Shellenberger (2007) note that environmentalists "defined their politics in the negative. They write books like The Limits to Growth, The Population Bomb, and Collapse, which focus our attention on the destructive power of humankind rather than on our creative potential" (p. 120).

Jamison (1996) observes that powerful, well-financed organizations such as Greenpeace, the Worldwatch Institute, and the World Wildlife Fund emerged in the 
1960s and early 1970s. Jamison argues that it was the emergence of a large and active environmental movement, and the concurrent creation of environmental organizations, that created the unique identity that defines the movement to this day.

An important contribution to explaining the subsequent evolution of the environmental movement is provided by Sachsman (1996). He contends that it was the combination of new social movements and new social media - primarily television - that was key to the successful emergence of the environmental movement in the late $1960 \mathrm{~s}$ and early 1970s. Prior to this time, there were no environmental reporters - yet only a few years later media outlets routinely covered environmental matters. Sachsman argues that the Santa Barbara oil spill of 1969 is an important milestone. This was the first mass media environmental disaster to show images of oil-soaked birds and beaches, and the effect was enormous. Now everyone could see highly emotive images of the impact of industrial activity. Indeed, from the 1970s onwards the environmental movement begins to employ images, symbols, advertisements, and public demonstrations in highly effective ways to gain public attention. The challenge for the movement was that these powerful images were almost always negative, and a "doom and gloom discursive frame ... does not motivate people beyond the already committed" (Barry, 2004, p. 182).

The apex of the environmental movement as a mass social movement is likely 1970. Earth Day, April 22, 1970, witnessed 20 million Americans turning out to demonstrate their concern for the environment (Rome, 2003; Werbach, 2005). After that point, the number of individuals who engage in environmental protests begins to decline. As predicted by social movement theory, the passion of a grassroots, mass movement is rarely sustained over a long period of time. 
Nevertheless, Rome (2013) believes that the first Earth Day had a profound and long-lasting impact on environmental issues that effectively set the stage for the subsequent evolution of environmentalism and the environmental movement. For example, much of the foundational environmental legislation in both the United States and Canada was put in place in the early to mid-1970s (MacDowell, 2012). In his assessment of the event, Rome (2013) writes:

Earth Day led to a tremendous increase in grassroots activism ... the number of local environmental organizations nearly doubled from 1968 to 1973 . The new groups lobbied in state capitols, organized recycling programs, and established “ecology centres.” Earth Day also inspired institutional change. Environmental education took root. News editors assigned reporters to environmental beats. (p. 209)

Rome attributes the success of the first Earth Day to the fact that it involved thousands of grassroots events organized and held at the local community level; there was little top-down coordination from a central body. He contrasts this to the performance of the twentieth anniversary of Earth Day in 1990, which was centrally coordinated but had a smaller turnout. This observation has implications for the future of environmentalism that I return to in Chapter Six.

Dunlap (2004) notes that "the early enthusiasm faded by the late 1970s, but the movement continued" (p. 12). He argues that a new phase of environmental thinking emerged in the 1980s, and that "environmentalism reached a crossroads. Despite all it did, pollution continued, population grew (though a bit more slowly), extinction rates 
rose, and wilderness dwindled. Some environmentalists said the movement had failed, and a strong, deep, and sometimes bitter debate developed" (p. 122).

The 1980s also witnessed the emergence of a strong, counter-movement that "sought to restrain environmental action" (Hays, 1987, p. 10). Sabin (2013) contends that the extreme positions of many leading environmentalists "helped spark the backlash against the environmental movement in the United States and helped generate support for equally extreme positions taken by conservative opponents" (p. xi). Hays (1987) argues that the emergence of a strong opposition provides insight into the evolution of environmentalism over the ensuing decades:

the intellectual activities of environmentalists were influenced by their opponents, who dominated the definition of environmental issues. Hence, public environmental debate often was shaped by negative rather than positive assertions about environmental affairs: anti-technology, bad science, single-issue politics, adversarial strategies, opposition of the environment and the economy, belief in a no-risk society, hostility to cost-benefit analysis, and elitism. (p. 247) With respect to environmentalism in the 1980s, Dunlap (2004) contends "the confusions and contradictions so evident in the 1980s should not be seen as signs of collapse but as products of environmentalists' engagement with these deeper questions" (p. 147). Brand (1990) contends that starting in the 1980s, the original activist impulses of environmentalism began to be incorporated into contemporary cultural and social life, and the critique of modernization started to weaken in the face of economic recessions and a neo-conservative political agenda. According to Kraft and Wuertz (1996), this is also the time when the explosive growth of membership and financial resources that 
environmental organizations had experienced over the previous two decades started to wane. Many large environmental organizations began to partner with business to support their campaigns, even if such partnerships might call into question the values and independence of these groups. In the United States and Canada, a perception arose that the movement was fragmenting, and lacked a common vision for what a critical discourse on the environment really is. Criticisms of the environmental movement, and claims for the end of environmentalism, appear throughout the 1990s and into the first decade of the 2000s. It was at this time that Shellenberger and Nordhaus (2004) wrote their polemic The Death of Environmentalism. In the article, the authors condemn big environmental organizations and their leaders for being ineffective and unaccountable - or worse, failures. Shellenberger and Nordhaus argue that the way to resolve current environmental challenges is to invent and invest the way out. The article ignited an uproar within the environmental community that continues to this day.

Luke (2005) waded into the controversy initiated by Shellenberger and Nordhaus by critiquing their assumption that economic growth (albeit of the green variety) and public-private partnerships were the solution to the perceived failure of the environmental movement. He argued that this was tantamount to investing in the very systems that caused the environmental problems in the first place.

However, the furor illustrates another important element of the evolution of contemporary environmentalism and the environmental movement. From the 1980s through to the present, environmentalism has become ever more diverse - incorporating different perspectives about what I earlier defined as a way to conceptualize the human relationship with the natural world. One element claims that the solution is to work with a 
diverse range of partners, including business and government, to resolve the challenges created by our technologies and standards of living. This approach can be loosely described as ecological modernization, the concept that consumer capitalism and ecological sustainability can coexist (Bluhdorn \& Welsh, 2008). The trajectory of this idea can be traced back to the mid-1980s, when the reaction of the dominant power structures to the protests discourse of environmentalism was to adopt and co-opt some of the key precepts. This approach later appears in the 1987 Brundtland Report under the rubric of sustainable development, and continues through to the present in the form of technological approaches to resolving environmental problems.

Another trajectory witnessed a number of environmental organizations (Greenpeace and Earth First!, for example) retaining an activist agenda founded on a protest discourse critical of government and business. These groups have played an important role in exposing much of the greenwashing that occurs in contemporary consumer society, but their exhorting manner also places them on the outside of mainstream political and economic systems - and therefore largely unable to effect change from within.

The dimension of conservation and wilderness preservation continues to represent a strong theme in environmentalism. The basis remains a love of the natural world and its beauty, now bolstered by work of scientists from many disciplines. Biodiversity, endangered species, old-growth forests, and marine protected areas - all form part of this aspect of environmentalism. Large, well-funded environmental organizations in the United States and Canada, such as the World Wildlife Fund, The Nature Conservancy, 
and the Sierra Club, are active in national and international projects designed to protect species diversity and ecologically important habitats.

The early 1990s saw the emergence of environmental justice as a distinct dimension of environmentalism. Jamieson (2007) notes that the roots of environmental justice lie in the United States, involving poor people and people of colour. He argues that disadvantaged groups were focused on how the environmental burdens of a modern, industrial society were distributed - and not on conservation and wilderness issues. Nevertheless, Jamieson (2007) concludes that environmental justice adds an important dimension to environmentalism:

I have claimed that justice is at the heart of environmentalism and that the idea of environmental justice is multidimensional. It concerns the distribution of the benefits and burdens of our interactions with the environment, the need for participation in decisions that concern the environment, and the importance of expanding our conception of who is within the domain of justice. Viewing environmental conflicts in this light provides an opportunity for transforming environmentalism from a collection of views and prejudices united mainly by their opposition to various policies and projects into a set of positive visions that can guides us into the future. (p. 98)

Sandler and Pezzullo (2007) argue that the environmental movement and the environmental justice movement are separate and distinct, and that the latter has consistently "criticized what they consider the 'mainstream' environmental movement's racism, classism, and limited activist agenda" (p. 2). They also note that there is a gender 
difference between the two movements, with the environmental movement being characterized as overwhelmingly led by men.

Wenz (2007) concludes "there are no inherent conflicts between the goals of environmentalism and environmental justice" (p. 58), and Haq and Paul (2012) believe that a distinction between these two movements can be made, but frame environmental justice issues under the broader conceptualization of environmentalism.

The existence of multiple streams of environmentalism was identified by Martinez-Alier (2002). He created a typology of these streams, which he refers to as clusters, and identifies characteristic traits of each (Table 1). Martinez-Alier (2002) believes that they share a commonality in that the "environmental movement grows in reaction to economic growth" (p. 1).

Table 1

Clusters of Environmentalism Recognized by Martinez-Alier (2002)

\begin{tabular}{|c|c|}
\hline Environmental Cluster & Traits according to Martinez-Alier \\
\hline Cult of Wilderness & $\begin{array}{l}\text { - } \text { Preservation of pristine nature } \\
\text { - Indifference to economic growth } \\
\text { - } \text { Concerns about population growth }\end{array}$ \\
\hline Gospel of Eco-Efficiency & $\begin{array}{ll}\text { - } & \text { Sustainable (wise) use of resources } \\
\text { - } & \text { Focus on pollution } \\
\text { - } & \text { Belief in technology }\end{array}$ \\
\hline Environmental Justice & $\begin{array}{l}\text { - Focus on social inequalities } \\
\text { - Uneven distribution of growth and } \\
\text { impacts } \\
\text { - Social justice }\end{array}$ \\
\hline
\end{tabular}

Martinez-Alier (2002) contends that there are "points of contact and points of disagreement among these varieties of environmentalism" (p. 15). He also recognizes that individuals and organizations can belong to more than one cluster. In Chapter Five, I 
propose a three-cluster typology that draws on Martinez-Alier's conceptualization to create a profile of the research participants' area of environmental interest.

This brings us to the present. Environmental concern remains high on the public agenda as measured by polling, but a broad commitment to action is often aspirational. Many Western nations, including Canada, are reluctant to implement substantive environmental policies for fear that they will hamper economic growth - or worse, cause voters to turn away. A number of businesses have adopted sustainability practices, but primarily those that lead to cost savings.

By the 2000s, environmentalism and the environmental movement had become well established in the public discourse. At the same time, efforts to address global environmental challenges such as climate change, species loss, ocean acidification, deforestation, and toxic waste have not resulted in the policy and regulatory regimes needed to deal with these issues. An example of this lack of will includes the failure to arrive at an international agreement to set binding greenhouse gas emission reduction targets at Copenhagen in 2009. A report by the United Nations Environment Programme in 2012, Measuring Progress: Environmental Goals \& Gaps, notes this seeming failure to address the most pressing issues:

Over the last few decades, a great number of legally binding and non-legally binding goals and objectives have been adopted as part of over 500 multilateral environmental agreements (MEAs) negotiated through a variety of different international and regional forums to address environmental degradation. Despite the growing body of norms, the global environmental situation continues to deteriorate. (p. 1) 
In the early $2010 \mathrm{~s}$, comments emerged about the need for environmentalism and the environmental movement to change and reform in a time of generational transition. Kaufman (2011) characterizes this change as a rejection of a top-down, organizationalled approach in favour of a radicalized style that uses social media to foster protest. She believes that changes are already under way to change the tactics and the message of environmentalism. Michael Greenberg (2012) ties the resurgence of activism to the generational impulse inherent in the Occupy Wall Street protests that began in late 2011. Writing from an American perspective, he notes that "it seems possible that the wars and recessions of the past decade have given rise to a politicized generation that will have, over the coming years, a lasting effect" (p. 48).

The historical context portrayed above is by no means complete, but it provides a general sense of the evolution of modern environmentalism from its roots in a love of nature, through a concern with the harmful environmental effects of industrialization and consumerism, and an increasing focus on people as opposed to wilderness, to the current efforts to change what might be described as a social movement in need of transition.

\section{Critiques of Environmentalism}

There have been numerous criticisms and critiques of modern environmentalism, in many cases dating back to its origins in the 1970s. Much of this sustained criticism has come from within the environmental community, with concerns raised about the composition of the movement (and the constituent movement organizations), the lack of a unifying vision for what environmentalism is trying to achieve, the inability to address global environmental problems, and disagreements about the strategy and tactics employed by environmentalists to achieve their goals. Dunlap (2004) notes, "critics on 
the outside accused environmentalists of hypocrisy or lack of business sense; those within spoke of betrayal and called for action on principle" (p. 152). I group these critiques under the following categories:

1. Qualitative: There have been persistent criticisms that deal with the tone, attitude, and disposition of environmentalism. These include perceptions that environmentalism tends toward pessimism, and is characterized by opposition, activism, and misanthropy (Eder, 1988; Haq \& Paul, 2012; Jamieson, 2007; Sandler \& Pezzullo, 2007). Concerns about the makeup of the environmental movement, particularly that it has historically been male and white, have emerged from the environmental justice community (Gottlieb, 1993; Sandler \& Pezzullo, 2007). From a Canadian standpoint, some writers have noted that environmentalism is characterized as being predominantly an English and white perspective, and references to Aboriginal and French Canadian environmental viewpoints are noticeably absent (Forkey, 2012; MacDowell, 2012). Cronon (1993) points out that environmental knowledge is socially constructed and historically contingent, making it difficult to argue for any scientific objectivity and truth as the basis for environmental discourse.

2. Framing: An associated criticism is that environmental problems are framed in negative or apocalyptic language and images (Dunlap, 2004; Nordhaus \& Shellenberger, 2007; Sabin, 2013; Taylor, 2010). Barry (2004) notes that a "doom and gloom discursive frame ... does not motivate people beyond the already committed" (p. 182). Peterson del Mar (2006) points out "that not a few environmentalists have issued prophesies that have been at once apocalyptic and absurd has served to discredit reasonable and credible warnings" (p. 202). According 
to Buell (2003), environmentalism has consistently been framed as a crisis, and after decades of warnings and disasters such a crisis mentality has been normalized in the general population. Cronon (1993) writes that the assumptions on which environmentalism were founded deserve to be reviewed, and that "we shouldn't evade that task for fear that it will weaken the larger political movement, since any movement worth defending - as environmentalism surely is - can only be strengthened by fostering rigorous critical analysis and debate" (p.12). As noted earlier, Sabin (2013) suggests the negative claims by environmentalists have invited scepticism, and helped provoke the strident backlash against the movement that has occurred over the past decades. He further argues, "though ritually satisfying and motivating for partisans, the rhetorical conflict helped produce legislative paralysis and deepening rancor" (Sabin, 2013, p. 8).

3. Elitist: Several writers have suggested that environmentalism has become the domain of intellectuals and elites - and is indifferent to people who are trying to make a living and support their families (Dunlap, 2004; Nordhaus \& Shellenberger, 2007; Taylor, 2010). Nordhaus and Shellenberger (2007) in particular argue that environmentalism is a consequence of prosperity, and that environmentalists are out of touch. They claim that "failing to make material prosperity for all a central part of their politics, environmentalists have to defend themselves against accusations that they are elitists who are more concerned with protecting beautiful places than in improving the lives of billions of people" (p. 38). This critique shows up in the broader discussions of the jobs versus the environment arguments that characterize much of contemporary environmental discourse. 
4. Structural: Concerns have been raised about the fragmentation of the movement, its incoherence, and the lack of a unifying vision (MacDowell, 2012; Park et al., 2008; Peterson del Mar, 2006). There have also been comments about the professionalization of the movement into organizations focused on managing and controlling environmental problems, at the expense of the broader participatory nature that characterized environmentalism in the 1960s and 1970s (Gottlieb, 1993). Rome (2013) argues that the environmental movement, at least in the United States, has evolved into an inside game involving professional elites and political actors, at the expense of broad-based organizing and public involvement. Shellenberger and Nordhaus (2004) claim that environmentalism has become a special interest unable to think beyond its own history and ideology, and that major changes are required in order to grapple with issues such as global climate change. Kingsnorth (2013) argues that environmentalism has been co-opted, and is now part of a system that supports a growth and consumer economy. The fragmentation is noted by Haq and Paul (2012), who contend that differences and disagreements about the right approach often lead to internal conflict over the right strategies to undertake.

5. Effectiveness: A 2012 report from the National Committee for Responsive Philanthropy (Hansen, 2012) notes:

Grantmakers made at least $\$ 10$ billion in grants to environmental causes from 2000 through 2009, funding primarily top-down strategies. Yet, we have not experienced significant policy changes at the federal level in the United States since the 1980s remotely commensurate with the level of funding invested toward these ends. From 1989 to 2009, among all environmental public charities, 
environmental organizations with budgets higher than $\$ 5$ million consistently received 40-50 percent of the contributions, gifts and grants, and 50-60 percent of revenue. (Hansen, 2012, p. 4)

There have been claims that the environmental movement has been co-opted by the very forces it sought to change. Wissenburg and Levy (2004) note that “environmentalism can be accommodated, pacified and neutralized, generally because it addresses the environmental issues in terms of concepts and values, such as knowledge, judgement, interests, welfare, beauty, sustainability and justice” (p. 193). Shellenberger and Nordhaus (2004) argue that decades of efforts and investments by the environmental community have produced few tangible successes in dealing with critical issues such as climate change.

I noted earlier that critical reflection and assessment is necessary for social movements to transform themselves in times of inertia. The critiques noted above are the foundation for what many writers articulate as the next iteration of environmentalism.

\section{Themes of Contemporary Environmentalism}

In synthesizing the preceding material, it is possible to discern several themes about what constitutes the current condition of environmentalism:

- As a worldview, environmentalism is heterogeneous and diverse, and has tended to accommodate new outlooks, outcomes, and approaches rather than reject them. Taylor (2010) describes this condition as a "global environmentalist milieu in which shared ideas incubate, cross-fertilize, and spread. It is a process characterized by hybridization and bricolage" (p. 14). A shared perspective is that humans are embedded in, not masters of, the natural world. 
- In the context of accommodating new perspectives, environmentalism can be said to demonstrate a propensity for change and adaptation. The historical context shows an evolution of focus over the past half century. Those who believe in environmentalism have shown an ability for self-reflection and learning, the outcome of which is a determination to find ways to reform and change to become more effective. The strategies and tactics have changed from an approach involving small groups of people interacting primarily with government, to a social movement involving large numbers of participants. In the last decade, the incorporation of social media into the environmental tool kit has enabled new forms of communication and mobilization.

- The diversity that characterizes environmentalism encompasses viewpoints that focus on wilderness conservation and preservation, green technologies, and environmental justice. It includes moderates engaged in incremental change, and activists who push for transformative change to the social and economic order. There are environmentalists who believe that the current economic system with its emphasis on growth and consumption is the root of modern environmental problems, and those who believe that market solutions and technology can solve the challenges we face.

- A Cassandra theme runs through much of modern environmentalism, which emphasizes threats, degradation, loss, collapse, and apocalypse. This negative attitude attracts like-minded supporters, but does not resonate with the larger population.

- Modern environmentalism has been in existence for half a century, and notwithstanding its popular origins among the Baby Boomers, now involves other generations who came after them. However, the founding generation in many ways continues to define environmentalism, shaping it through decisions and priorities, 
organizational structures and campaigns, and the provision of funding. This has implications as the older generation begins to retire from their involvement - and younger generations that do not share the formative experiences and views of their parents assume their role in defining environmentalism.

- The environmental movement, a diverse social movement that emerged alongside modern environmentalism, has evolved to include well-resourced, professional organizations that project a strong voice on environmental matters. The presence of such institutions is seen both as a strength for securing resources and undertaking mission-based projects, and as a limiting factor in relationship to supporting and encouraging local community and grassroots efforts.

- At the individual level, those who hold environmentalism as their worldview have shown enormous passion for their beliefs. Over the course of the last half century, this has manifested in changes to personal lifestyles, participation in social movement events, and choices about philanthropic and volunteer actions.

- In its formative years during the 1970s, modern environmentalism galvanized the public in the United States and Canada, and inspired the creation of seminal legislation and the agencies necessary to monitor and enforce environmental standards. However, over the last three decades, the ability to address global environmental challenges such as climate change, species loss, ocean acidification, deforestation, and toxic waste has been less effective. This ineffectiveness likely reflects the complexity and costs (both economic and political) of concerted action, but also a lack of urgency and will to address problems that appear to have long-term 
consequences. All the while, polling indicates that the environment remains a high concern for the general public.

- The environmental movement and environmentalists have been the subject of concerted attacks and campaigns of disinformation that attempt to frame the scientific evidence as inconclusive, or as part of a narrative that environmentalists do not care about people's jobs, communities, and material standards of living. Some business and political interests have actively promoted such environmental scepticism. The themes noted above support my broad definition that modern environmentalism is a way to conceptualize the human relationship with the natural world, a critique of the excesses of modern industrial society, and the foundation for a diverse social movement seeking to change economic and political systems. In Chapters Five and Six, I contrast the themes noted above against those that emerged from the research. The overall suggestion is one of continued change instead of transformation; in which younger people who care about the environment are more narrowly focusing their outlooks, changing their tactics, and embracing new attitudes when compared to the contemporary themes noted above.

\section{Future Visions of Environmentalism}

I begin this section with a quote from Dunlap (2004), who writes that "it seems certain that environmentalism has a future, for it developed in response to real problems and deep human needs that still exist" (p. 148). Much of what the environmental movement initially advocated for has been incorporated into mainstream political and economic institutions. In response to the calls for action during the formative years of the environmental movement in the late 1960s and 1970s, governments created departments 
of the environment, enacted environmental laws, and cast themselves in the role of environmental guardians. Businesses responded to increasing consumer demands that they go green through the creation of environmental products and sustainability practices. Individuals have similarly changed their own behaviours. Dunlap (2004) writes, with respect to environmentalism, "how people, over the past forty years, have changed their values and their lives in response to their new understanding of their place in the world" (p. 94). However, after five decades of effort by the environmental community, many of the global indicators for environmental health are moving in the wrong direction.

Far from being lamentable, this less effective turn could be seen as the normal evolutionary pattern that social movements go through. In particular, the transformation of a movement into professional organizations often marks the end of mass activism on a particular issue. However, I maintain that when social movements - as well as their conceptualizing frameworks - arrive at a point of stasis, they must reinterpret the issue and change their tactics in order to achieve their goals. According to Dunlap (2004), environmentalism has been at this crossroads before. He points out:

the confusion and contradictions so evident in the 1980s should not be seen as signs of collapse but as products of environmentalists' engagement with these deeper questions. Having reached the limits of accepted categories and conventional action, they had to find paths, and that meant wandering and stumbling. (p. 147)

Recent visions of what the next iteration of environmentalism should look like, conceptualized in the last decade, can be summarized under five themes: an increasing emphasis on people; a focus on local and grassroots organizing that characterized the 
early years; a hopeful vision for the future; a deepening spiritual perspective; and the long view. Most of these views reflect the perspectives of the research participants profiled in Chapter Five; others do not. In all cases, the future visions noted are from the perspective of individuals at least a generation older than the participants who are the subject of the dissertation. I elaborate on the similarities and differences in Chapter Six.

\section{Focus on people.}

Advocates of this perspective (Jamieson, 2007; Sandler \& Pezzullo, 2007; Wenz, 2007) argue that environmentalism must explicitly link the natural and the human environments, and promote democracy, equality, and social justice. This theme incorporates a view that changes to human behaviour and systems are more likely to occur when an environmental issue impacts an individual at a personal level. Haq and Paul (2012) claim there is a need to provide "a positive agenda for the future that focuses on human wellbeing" (p. 96).

\section{Local and grassroots.}

Haq and Paul (2012) argue there should be "a greater focus on grassroots action and green localism" (p. 99). They believe that engaging the public is best achieved through local groups focused on local priorities. They also contend that local groups should increasingly act in coalitions, and that "a new global generation of grassroots groups will be central to providing the power and legitimacy this green coalition needs" (p. 25).

Sandler and Pezzullo (2007) note that "local environmental groups that have autonomy over their agenda and are not pulled along by institutional inertia may also find more opportunities for effective alliances" (p. 317). 
Park et al. (2008) echo this call for a return to community-based models of engagement, arguing that "more serious forms of civil engagement, political participation, and articulation of what people really want and need are urgently required" (p. 10). Theda Skocpol, a political scientist who studies social movements, likewise advocates for local organizing and coalitions (Lemann, 2013). Hansen (2012) contends that more environmental victories will be achieved by "increasing funding for grassroots communities that are directly impacted by environmental harms and have the passion and perseverance to mobilize and demand change" (p. 1).

\section{Hopeful vision.}

Proponents of a hopeful vision argue that the motivation to effect change is driven more by visions of hope, instead of despair. Jamieson (2007) contends there is a need to transform "environmentalism from a collection of views and prejudices united by their opposition to various policies and projects into a set of positive visions that can guide us into the future" (p. 98). Hawken (2007) notes "no speaker wants to leave an auditorium depressed, however dark and frightening a tomorrow is predicted by the science that studies the rate of environmental loss" (p. 1).

\section{Deepening spiritual perspective.}

A number of scholars (Dunlap, 2004; Hays, 1987; Taylor, 2010) emphasize the spiritual dimension of environmentalism, and suggest that the future will involve a deepening reverence for nature. Taylor (2010) believes that adopting a view "that everything in the biosphere is interdependent, intrinsically valuable, and sacred" is central to the way forward (p. 102). Dunlap (2004) agrees with this sentiment, arguing that "seeing environmentalism in religious terms would focus discussion about what 
ought to be done, help environmentalists confront their opponents, provide a way to make common cause with outside groups, and allow environmentalists to appreciate more clearly their own movement" (p. 164).

\section{Long view.}

Park et al. (2008) argue that a more effective environmentalism "must be a forward-looking task, and not simply an exercise in criticizing past or ongoing failures" (p. 9). Haq and Paul (2012) believe that the future of environmentalism must integrate society, culture, economy, ecology, and equity into a vision of a desirable future. They argue that in order to overcome the scepticism of those who oppose environmental initiatives, "environmentalists may need to clarify their worldview and undertake, among other things, an internal debate about the role of technology in addressing new global environmental challenges" (p. 95). This is a view echoed by Nordhaus and Shellenberger (2007), who argue for an "explicitly pro-growth agenda that defines the kind of prosperity we believe is necessary to improve the quality of human life and to overcome ecological crises" (p. 15).

\section{Summary}

In this chapter, I have provided contextual material regarding the meaning of modern environmentalism, the environmental movement, and environmentalist. I have outlined how environmentalism has evolved over five decades, and that it has tended to add on new views and perspectives rather than undergo radical transformation. I also point out that addressing the dialectic between being active and being an activist is important for the future of environmentalism as a positive, broad-based worldview. 
I characterize environmentalism as a strong voice, but one that needs to adapt to new circumstances - particularly the evidence that key global environmental indicators show continued degradation of the natural systems upon which human society and other species depend. In this context, the perspective that environmentalism and the environmental movement are stuck and need to reappraise the way forward is a pervasive theme. This is ably illustrated by Dunlap (2004), who states "in 40 years it has changed but not transformed American society, and its established tactics and programs seem unlikely to do much more than they have" (p. 149). I conclude with visions for the future of environmentalism articulated by writers and scholars. The next chapters assess whether those visions are coming to pass, as evidenced by the beliefs and actions of a younger generation of environmentalists. 


\section{Chapter Three: Theoretical Frameworks}

\section{Introduction}

In Chapter One, I defined environmentalism as a way to conceptualize the human relationship with the natural world, a critique of the excesses of modern industrial societies, and the foundation for a diverse social movement seeking to change economic and political systems. In Chapter Three, I turn to social movement theory and generational theory as frameworks from which to ground and focus the research. I apply these two theoretical frameworks in order to understand how environmentalism emerged and has evolved. Both theories predict how change occurs over time, and as the purpose of this dissertation is to gain insight into how contemporary young people who care about the environment are interpreting environmentalism, then such theories can help explain a finding of continued change.

Social movement theory explains how an issue or injustice can grow from a belief held by a small group of people to collective action that seeks transformative social change. Environmentalism is in part a coherent worldview, what Aerts et al. (1994) refer to as a shared view that provides a frame of reference and a sense of direction for how people find their way in the world. Like social movements, "new worldviews often start with the views of small groups or sub-cultures, and prepare, step-by-step, new concepts of reality" (Aerts et al., 1994, p. 9). Understanding how social movements evolve provides a useful framework for explaining the emergence and evolution of environmentalism as a worldview since the late 1960s, and for predicting that it will continue to change in the future. 
Generational theory focuses on how generational cohorts from distinct time periods shape and define themselves, and the world around them, through the shared experience of unique events and circumstances. Like social movement theory, generational theory also predicts how social change happens. In this case, the change occurs through generational consciousness and replacement, rather than the impact of grievance- or identity-based protests. The emergence of modern environmentalism in the late 1960 s can be understood in part as a generational phenomenon. As the purpose of my research is to discern whether a generational shift is under way with respect to how contemporary young people interpret environmentalism, I apply generational theory to help ascertain whether such a shift can in part be explained by experiences and characteristics that have a generational dimension.

In turning to theoretical frameworks, I am guided by Anfara and Mertz (2006), who examined the role that theory plays in qualitative research. They define theoretical frameworks as "any empirical or quasi-empirical theory of social and/or psychological processes, at a variety of levels (e.g., grand, mid-range, and explanatory), that can be applied to the understanding of phenomena" (p. xxvii). Anfara and Mertz contend that theoretical frameworks are central to how the researcher frames the research questions, chooses methodologies and methods, and interprets the emerging data. I believe that modern environmentalism can be seen as both a generational phenomenon and the foundation for a social movement, and I refer to generational and social movement theory in the following sections to help explain and interpret the research findings. 


\section{Social Movement Theory}

An appropriate starting point for an appraisal of social movement theory is a quote from Ted Gitlin, an activist instrumental in some of the early student movements in the United States during the 1960s. Gitlin (2003) writes, "movements are not centralized think tanks that adopt and enforce party lines. They are mélanges, dispersed, polycentric and fluid, their positions all over the lot. Movements frustrate our hopes for orderly reason" (p. 101). Nevertheless, theorists have studied social movements in order to discern patterns of formation and evolution.

A body of literature on social movements has emerged over the past four decades (e.g., Barry, 2004; Brand, 1990; Dalton \& Kuechler, 1990; Davis, McAdam, Scott, \& Zald, 2005; Eder, 1988; Rootes, 2004; Snow, Soule, \& Kriesi, 2004; Staggenborg, 2008; Talshir, 2004; Tilly, 1984). Much of this work has dealt with the appearance of social movements since the 1960s, including those focused on the environment, civil rights, women's rights, gay and lesbian rights, nuclear disarmament, and the war in Vietnam. Clemens (2005) acknowledges the centrality of this period to the creation of social movements, noting that "the great protest wave of the 1960s and 1970s championed a rejection of politics as usual" (p. 362).

Social movement theory is distinguished from social theory in general. Barry (2007) notes, "social theory is the systematic study of human society, including the processes of social change and transformation" (p. 9). From this perspective, social theory can be envisioned as a meta-theory under which the study of social movements as mechanisms for change can occur. 


\section{What is a social movement?}

A social movement typically arises in response to a contested issue, grievance, or injustice. Tilly (1984) argues that social movements are "a series of interactions between power holders and persons successfully claiming to speak on behalf of a constituency lacking formal representation" (p. 306). The goal is to drive fundamental change or transformation of "cultural arrangements, public opinion, and government policies" (Staggenborg, 2008, p. 1). A central feature of social movements is that they involve groups of people engaged in collective action in the pursuit of a goal (Snow et al., 2004). Characteristics of social movements are noted in Table 2.

A number of writers (Brand, 1990; Dalton \& Kuechler, 1990; Talshir, 2004) have observed that modern social movements in the Western world are predominantly middle class in nature. Dalton, Kuechler, and Burklin (1990) distinguish these newer movements from their predecessors, including "food riots and tax revolts in the eighteenth century and the revolutionary movements of the nineteenth" (Dalton et al.,1990, p. 7). Dalton et al. further differentiate social movements that emerged in the 1970s, including environmentalism, noting that they manifest as an alternative to the dominant structure of industrialized societies.

The suggestion is that many of the movements of the 1960s and 1970s were a postwar phenomenon involving a generation of younger, well-educated, middle-class individuals who began to question a focus on affluence and consumerism as the basis for measuring quality of life. Environmentalism can be viewed in this light. 
Table 2

Characteristics of Social Movements

\section{Characteristic}

- Form around an unresolved issue, grievance, or injustice, Tilly (1984) often between a marginalized constituency and a privileged group or authoritative structure

- Seek to create social change or transformation by questioning or destabilizing the status quo

- Depend on committed individuals and networks of activists to induce action and mobilize people

- In their early stages, often appear spontaneous and nonhierarchical

- The early stages are a period of consciousness-raising; the issue must be successfully defined and framed in order to gain public attention

- Grow to involve larger groups of people engaged in collective action

- Assuming the issue gains sufficient profile, movements can transform the political discourse and spark change

- The ultimate ends of social movement activism are the redistribution of power and resources to create a more just society

- If they endure, social movements develop the institutional capacity to coordinate action and mobilize resources, and social movement organizations emerge to support the movement's goal(s)

- If a settlement or understanding between the contending forces can be reached, or there is a sufficient response to the original grievance, the movement can tend toward demobilization and dormancy

- The movement must reframe the issue(s) and adapt to new circumstances in order to maintain momentum and relevance

\section{Reference}

Strang \& Jung (2005)

Strang \& Jung (2005)

Schneiberg \& Soule

(2005)

Staggenborg (2008)

McAdam \& Scott (2005)

Scully \& Creed (2005)

Davis et al. (2005)

Zald et al. (2005)

Campbell (2005)

Snow et al., (2004)

Schneiberg \& Soule (2005)

Scully \& Creed (2005)

Davis et al. (2005)

Brand (1990)

Koopmans (2004)

McAdam \& Scott (2005)

Koopmans (2004)

Rootes (2004)

Williams (2004) 
It is also possible to distinguish between identity-based and interest-based social movements. In the former, the participants largely speak from the perspective of marginalization or oppression, and their goal is to gain respect for a different way of being (Scully \& Creed, 2005). Identity-based discourse and actions are key elements of such movements. Examples include movements advocating for the rights of gays and lesbians, minorities and people of colour, and to some extent women's rights.

Scully and Creed (2005) distinguish identity-based movements from those "that arise around shared interests or issues, such as peace, the environment, anti-nuclear, prochoice or prolife, welfare rights, or labour movements" (p. 326). Interest-based movements are noted for having specific agendas and goals, rather than outcomes based primarily on inclusion and equality.

In acknowledging that social movements have multiple interpretations, I prefer the definition proposed by Snow et al. (2004):

Social movements can be thought of as collectivities acting with some degree of organization and continuity outside of institutional or organizational channels for the purpose of challenging or defending extant authority, whether it is institutionally or culturally based, in the group, organization, society, culture, or world order of which they are a part. (p. 11)

\section{The formation and evolution of social movements.}

Common to the literature is a claim that social movements form during periods of social tension or uncertainty, together with a perception that existing institutional structures are unable to effectively deal with an observed problem or injustice. Brand (1990) refers to the movements of the 1960s as arising in a moment of "a general cultural 
crisis, in an atmosphere conducive to a spreading critique of modernization” (p. 25).

Dalton and Kuechler (1990) echo this, claiming that the social movements of the 1960s formed as a collective protest against contemporary societal conditions.

Eder (1988) cites research to show that social movements are common in modern societies, with groups regularly mobilizing to challenge aspects of the existing order. As movements build and become established in the public consciousness, they take on shared beliefs that permit both a sense-making function and the organizational capacity to effect change. Eder argues that once a movement reaches this stage, it inevitably begins to institutionalize. This institutionalization can in turn lead to the normalization of the movement into society, thus negating its original grassroots character (Eder, 1988).

Once formed, the defining characteristics of social movements include shared beliefs and interests, networks of information distribution, the use of protest, and the development of the professional capacity to support collective action (Gladwell, 2010; Talshir, 2004). Dalton and Kuechler (1990) also note that social movements typically have a core membership, a significantly large body of sympathizers, and a nonhierarchical structure. This open structure is often unable to sustain discipline and focus, and can lead to a professionalization of the movement that can undermine its grassroots origins. It is possible to see such trajectories in the contemporary Occupy Wall Street and Idle No More movements. In the case of Occupy, the organizing was done as a collective exercise. David Graeber (2014), a social theorist who participated in and helped document the actions in New York, writes "When operating by consensus, a group does not vote; it works to create a compromise, or even better, a creative synthesis, that 
everyone can accept" (p. 30). Social movement theory would predict that in the absence of structure and strong leadership, a movement can lose momentum.

A number of studies describe the evolutionary pattern of social movements, from initial mobilization through to their ebbing into dormancy. Brand (1990) claims that social movements mobilize in a period of cultural crisis, reach an apex, and then subside into an inactive state. Like Eder (1988), he argues that one of the reasons these movements ebb is that they become institutionalized, a claim supported by Barry (2004), and Nordhaus and Shellenberger (2007). Koopmans (2004) prefers the term waves instead of cycles, and asserts "The notion of cycles suggests a periodically recurring sequence of phenomena" (p. 21). He believes that periods of crisis are themselves episodic, representing increasing and decreasing levels of contention in society. Jamison (1996) likewise discerns the recurring nature of social movements, and contends that they are essentially an early warning sign that a problem is emerging with respect to existing institutional structures - which if not dealt with will lead to a protest discourse that can mobilize a significant segment of society.

If the target of the movement's protests responds with even a modest commitment to accommodation or change, this may precipitate movement demobilization. Zald et al. (2005) note, "Even if movement leaders and key constituencies are not satisfied with the bargain encapsulated in a bureaucratic program or in a regulatory policy and agency, the movement can demobilize and accept stasis" (p. 262).

In the context of the extraordinary wave of social movements that emerged in the 1960 s, the rise of the environmental movement is noteworthy. A number of researchers (Dalton \& Kuechler, 1990; Jamison, 1996; Rootes, 2004; Talshir, 2004) argue that the 
environmental movement has been a key factor in the protest discourse aimed at modern society, and that the continued environmental critique of the last few decades has led to significant changes in the way the public view environmental issues, as well as the way in which institutions respond to movement demands.

With respect to Koopmans's claim for waves of social movements, he suggests "the wave metaphor ... simply refers to the strong increase and subsequent decrease in the level of contention" (Koopmans, 2004, p. 21). Koopmans argues that mobilization and demobilization are iterative processes that stretch across time and space, and that movement actors attempt to "devise new strategies of contention, be they innovative forms of action or organization, novel alliances, or reformulated demands and ideological frames” (p. 41). I believe Koopman's assessment of social movements can be applied to the environmental movement, which has demonstrated an ability to evolve and adapt. In addition, the findings of this dissertation lend support to the claim that regeneration is a regular characteristic.

The claim for adaptation is echoed by Rootes (2004), who argues that the environmental movement has successfully demonstrated the capacity for renewal:

Contrary to what sociologists have often assumed about the inevitable fates of social movements - bureaucratization, institutionalization, ossification and, ultimately, death - environmental movements appear so far to have beaten the odds. ...Indeed, there is evidence of a cycle of regeneration that maintains the dynamism of the movements. (p. 633) 


\section{The application of social movement theory.}

Several aspects of social movement theory are applicable to my research, including an understanding of why the environmental movement emerged when it did, how it has evolved over time, and how a younger generation is interpreting environmentalism and experimenting with new forms of action.

The first aspect has to do with the initial identification of an issue or injustice, mobilizing people and resources to create change, and the reaction of those in authority who deal with the movement's demands. The evolution of the environmental movement, and the evolution of environmentalism as the rational and emotive basis for the movement described in Chapter Two, can be seen as evidence of such a pattern.

If the response to the issue is adequate, it can precipitate a movement's demobilization. However, the response is likely never enough to transform the system that caused the issue in the first place. Instead, just enough action is undertaken to mitigate the observed grievance. In this light, the environmental movement's actions can be seen as a constant effort to identify, mobilize, and effect change - as the underlying political and economic systems that precipitate environmental degradation remain largely intact. Understanding how social movements emerge and evolve is therefore helpful for recognizing how a worldview such as environmentalism must also adapt in the face of new scientific evidence, changing political orders, and shifting societal norms.

Furthermore, if social movement theory predicts how movements emerge and adapt, the theory also illustrates how environmentalism as the underlying framework for the environmental movement might be undergoing a similar process. As I noted in Chapter One, environmentalism and the environmental movement can be viewed as 
integrated phenomena - they have evolved in tandem. If environmentalism is evolving, I want to discern whether young people believe that such change is occurring. Specifically, I would expect to see indications that the change would mirror certain characteristics of this generation (for example, their use of social media technology), and that the language might be shifting (for example, individuals might reject certain terms as a reflection of something that does not resonate with them). In Chapter Five, I find that transition is a primary theme among the participants.

The final aspect is to understand if the participants recognize that change involves purposeful and sustained action to reframe the issues, build new coalitions and constituencies, and reinvent the organizational tactics necessary to address the kinds of environmental changes they desire. In Chapter Five, I find that the research participants are aware that new approaches are required. More importantly, at least half are applying their understanding toward new ways of defining the issues, creating networks, and developing fresh tactics such as the use of social media tools in their work.

\section{Generational Theory}

\section{Introduction.}

I have outlined how social movement theory can explain the appearance of modern environmentalism in the late 1960s, together with its subsequent evolution. Generational theory provides a complementary interpretation of how environmentalism emerged, and how social change occurs through generational replacement. A number of writers (Edmunds \& Turner, 2002; Foster, 2013; Hazlett, 1992; Mannheim, 1970; Marias, 1970; Owram, 1996; Rintala, 1979; Wohl, 1979) have written about the formation of 
generations, and how active generations play a role in social and cultural change. In describing the Baby Boomers, Edmunds and Turner (2002) note:

The size and strategic location of the post-war generation has proved to be an important and highly visible aspect of social change in the twentieth century. In cultural and political terms, the social consequences of the baby boomers or sixties generation could not be ignored. There is general agreement that this generation has played an especially important part in transforming the social, cultural and political climate of the contemporary world. (p. 3)

I concur with their observation, and believe that the events, campaigns, and movement building that occurred in the environmental community during the $1960 \mathrm{~s}$ and 1970s have helped to define modern environmentalism. In this context, members of the generation that built the environmental movement have been both active and pervasive. Their notion of environmentalism has tended to dominate much of the thinking and discourse over the past five decades. Owram (1996) argues that environmentalism is one of the significant social issues raised by the Baby Boomers in the 1960s, and notes that it did not exist before that time (p. 314). As the Baby Boomers enter retirement, they continue to exert influence through gifts of funding they provide to environmental organizations that are often tied to outcomes that reflect their views on environmental issues.

This generation - the postwar Baby Boomers born between 1946 and 1964 - is now approaching an age where many are retiring from active professional life. The generations that will come after them do not share the same formative experiences and assumptions. Generational theory predicts that social change can occur through 
generational replacement. The implication for a younger generation replacing a dominant cohort that largely defined modern environmentalism is that change will occur not only through the emergence of new ideas, worldviews, and tactics, but through the gradual disappearance of those who came before. Pilcher (1994) notes that if a social movement is distinctly generational in nature, it will lose its solidarity and demobilize as younger cohorts displace the founding generation. I do not believe the environmental movement will fail as the Baby Boom generation retires from active life; only that they have defined its formative views and that succeeding generations will add their own meanings. The suggestion is that both a generational transition and the identification of new interpretations must occur for the movement to evolve. In Chapter Five, I note that the research participants believe a transition is under way, which implies evolution instead of an outright rejection of existing views and strategies.

Finally, Jaeger (1985) argues that the claim that certain historical circumstances "tend to lead to specific formative experiences during adolescence and that they, in turn, lead to generational contexts and generational communities according to Mannheim's definition, can be viewed as a solid and productive hypothesis" (p. 286).

\section{What is generational theory?}

Generational theory states that cohorts of individuals in their formative years (late adolescence and early adulthood) who undergo the experience of a major event or trauma such as war, upheaval, natural catastrophe, economic dislocation, or population boom can develop a collective consciousness that differentiates the group from others (Edmunds \& Turner, 2002; Mannheim, 1970). The phenomenon may manifest at different geographic scales and cultures (Pilcher, 1994). 
Generational theorists further claim that within a generational cohort, there can exist different generational units. Mannheim terms these "differentiated, antagonistic generation-units. Together they constitute an 'actual' generation precisely because they are oriented towards each other, even though only in the sense of fighting one another" (Mannheim, 1970, p. 398). Edmunds and Turner (2002) argue that "the notion of generational unit can be useful to understanding contemporary generational movements" (p. 9). The implication of generational units for this research is that those who are passionate about environmental issues, whether in the 1970 s or the 2010 s, constitute a smaller proportion of the overall generational cohort. I do not argue that environmentalism is the dominant worldview, but one of many contending visions.

Karl Mannheim was a pioneer in formulating a theory of generations that incorporates views on collectively shared life experiences, clusters of opportunities, and common time frames (Edmunds \& Turner, 2002). In The Problem of Generations, written in 1928, he concluded that generations acquire a certain social solidarity based on their shared worldview, and that this persists even as the cohort ages (Mannheim, 1970).

Foster (2013) builds on this thinking, but contends that generations are constructed by discourse. She argues that treating generation as a discourse: is to conceptualize "generation" as a vehicle for thought and action; it is to posit that "generation" (as a concept networked to a lexicon of other specific concepts) is a mental structure that provides people with, and limits them to, specific way(s) of understanding, speaking about and acting in the world around them. (p. 23) Foster believes that generational discourse plays a role in social change. She contends that the aforementioned mental structures impact personal choices and decision 
making, and that such responses over a larger population can lead to new ways of thinking and action. Relevant characteristics of generational theory are shown in Table 3.

Table 3

Characteristics of Generational Theory

Characteristic

- Generations form in relation to major events (e.g., war and disaster), or times of rapid social change (economic depression, large population increases or decreases), leading to a collective consciousness among people who share the experience at the same stage of life

- Generations are a way of encapsulating the unique experiences and worldviews of people born at different times

- A generation is a cohort of individuals born and raised within the same historical and social context, who consequently share a common worldview

- Formation of a generational worldview is most pronounced when the major event or trauma is experienced by individuals in their late adolescence and early adulthood

- Once formed, worldviews persist through a person's life

- Generations are most distinct in the centre of the age cohort, less so at the boundaries; within a generation there can be more than one generation unit with different worldviews

- Generations can be viewed as mechanisms of social change

- Social change occurs through generational replacement
Edmunds \& Turner (2002)

Mannheim (1970)

Wohl (1979)

Mannheim (1970)

Pilcher (1994)

Lyons, Duxbury \&

Higgins (2007)

Braungart (1984)

Mannheim (1970)

Rintala (1979)

Mannheim (1970)

Rintala (1979)

Mannheim (1970)

Pilcher (1994)

Braungart (1984)

Edmunds \& Turner (2002)

Mannheim (1970)

Abramson \& Inglehart

(1995)

Mannheim (1970)

Pilcher (1994)

Edmunds and Turner (2002) note that generations are constructed through collective action and narratives, and that a feature of modern societies is the failure of cultural transmission between generations. This can result in intergenerational tensions, 
misunderstandings, and conflicts - particularly as a new generation rebels against the dominant culture of the older one. Will they embrace the foundational architecture of the existing worldview, or will they reject it as ineffective and out of touch? Do they think of older generations as mentors, or as impediments to change? A generational perspective is relevant to understanding the emergence and evolution of both environmentalism and the environmental movement.

\section{The youth dimension.}

A common element of the literature on generational theory is that generations are forged in late adolescence (Hazlett, 1992; Jaeger, 1985; Mannheim, 1970; Owram, 1996; Pilcher, 1994; Rintala, 1979). Mannheim believes that it is experiences in youth that serve as the basis for how one interprets later events. Rintala (1979) notes that it is "late adolescence and early adulthood ... that according to generations theory, are the formative years during which a distinctive personal world view, which remains unchanged in its fundamentals through old age, is formed" (p. 14). Pilcher (1994) contends that social generations are created as the result of formative experiences during youth. Braungart (1984) suggests that youth movements are collective actions of conscious generational units to mobilize and bring about social change. Abramson and Inglehart (1995) argue that a person's basic values are formed by the conditions that existed during pre-adult years. Hazlett (1992) concludes that an individual is "most aware of one's membership in a generation during the coming-of-age years ... when one is first entering the arena of history, rebelling against parental institutions, and experimenting with adult identities" (p. 77). 


\section{Generational consciousness among the Millennials?}

As previously noted, generational theory predicts that generational consciousness arises out of the shared experience of major events that a cohort participates in during their formative years. The question therefore arises as to what unique circumstances might inform the collective consciousness of the Millennial generation. Furthermore, what phenomena do the subset that cares about the environment share? I stress that the events that shape a generation are not the same as generational attributes. Polling and research about the Millennials suggest certain generational characteristics, although I note in the next section on Limitations of generational theory that caution must be taken when generalizing to an entire cohort.

1. Absence of War and Civil Disruption: Generational theory emerged out of research on young adults who had experienced the First World War, and was further developed after the Second World War (Mannheim, 1970; Rintala, 1979; Wohl, 1979). The theorists were grappling with the profound effects of global warfare to show how the experience differentiated this coming-of-age cohort from other generations. The theory was subsequently developed to add other major events such as the Great Depression, civil strife, catastrophic disasters (i.e., prolonged drought and famine), and population booms such as the Baby Boomers. What is perhaps unique to the Millennials, at least in the Western world, is the absence of major wars and civil strife that has characterized previous generations. However, there are other major circumstances that can be applied, as noted in the following points.

2. Technology: Technology has had an impact on the Millennial generation. They grew up with personal communications devices, the internet, and social media. A Pew 
Research poll on social trends conducted in 2014 noted that Millennials "are 'digital natives' - the only generation for which these new technologies are not something they've had to adapt to. Not surprisingly, they are the most avid users" (p. 3). A 2010 Pew study also noted that Millennials are enthusiastic users of technology, and concluded that social media and technology "are a badge of generational identity. Many Millennials say their use of modern technology is what distinguishes them from other generations" (p. 25). Studies undertaken on Canadian Millennials support the Pew findings. Bibby (2009) found that $98 \%$ of Millennials are using computers at least one hour a day (p. 88). Moreover, it is not that Millennials spend more time with technology that is the primary characteristic - but how it is used. The Pew studies $(2010,2014)$ note the impact of mobile devices and social media is to create networks of friends and like-minded groups. Millennials have also adopted social networking sites to create personalized profiles far more than any other generation (Pew Research Center, 2010, p. 28). Bibby's research shows that social media technology has led to an increase in the number of friends a young adult has, "in 1984, 49\% indicated that they had 4 or more close friends; today that figure stands at 72\%" (Bibby, 2009, p. 31). Bibby further notes "friendship possibilities have no geographical limits. With the basis for 'virtual communities' not locale but common interests, new social links can be established with anyone, anywhere." (p. 34). Personal technology, social media, and new ways of forging networks are a major circumstance or event that has defined the Millennials and sets them apart from other cohorts. The distinction fits the prediction of generational theory. As noted in Chapter Five, these characteristics are also major themes among the research participants. 
3. Economic Recession: The global economic recession of 2008-2009 has been characterized as the most severe since the Great Depression of the 1930s (Wessel, 2010). Generational theory predicts that the experience of a deep economic recession can impact a generation of young adults who are establishing themselves through work and school. The 2014 Pew Research study found that "Millennials are also the first in the modern era to have higher levels of student loan debt, poverty and unemployment, and lower levels of wealth and personal income than their two immediate predecessor generations" (p. 5). The study goes on to say that "today's young adults face more economic challenges than their elders did when they were first starting out" (p. 5). The suggestion is that debt and poor employment prospects will define the Millennial generation as much as social media and technology. However, I caution that such a description is being applied to an entire generation. In Chapter Five, I indicate that the research participants are part of a subset that is well educated, has close connections to family, describe themselves as middle class - and while they might have high student loan debts, they are entering the work force with optimism about their economic future. Checking back on the group a year after the interviews, most of them had secured employment in areas relevant to their education and experience.

4. Environmental Issues: A final element of generational consciousness applicable to this dissertation is the increased awareness of global environmental challenges. The research participants in particular raised climate change as a critical challenge. In Chapter Four I note that shifting baseline syndrome, the idea that people take as their reference point the conditions that existed when they grew up, indicates that the 
Millennials emerged at the same time that scientific evidence was showing climate change was already occurring. It was not something the generation learned later in life. This was clearly evident among the research participants; however, it is not so evident among the broader Millennial population. A 2010 study by the Yale Project on Climate Change and the George Mason University Center for Climate Change Communication found that contrary to suggestions that young Americans who grew up with scientific evidence of climate change would be more concerned about it, "American between the ages of 18 and 34 are, for the most part, split on the issue of global warming and, on some indicators, relatively disengaged when compared to older generations" (Feldman, Nisbet, \& Leiserowitz, 2010, p. 2). The 2014 Pew study supports this ambiguity, stating that "Millennials are also somewhat less likely than older adults to describe themselves as environmentalists - just 32\% say this describes them very well, compared with at least four-in-ten among all older generations" (p. 10).

It is important to stress, however, that generational theory does not argue for single, monolithic generational views. The presence of differentiated units within a generation is an essential element of the theory. The indication that young people who care about the environment might have a common understanding of the challenges that is different from a poll of the broad spectrum of Millennials does not imply inconsistency. I discuss this further in Chapter Five.

\section{Limitations of generational theory.}

Some theorists (Foster, 2013; Hazlett, 1992; Jaeger, 1985) have argued that attempts to generalize and stereotype generations from smaller cohorts of individuals lack 
evidence. Social activist Todd Gitlin (2003), in describing the youth dimension of social movements of the 1960 s, notes "generational blocs do not march like unified phalanxes. In the true down-on-the-ground sixties, radicalism was not all of a piece. Sex-drugsrock'n'roll, the soft part, was not glued to political radicalism, the hard part' (p. 30). Jaeger (1985) posits that efforts to generalize "shows only that those who search with enough evidence for analogies in historical tables will always come up with something" (p. 282).

Foster (2013) argues that from a sociological perspective, categorizing individuals as part of a generation "represents an attempt to capture and contain people in a way that can overstate their commonalities and underestimate their propensity to change, or to be anomalous" (p. 18). Hazlett (1992) believes that the literature on generations tends to be male-dominated, reflecting the idea that traumas such as war tend to be mostly about the experiences of men. He notes that the development of group consciousness among women in the early 1970 s "produced the need and the desire to define themselves in their own terms ... their primary group identification, however, was not the generation (though there were some female generationalists in the later phases of this group's output), but all women, past, present, and future" (Hazlett, 1992, p. 92).

I acknowledge these criticisms, but argue they do not lead to a rejection of generational theory. A careful reading shows that the proponents of the theory do not argue for a reductionist approach that defines generations with certain qualities and attitudes. Instead, they argue that generational consciousness and replacement can be seen as mechanisms for social change. 


\section{The application of generational theory.}

There are elements of generational theory that are useful for explaining the rise of modern environmentalism and the environmental movement. Generational theory can help explain the emergence of environmentalism among young people in the late 1960s and early 1970s. According to the theory, a generation in their formative years (constituted by different generational units, at different locations) can develop a social consciousness based on a shared experience, and that consciousness is reinforced through competition with an existing generation in power. The challenge, as noted by Edmunds and Turner (2002), is that evidence for such a pattern is often seen in hindsight - unless the shared experience is powerful and widespread.

In explaining the emergence of environmentalism, it is noteworthy that environmental historians argue there is a link between the emergence of the Baby Boomers (those born between 1946 and 1964) and modern environmentalism. MacDowell (2012) writes that environmental issues were popular within the 1960s counterculture movement, finding inspiration in the early naturalist writings of Thoreau and Muir. Forkey (2012) argues that provinces like Ontario "felt the baby boom in a significant way: its population rose from 3.8 million in 1946 to 6.2 million in 1961” (p. 80). He notes that it was during this time that Ontarians visited provincial parks in record numbers, and that the growing affluence of the time "pushed people outdoors, especially to spend more time with their children" (p. 80). Forkey contends that this childhood experience of nature was a formative element in the later emergence of environmentalism, as many of these children entered adulthood and became part of the environmental movement. McKenzie (2002) discerns the emergence of a counterculture 
generation in the 1960s, with a new environmental consciousness rooted in outdoor experience among a younger, physically active population (p. 62). Haq and Paul (2012) believe that the emergence of a counterculture in the late 1960s was "driven by a new generation of young people who were openly critical and rebellious" (p. 7). They contend that the emergence of this generation was the foundation for the emergence of the modern environmental movement.

Rome (2003) notes that millions of young people were attracted to environmental causes in the late 1960s, and that this helped make environmentalism a social movement. Finally, Mark Fiege (2012) suggests that the rising level of affluence after the Second World War in the United States "gave husbands and wives a level of economic security that encouraged them to produce some seventy-five million children between 1946 and 1964" (p. 374). He contends that the emergence of this cohort into adulthood in the late 1960s helped to propel the environmental movement.

Edmunds and Turner (2002) note generations often appear in hindsight identifying them while they are forming, or predicting future characteristics, is subject to too many unknowns. Nevertheless, there are several factors involved in the application of generational theory to the current generation of young adults:

1. The size of the generation currently in their twenties (often referred to as Millennials) ${ }^{1}$ is similar in size to the Baby Boom cohort who are their parents. I noted earlier that one of the predictors for the development of a generational consciousness is the size of a cohort when contrasted to those who became before it. What is different in the case of the emerging generational cohort is that there still exists a

1 There are multiple interpretations for what year the Millennial generation starts, ranging from 1977 to 1983. Pew Research in the United States uses 1981. 
large, active demographic bulge further ahead of them in age. They are not the only population boom - but it is a certainty that they will replace the boom that is their parents.

2. Most of the writers of generation theory refer to some distinguishing experience that is different from other generations. I noted earlier that communication technology and the experience of economic challenge are often used to characterize and distinguish those in their twenties. In the case of technology, scholars such as Bibby (2009) argue that the volume of information available to Millennials through the internet, the amount of time they spend online, the way they use communications technology, and the fact that they grew up with it, sets this generation apart from previous ones. With respect to the economic challenges that have resulted from the recession of the late 2000s, it is likely too early to determine the long-term impact on the Millennials, but the emerging data suggest that this generation is facing a future different from that of their parents. According to Generation Squeeze (2014), an initiative of the University of British Columbia that focuses on the challenges facing younger generations, "While the economy doubled since 1976, average wealth for Canadians aged 25-34 fell $41 \%$. At the same time, average wealth grew $176 \%$ for those aged 55-64” (p. 1).

3. In Chapter Four, I refer to shifting baseline syndrome, the idea that people take as their reference point the conditions that existed when they grew up. The generation in their twenties grew up with the notion that climate change was a reality already occurring around them. It was not something they learned later in life. As such, it is possible to predict contemporary young adults who care about the environment will 
be more concerned with adapting to the impacts of climate change - rather than mitigation - knowing that it cannot be prevented.

4. There are generational differences based on shared experiences, the evolution of social media and popular culture, the complexity of emerging global environmental challenges, and the economic disruptions that the current generation of young adults have faced in the preceding half decade. Whether these differences are significant enough to lead to the development of a generational consciousness as defined by generational theory is not completely clear - but there are indications that Millennials themselves believe they are a distinct generation. The 2010 Pew Research report notes that "Most Millennials (61\%) ... say their generation has a unique and distinctive identity" (p. 5). That is why the integration of deep storytelling through phenomenological research is important. The goal is to look for common themes among a diverse group of younger individuals, based on environmental beliefs, values, attitudes, and behaviours. I seek to discern and interpret whether new interpretations of environmentalism are emerging among a younger generation.

\section{Summary}

Social movement theory provides an explanation for the emergence of environmentalism and the environmental movement in the late 1960s, how they evolved over the subsequent four decades, and why they were challenged during that time. Many of the criticisms of the environmental movement I described in Chapter Two can be viewed as outcomes predicted by social movement theory. Furthermore, the theory states that social movements must reframe the issue(s) and adapt their tactics if they are to 
continue. Such adaptation is supported by the participant responses on the future of environmentalism I describe in Chapter Five.

Generational theory also provides an explanation for the emergence of modern environmentalism in the late 1960s. Moreover, it can be applied to predictions that it might change in the future. The theory posits that the core beliefs and values that an individual acquires in their formative years (adolescence and early adulthood) remain with the person throughout their life. Baby Boomers with distinct worldviews largely defined environmentalism in the late 1960s and early 1970s, and subsequently shaped its evolution through their professional lives. To use an analogy, they are the architects of modern environmentalism - and the structures they put in place have tended to shape the movement, organizations, and tactics that have made up the environmental community over the past half century. The leading edge of this cohort is beginning to retire from active careers. One of the tenets of generational theory is that social change occurs through generational replacement. It is possible to predict that the vision for the future that many in the environmental community have called for will happen as much through the diminishing influence of the Baby Boomers, as it will through the introduction of new ideas, tactics, and leadership. Understanding the beliefs and values of the generation in their twenties who are concerned about environmental issues is a possible indicator of how environmentalism might evolve. I return to this point in Chapters Five and Six. 


\section{Chapter Four: Research Design}

\section{Introduction}

The purpose of my research is to gain insight into how young people who care about the environment interpret environmentalism, and to apply the results to the organization in which I work. As noted in Chapter One, the motivation for the study arose from conversations with younger staff at the David Suzuki Foundation. Through my interactions with this group, I became aware that their approach to environmental issues might have a generational dimension. I was curious to know more about this observation, and chose it as the subject of my doctoral research. In particular, I was interested in questions of how young people might be conceiving environmentalism and what were the experiences that might inform their views.

To achieve the research purpose, I conducted a phenomenological study of a group of young environmentalists from British Columbia. I drew on their stories of what environmentalism means to them, how they try to live their lives in accordance with their beliefs about the environment, what they think of the modern environmental movement, and how they perceive the future of environmentalism as a way to conceptualize the human relationship with the natural world.

As noted in Chapter Three, I applied social movement theory and generational theory to the research to provide a foundational context for the information that surfaced through the participant interviews. Anfara and Mertz (2006) note that "A theoretical framework has the ability to (1) focus a study, (2) reveal and conceal meaning and understanding, (3) situate the research in a scholarly conversation and provide a vernacular, and (4) reveal its strengths and weaknesses." (p. 192). 
I chose phenomenology as my research methodology because I was interested in the experiences and understandings of the participants at a deeper level than what might emerge through a survey or questionnaire. Following this approach, I conducted face-toface interviews with 20 individuals, and then used a qualitative data analysis software program to help me interpret the themes and perspectives that emerged. Chapter Four describes the research design, and provides the rationale for the questions asked during the interviews.

\section{Qualitative Research}

I begin with a reference to qualitative research methodologies in general, for the value of such approaches is that they permit a full description of human experiences that is not possible with quantitative methods that separate an individual's story from the analytical outcome (Kvale \& Brinkman, 2009). Hesse-Biber and Leavy (2011) note that "qualitative researchers are after meaning. The social meaning people attribute to their experiences, circumstances, and situations ... are the focus of qualitative research. Therefore, at the heart of their work, qualitative researchers try to extract meaning from their data" (p. 4).

In the context of choosing either a qualitative or a quantitative approach, Silverman (2006) argues that the decision is contingent on what the researcher is trying to find out. He contends that "the main strength of qualitative research is its ability to study phenomena which are simply unavailable elsewhere" (p. 43). Hesse-Biber and Leavy (2011) further note that:

Qualitative approaches to research typically use qualitative "inductive" methods. This means projects frequently begin with the accumulation of specific data, the 
analysis of which leads to a more general understanding of the topic. Therefore, guiding research questions are generally open-ended, allowing for a multiplicity of findings to emerge. (p. 9)

The above-noted writers stress the inductive nature of qualitative research, in contrast to the more predictive approach that characterizes quantitative methodologies. From the qualitative perspective, the researcher interacts with the participants, rather than treating them as objects of investigation. It was in the context of seeking to understand how young people who care about the environment might be interpreting environmentalism that I chose a qualitative approach, and identified phenomenology as the appropriate methodology to achieve this purpose.

\section{Research Methodology}

Phenomenology.

Simply put, phenomenology is a methodology to describe and interpret the way various experiences are conceptualized and understood by individuals. It captures the subjective viewpoint of the participant's experience, and results in descriptions that allow the researcher to ascribe meaning. In phenomenology, individuals are the units of analysis and the basic research method is the interview.

From an historical perspective, phenomenology illustrates the evolution of Western philosophy over the early twentieth century. Edmund Husserl, a German philosopher, introduced the concept of phenomenology in 1900 (Sokolowski, 2000). Groenewald (2004) and Moran (2000) describe this period as a time of crisis in philosophy, particularly as it relates to an emerging criticism of the positivist, empirical 
scientific methodologies that had dominated the nineteenth century. Phenomenology was seen as a way to revive philosophy by returning to the individual human experience.

Over the course of the twentieth century other philosophical movements emerged to challenge the phenomenological approach. Nevertheless, phenomenology has a long history of practice, and has recently re-emerged in the health and education fields where it has made a significant contribution to understanding the day-to-day experiences of nurses, patients, and teachers (Caelli, 2001; Moustakas, 1994).

As an illustration of the application of the phenomenological approach, I note the use of this methodology by Lisa Korth in her 2008 dissertation Environmental Literacy of San Marcos River Conservationists. Through her research, Korth drew upon the stories of river conservationists to show that positive experiences in nature are a key determinant of lifelong environmental literacy. Her use of phenomenology was the basis for her findings about integrating field experiences into environmental education programs.

A further example is provided by Worthy (2013), who employed phenomenology in his studies of how people have become disconnected from the natural world. He stresses the importance of studying the human experience, and argues that "phenomenology differs greatly from the analytical study of ideas that are only indirectly associated with experience, such as propositions and logical principles, which is the concern of much modern, academic philosophy" (p. 75). Worthy's comments reflect the notion that a phenomenological approach focuses the research on understanding and interpretation. 


\section{Advantages of phenomenology.}

The phenomenological approach focuses on describing and analyzing the essence of human stories and experiences. It is part of what Hesse-Biber and Leavy (2011) term the interpretive strand of qualitative research, which "focuses on understanding, interpretation, and social meaning" (p. 17). The advantages of this approach include:

- It is an effective way to understand how an individual experiences a particular phenomenon (Hesse-Biber \& Leavy, 2011).

- The process focuses on an individual's experience - and proceeds from the assumption that individuals describing the same phenomenon may have a shared view (Marshall \& Rossman, 2011).

- Open-ended interviews lend themselves to an informal, interactive process that allows the participant to provide an in-depth description of their experiences and thoughts (Moustakas, 1994).

- Phenomenology provides a systematic structure for collecting and analyzing data (Moustakas, 1994).

- The approach focuses on understanding the whole of an individual's experience, which is important for integrating the way a person acts on their values and beliefs (Sokolowski, 2000).

\section{Disadvantages of phenomenology.}

- It can be time consuming. For my research, it took approximately a year to conduct 20 interviews, transcribe them, and conduct the process of phenomenological reduction and analysis. 
- The sample size is small, and the results may therefore say more about the participant group than they do about the larger population. However, I noted earlier that this group is networked with like-minded individuals, so there can be an inference that that their views might be more widely held.

- There is an issue of researcher bias during the analysis. I raised this concern in Chapter One, and indicated that I tried to maintain a conscious reflexive stance through active and regular journal entries throughout the research.

\section{Choice of phenomenology.}

From the above, I considered phenomenology as the appropriate method to gather information about how an individual understands environmentalism. I wanted to integrate stories about the participants' background, values, and beliefs, together with their descriptions of what environmentalism means to them, to determine what shared views and common themes might emerge. The outcome would allow me to gain a deeper understanding of the phenomenon being studied, namely to gain insight into how young people who care about the environment interpret environmentalism.

However, my choice of phenomenology as the research methodology was also based on my professional experience. For a decade, from 1998 through to 2008, I was a detention monitor for both the International Committee of the Red Cross and the Canadian Red Cross. In this capacity, I worked in prisons in Rwanda, as well as across Canada. The role of a monitor is to assess the conditions under which vulnerable groups are detained, work with the authorities to correct issues of non-compliance with applicable standards, and formulate recommendations for improving systems of detention. The basic instrument for undertaking this work is the concept of interview 
without witness, which is essentially a phenomenological approach. This involves the monitor engaging detainees in confidential one-on-one interviews in order to understand the experiences of detention. It is a highly effective means for piecing together how organizational systems work, primarily because an in-depth synthesis of direct experiences permits a deeper understanding than occurs through simple observation or the analysis of written reports.

It was therefore in the context of my professional experience with detainee interviews that I chose my methodological approach, as I believe that individual storytelling among a smaller group of individuals can help draw out important themes and conclusions. Phenomenology offered the ability to develop deeper stories about how individuals perceive and understand an issue, together with an established analytical process to synthesize meanings from multiple perspectives.

\section{Research Methods}

Individual interviews are the primary method for conducting phenomenological research. Other methods exist to capture the attitudes and stories of individuals including focus groups, surveys, and narrative analysis. I chose one-on-one interviews for several reasons:

1. I have found that the dynamics of a focus group can hinder the ability of participants to confide deeper hopes and fears. A certain amount of groupthink can also emerge, which may hinder the free expression of an individual's story.

2. With respect to surveys, the challenge is that they are often not flexible enough to allow the research to explore a particular storyline to a deeper level. In addition, 
surveys do not permit clarification or emerging lines of questions that are characteristic of the interview approach.

3. Finally, narrative analysis - in which the researcher analyzes the written stories of an individual - can be a burden on those who are undertaking the writing. My experience with verbal storytelling is that this is the method best suited to understanding values and perceptions.

\section{Sample size.}

The practice of phenomenology is based on one-on-one interviews. A number of researchers who use this approach (Caelli, 2001; Moustakas, 1994; Sokolowski, 2000) have indicated that there is an optimal number of participants involved in a study, somewhere between 10 and 20 being manageable.

Determining a purposive sample size is not arbitrary. Bowen (2008) notes that the goal is to obtain information until "the data set is complete, as indicated by data replication or redundancy" (p. 140). He terms this saturation, "the point at which no new insights are obtained, no new themes are identified, and no issues arise regarding a category of data.” (p. 140). Guest, Bunce, and Johnson (2006) assess several qualitative research approaches, and note that purposive sample sizes can reach saturation in anywhere from six to 35 participants. In each instance, the size depends on the methodology used and the homogeneity of the sample. They reference one researcher who conducted phenomenological studies, noting "The magic number of six interviews is consistent with Morse's (1994) recommendation for phenomenological studies" (p. 78). In any event, Guest et al. conclude, "If the goal is to describe a shared perception, belief 
or behaviour among a relatively homogenous group, then a sample of twelve will be sufficient" (p. 76).

\section{Participant selection.}

Guest et al. (2006) note that in purposive samples the "participants are selected according to predetermined criteria relevant to a particular research agenda" (Guest, p. 61). The primary criteria for my research included:

1. The participants had to be in their twenties. This was done to align with demographic data used to delineate the Millennial generation (i.e., born after 1981). I kept the bottom cut-off age at 20 in order to ensure the participants had gained post-secondary education and work experience.

2. The participants had to be interested in, indeed passionate about, environmental issues. I made the assumption that those who had a strong interest in environmental issues early in their choice of academic focus and professional careers were more likely to work in, or attempt to influence, the environmental sector later in life. This assumption was consistent with observations of individuals who were involved in the founding of the modern environmental movement in the 1970s, noted in Chapters Two and Three.

3. The participants had to be currently residing in British Columbia (B.C.). The focus on B.C. was done primarily to make the research manageable, as I conducted the interviews where the individuals lived. But B.C. also has a rich environmental legacy that celebrates the natural environment. It is home to campaigns to stop logging at Clayoquot Sound, vocal debates about oil pipelines, and efforts to make Vancouver the greenest city in the world (City of Vancouver, 2011). 
4. Finally, a balance of other criteria was sought, including gender, ethnicity, occupation or post-secondary field of study, and urban vs. rural residence. My approach to First Nations youth included an urban and a rural dimension, in that the participants had lived in cities as well as remote communities.

I approached nine community and academic leaders to help me identify individuals who had an interest in environmental and sustainability issues (Appendix A). It is important to stress that I asked these individuals to recommend research participants who cared deeply about environmental issues, who exercised leadership in the environmental community, or who were passionate about their fields of study in the areas of sustainability, conservation, ecology, or community organizing.

The decision to work with academics from universities and technical schools was based on the assumption that youth currently or previously enrolled in programs that deal with environmental sciences, sustainability, engineering, or resource management would have developed their own ideas and perceptions of environmental issues. I contacted who were working in the environmental field as managers, consultants, and organizers who had contact with young environmentalists. Approaching First Nations leaders to identify participants was based on the observation that they have an understanding of the interests and experiences of youth in their communities.

In seeking their help, I asked these leaders to identify participants based on selection criteria that included age, gender (both men and women were sought), ethnicity, and an assessment of the individual's interest and ability to undertake the research. I was particularly interested in including First Nations participants, as I wanted to explore 
whether they held views about environmentalism that was different from the nonAboriginal population.

The limitations to the research approach, as noted in Chapter One, are that the participants do not represent the attitudes and perceptions of Millennials at large. However, the purpose of the research is to gain insight into how the subset of young people who care about environmental issues are interpreting environmentalism. I sought to find, among the group of participants I approached, whether there were common themes and perspectives that might emerge.

In my dissertation proposal, I indicated that I would engage up to 20 individuals. I conducted the interviews over the period from August 2012 to June 2013, and found that data saturation (i.e., no new themes emerged) was largely obtained after conducting about 10 interviews. However, early in the interview process I noted a pattern in the responses that indicated the participants could be divided into three subgroups based on their field of environmental interest, which I explain further in Chapter Five. Once I had identified this pattern, I added two more interviews to obtain a larger number of participants for one particular subset. I also concluded I did not have sufficient gender representation, and added an additional male subject. In the end, I interviewed 20 participants, at which point I determined that I had reached saturation for my assessment of the overarching categories of information, as well as for obtaining adequacy for the subsets of environmental interest and gender. 


\section{Participant recruitment.}

The next step was to approach the potential participants to determine their willingness to take part in the research. This started with a telephone conversation outlining the proposed study, followed by a one-hour face-to-face interview conducted in private. Each individual was asked to sign a letter of consent acknowledging that confidentiality would be maintained throughout the study process.

I left myself open to identifying further participants through the initial stages of the research using snowball sampling (Hesse-Biber \& Leavy, 2011). This was based on the need to ensure a diversity of participants, and the expectation that the participants themselves could identify individuals with relevant opinions on my research. Two individuals came forward through this process.

\section{Interview guide.}

I created an interview guide that incorporated thematic categories, as well as semi-structured questions to facilitate a flexible approach to the discussions (see Appendix B). The flexibility was calculated to encourage deeper conversations on particular topics, while allowing the participants to feel at ease during the interview process.

The guide included six thematic categories and 14 questions. Consistent with a semi-structured approach to interviewing (Kvale \& Brinkmann, 2009) the questions provided a framework for the interviews, rather than rigidly structuring them. Each conversation went deeper, but it was necessary to return to the guide in order to achieve consistency among the participants' responses. The general form of the questions 
emerged from the preliminary literature review, and discussions with academics in the environmental field that I undertook during the dissertation proposal phase.

I asked the participants the same questions, in the same order. All interviews were recorded and transcribed, and the transcriptions entered into a qualitative data analysis software program.

\section{Interview Questions}

The purpose of my research is to discern whether a new form of environmentalism is emerging among young people who care about the environment. To this end, I designed the research approach to identify common themes among the participants regarding how they conceptualize and make sense of environmentalism. The interview questions were crafted to reveal responses that incorporated an individual's beliefs, motivations, hopes, fears, and awareness of environmental issues from the perspective of a young adult.

\section{Category 1 - participant's background and experiences.}

The initial category of questions explored how the individual developed an awareness of the environment. I was particularly interested in whether participants spent time outdoors as children, as well as the influence of their parents on their decision to become involved in environmental issues. The discussions also delved into the reasons for each individual's choice of post-secondary education.

\section{Question 1: Tell me about your outdoor and nature experiences as a child.}

The first question created a foundation for the remainder of the interview through the experience of telling stories from a participant's childhood. My intent was to allow the individual to become relaxed with the process, and begin with a personal description 
of their early exposure to the natural world. I also encouraged the participant to describe how their early experiences in nature were influenced by their parents, on the assumption that parents who are active in the outdoors will in turn expose their children to the natural world through outdoor activities and family-oriented events (Chawla, 2006).

Childhood experiences in nature have been shown to lead to a number of positive cognitive and emotional qualities (Louv, 2005; Wells, 2000). Richard Louv has written that early exposure to the natural world enhances a child's development, and confers emotional benefits, heightened sensory skills, and enhanced curiosity and creativity, as well as the cognitive conditions for sustained intellectual development (Louv, 2005). He notes that "The protection of nature depends on more than the organized strength of stewardship organizations; it also depends on the quality of the relationship between the young and nature - on how, or if, the young attach to nature" (Louv, 2005, p. 154). This question was meant to test Louv's claim, by establishing whether the participants had developed such a relationship.

I also asked each individual to tell me their favourite outdoor experience, permitting them to use emotive language to describe an event that stood out in their childhood. Telling memorable personal stories is consistent with what Marshal Ganz, a senior lecturer at Harvard University who works in the field of grassroots organizing, argues is key to communicating the values that call a person to act. Ganz (2008) notes: Telling one's story of self is a way to share the values that define who you are not as abstract principles, but as lived experiences. We construct stories of self around choice points - moments when we faced a challenge, made a choice, experienced an outcome, and learned a moral. We communicate values that 
motivate us by selecting from among those choice points, and recounting what happened. (p. 10)

Closely related to the descriptions of childhood experiences in nature that emerged from this question was an examination of how the individual became interested in environmental issues. I wanted to determine if there was a connection between childhood experiences and the subsequent choice of academic programs or careers.

\section{Category 2 - participant's description of their generation.}

As previously noted, the purpose of my research is to discern whether a new interpretation of environmentalism is emerging among young people. The participants were in their twenties at the time of the interviews, and are termed Millennials by demographers, statisticians, and popular writers. I argued in Chapters Two and Three that environmentalism can be construed as a generational phenomenon, in that it was largely defined by members of the Baby Boom generation (i.e., those born between 1946 and 1964). I wanted to explore whether the interpretation of environmentalism among a group of young adults might also have a generational dimension. The generational category allowed the participant to place themselves in the context of existing literature (academic and popular), demographic data, technology, and social media depictions of generations.

\section{Question 2: How would you describe your generation?}

The purpose of this question was to determine whether the participants identified with a particular generation, how they described and named it, and whether they characterized their generation as one that is optimistic or cynical. Some commentators and writers have made broad and often uninformed generalizations about generations, and tend to take terminologies created by others as their starting point (see, for example, 
Strauss \& Howe, 1991). As noted in Chapter Three, the expression "Generation Y" (also known as Millennials) was crafted by people who are not a part of that generation. Rather, individuals from older age cohorts established the name and the defining attributes.

I sought to establish if the participant identified with a particular generational name or category. More importantly, I wanted to determine if the participant felt solidarity with similarly aged individuals, and what they themselves felt might characterize their age group.

\section{Category 3 - participant's environmental beliefs and motivations.}

The third category explored what environmentalism meant to each participant, how it manifested itself in their day-to-day lives, the values and experiences underpinning their understanding of environmentalism and sustainability, and the barriers to achieving what they hope would be a life aligned with their environmental beliefs. This thematic area is core to the research. The questions were designed to elicit personal descriptions of environmentalism and sustainability, as well as to explore how the participants integrated views about the environment into their lives. Category 3 , together with Category 6 on the future of environmentalism, are central to the research purpose of gaining insight into how young people who care about the environment are interpreting environmentalism.

\section{Question 3: What is environmentalism to you?}

The question on environmentalism occurs after the participant tells the story of their upbringing, and was calculated to take place about one third of the way through the interview. The discussions to this point focused on the individual's childhood experiences 
in nature, how they developed an interest in environmental issues, and how they identified with people of a similar age. With this question, the participant begins to identify their thoughts about what environmentalism means to them. The question was open-ended, and allowed individuals to shape their views with only minor clarifying questions to obtain as complete an answer as possible.

\section{Question 4: What would a sustainable life look like for you? How would you}

\section{live that way?}

Following from the story of the individual's upbringing, and how they characterize environmentalism, I wanted to explore how the participants integrated environmental behaviour into their daily lives. This was framed under the concept of sustainability. Sustainability has multiple meanings (Hawken, 2007; Speth, 2008;

Wackernagel \& Rees, 1996), but I prefer the one articulated by John Robinson from the University of British Columbia (Robinson, 2004). Robinson notes that "sustainability is itself the emergent property of a conversation about what kind of world we collectively want to live in now and in the future" (p. 382), and that "the preferred term, 'sustainability' focuses attention where it should be placed, on the ability of humans to continue to live within environmental constraints” (p. 370). I chose Robinson's description because it places people instead of technology at the heart of sustainability, and is oriented toward the future.

The question was also intended to determine whether a participant's understanding of environmental challenges and issues was matched by their determination to take personal responsibility for their own actions on day-to-day basis. I 
wanted to explore whether they would make the connection between how they lived their personal lives and how they depicted sustainability.

Question 5: What beliefs, values, or experiences motivate and shape your choice to live a sustainable life?

This question was designed to uncover what led a participant to become interested in environmental issues by looking at how they linked their interest to their personal values or beliefs. The linkage could take the form of family upbringing, religious orientation, community of peers, or transformational experiences in their lives.

\section{Question 6: What stands in the way of you doing so?}

I also wanted to understand what barriers existed to the participant's depiction of an ideal sustainable life. I assumed that this group was relatively well off, based on descriptions of their upbringing and level of education, so exploring what gets in the way of achieving a sustainable life would facilitate a discussion about systemic barriers at a level beyond basic issues of income or access to post-secondary schooling. I was also curious about whether the participant would bring up the intergenerational factor, in particular if they felt that older generations had created standards and structures that made it difficult for them to pursue a sustainable lifestyle.

Category 4 - how does the participant make sense of current environmental

\section{challenges and issues?}

The fourth category of questions was designed to allow the participant to describe their awareness and understanding of current environmental challenges, how they perceive human activity to have impacted the environment at the local and global scale, 
how they feel about this, and whether they place blame on previous generations for their perception of the current state of the environment.

\section{Question 7: How do you perceive the current health or state of the}

\section{environment?}

The research participants were selected because of their interest in environmental issues. Many had heard about or witnessed examples of environmental change during their childhood or careers. In some instances, the participant had studied environmental impacts at university and technical school, and had formed an understanding based on that knowledge. This question was designed to allow the individual to express their understanding of the health of the environment at this moment in time.

The question also draws on the concept of shifting baseline syndrome, a term coined by Daniel Pauly from the University of British Columbia in 1995. Pauly applied the syndrome to the marine sciences, demonstrating that younger researchers took as their reference point the current level of fish stocks in areas they were studying - without regard to historic and prehistoric levels. He argues that "this syndrome has arisen because each generation of fisheries scientists accepts as a baseline the stock size and species composition that occurred at the beginning of their careers, and uses this to evaluate changes" (Pauly, 1995, p. 430). Charles Sheppard (1995) extends the syndrome beyond marine sciences by noting "when we measure how much a system or an area has changed, we generally compare it with what we claim is its starting or baseline condition" (p. 766). From the perspective of my research, this implies that environmental concerns such as climate change would be taken as a given by the participants in my research - because climate change was a phenomenon that an individual in their twenties 
was aware of for their entire lives. I wanted to understand how an individual described their reference point for a description of the health of the environment.

Lastly, I probed for whether there was a difference in responses for a description of the environment at either the local or the global scales. I was curious to find out whether such a difference would show up, based on a prediction that the participants might be more positive about what they experienced in their own communities and regions because they were more aware of the actions being taken to protect, enhance, or regenerate the environment at the local scale.

\section{Question 8: How do you feel about this?}

This question was designed to allow a frank, emotive response to their depiction of the health of the environment. I was cautious of this question, as I was not sure what the responses would be. Caelli (2001) notes that phenomenological research conducted in the health care sector has shown that participants can go through a personal change during the study. She advises the researcher to be aware of this, on the basis that he or she bears some responsibility for the impacts of the research process on the participants themselves. Nevertheless, I felt I could not fully understand a participant's characterization of environmentalism unless I could also understand how they felt about the current state of the environment at a personal level.

\section{Question 9: Do you think current environmental challenges could have been} avoided?

The purpose of this question was to provide an insight into intergenerational concerns. I wanted to explore whether the participants would place blame on previous generations - particularly their parents (i.e., the Baby Boom generation). 
I also wanted to determine if the individual would make a connection between their depiction of the current health of the environment and historical factors such as the dependence on fossil fuels, the intensification of urban development, or the rapid population growth of the last half century. I earlier described shifting baseline syndrome, so this question was intended to explore whether the participant takes current technologies and development as their accepted reference point.

\section{Category 5 - how does the participant view the modern environmental} movement?

As noted in Chapter One, the discourse of environmentalism is sometimes conflated with the environmental movement and environmental organizations. I claimed that the movement should be viewed as a manifestation of environmentalism. I further argued in Chapter Three that social movements (which includes the environmental movement) go through stages of evolution, and that organizations can follow a similar path. This category of questions explores how the participant perceives the environmental movement and its constituent organizations.

\section{Question 10: How would you describe the environmental movement?}

This open-ended question encourages the participant to describe what they believe constitutes the movement. Such a description allows the participant to define what they believe a movement is, and how they would characterize the accomplishments of the contemporary environmental movement after almost a half century of existence.

\section{Question 11: Is the environmental movement as effective as it could be?}

The intent of this question was to elicit descriptions of the successes or limitations of the movement as they related to the environmental conditions described by the 
individuals in Question 7. As the purpose of my research is to discern whether a new interpretation of environmentalism is emerging, a participant's depiction of the movement as either being ineffective or needing to evolve would help me to understand whether environmentalism is undergoing a transition.

\section{Category 6 - how does the participant envision the future of}

\section{environmentalism?}

The final category focused on the participant's thoughts about the future of environmentalism, whether they were optimistic their vision could come about, and what they felt was necessary to achieve the future they described. Together with Category 3 , this set of questions is also central to the research in that the questions explore whether environmentalism is evolving, and how it might continue to do so in the future.

\section{Question 12: How do you perceive the future of environmentalism?}

I began this question by reminding the participants what they had previously said about what environmentalism means to them (Question 3). This was intended to determine whether they feel it is moving in the direction they described, or whether the future is different from their current understanding. I was seeking responses that would indicate whether they are part of a generation that is changing the face of environmentalism, or whether they felt there needed to be significant changes that may not be possible in the foreseeable future.

\section{Question 13: Are you pessimistic or optimistic this will occur?}

Similar to Question 8 (How do you feel about [the state of the environment]?), this question sought to understand the participant's subjective feelings about whether the future description of environmentalism they envision can be achieved. 


\section{Question 14: What would be needed to achieve the future you described?}

The final question is the reverse of queries focused on barriers and obstacles, in that it allowed the participant to talk about the systemic and personal attributes needed to achieve the kind of future they want to happen.

\section{Data Management}

I used NVivo (Version 10), a qualitative data analysis tool, to help me structure and analyze the information that emerged through the interviews. NVivo permits the researcher to enter, sort, and organize unstructured data from a variety of sources, including interview transcripts, journal entries, field notes, memos, and published works (Bazeley, 2007; Davidson \& Jacobs, 2008; Johnston, 2006). Such a tool is immensely helpful in the identification of emerging themes and concepts that arise through the data analysis phase.

According to Johnston (2006), NVivo has several attributes that lend themselves to qualitative research. The first is transparency, in that it is possible to "view not only the data, but also what a student has done with that data and to track the processes involved in the whole research journey" (p. 385). Given that qualitative research approaches have sometimes been criticized for being biased or lacking reliability (Hesse-Biber \& Leavy, 2011; Johnson, Onwuegbuzie, \& Turner, 2007; Silverman, 2006), the ability to demonstrate the research process through an audit trail enhances the validity of both the data and the subsequent analysis.

NVivo also has the capacity to integrate and uncover linkages in the data that are difficult to obtain through a manual coding and sorting system. Furthermore, the ability 
to add my own memos and emerging themes directly into the data system facilitated interpretation and analysis.

\section{Data Analysis}

A phenomenological approach to interview analysis typically includes the following elements (Groenewald, 2004; Hearns \& Deeny, 2007; Moran, 2000; Moustakas, 1994; Sadala \& Adorno, 2001; Sokolowski, 2000):

1. Review the transcripts in order to obtain a sense of the data and identify "meaning units." This typically involves multiple readings to recognize general concepts.

2. Cluster the meaning units into themes, followed by editing to reduce overlapping or redundant concepts. This process is known as phenomenological reduction (Moustakas, 1994).

3. Interpret the themes to arrive at summary descriptions of the experience or phenomenon.

I used NVivo to assist in creating these elements. This was done through the use of data attributes, coding, and reporting - as noted in the coding section below.

The outcome of the research analysis is a synthesis that reflects the participants' understanding of environmentalism. In the end, the researcher interprets and transforms the described experience of the participants into a new narrative. The results guide and support the interpretive appraisal necessary to achieve the research purpose.

\section{Coding.}

With NVivo, the data is sorted by source (i.e., participant interview), attribute (i.e., the characteristics of each participant, such as gender, age, and environmental interest), and node. A node can be created for each participant and emerging theme. 
I initially sorted the data into nodes for every questions asked, each containing the responses of all 20 participants. I then went through the responses in each question node, sentence by sentence, to discern patterns and themes. I created new nodes for the emerging themes, and labelled them with an appropriate description, based on either a recurring word or phrase, or a metaphor for the experience described (Ryan \& Bernard, 2003). For example, in Question 5 on beliefs, values, and experiences, participants talked extensively about their families and friends, or the communities in which they lived. I interpreted this as networks in which an individual was situated, and labelled the node accordingly.

Prior to detailed coding, I went back and combined or eliminated redundant themes. For instance, in Question 3, I initially had themes for personal responsibility, personal awareness, personal values and ethics, and passion, which I merged into a single theme, labelled “deeply personal.” Combining themes, which I previously described as the process of phenomenological reduction, is fundamental to building an understanding of the participants' perspectives (Groenewald, 2004).

Once I had established a structure for each question, I coded the participants' responses line by line, according to the appropriate thematic node. I also ensured that participant responses from other questions were added to the structure if they were relevant to the particular theme. I reviewed each question in the participant order listed on Table 4 (the order is based on the date of interview).

I found that the core themes emerged after assessing the first five participant responses. This pattern is illustrated by an example of interviews undertaken by Bowen (2008), who studied community-based antipoverty projects in Jamaica. In his description 
of the process, Bowen noted that "Frequent and widespread use of key terms suggested their relevance as conceptual categories.” (p. 144). Nevertheless, there were occasionally outlier nodes with one or two participant entries which I examined to see if they contradicted the primary themes (see Chapter 5 - Results).

By the end of the process, I had developed a structure containing 64 nodes. In my assessment of emerging themes and meanings, I chose primary themes based on the frequency of use (i.e., the majority of participants, over half, were represented in a particular thematic node). The remaining nodes, which typically contained five or fewer participant responses, were used to add further context to the primary themes, or to test contradictions. I also sorted the themes and meanings by gender and environmental interest, to determine if further patterns were apparent.

\section{Data Reliability - Trustworthiness and Rigour}

Qualitative analysis is sometimes questioned on the basis that the methodologies lack reliability (Silverman, 2006). The basis for this opinion is primarily that the results are often the interpretation of the researcher (which includes the possibility for bias noted earlier), that the sample is not representative, and that the results are not replicable. To overcome these challenges, the research needs to be thorough in its attention to how the data is gathered, recorded, coded, and analyzed.

Shenton (2004) describes four criteria that support trustworthiness in qualitative research - credibility, transferability, dependability, and confirmability. The issue of credibility is largely a factor of the procedures used to gather and analyze the data, and in this respect the sampling method and data saturation noted earlier are key. My approach to the research was to work with a purposively derived sample of 20 individuals. A 
sample of fewer than 10 might not provide sufficient data contrast and validation among participants, whereas a sample of greater than 20 is a daunting task for undertaking interviews, transcriptions, and coding. Furthermore, approaching individuals from different genders, ethnicities, occupations, and backgrounds provides a form of sampling that can "reduce the effect on the study of particular local factors peculiar to one institution" (Shenton, 2004, p. 66).

According to Shenton (2004), the issue of transferability can be addressed by a clear description of the context in which the research is undertaken. This includes details about the participants, but also the methods used to collect, record, manage, and interpret the data.

With respect to dependability, the trustworthiness of the research is enhanced by a clear description of the research design, while confirmability is addressed through my commitment to reflexivity and clearly articulating the biases I bring to the project. Ultimately, the trustworthiness of the research is based on my commitment to an ethical approach, transparency of methods, logical procedures for clustering and coding data, and clear principles for how the materials are interpreted and transformed into a narrative that articulates the purpose of my study.

\section{Informed Consent}

The study focuses on individuals who are just beginning their careers, and informed consent is an integral component of the research - I was clear with each participant about what their participation actually entailed. In this context, informed consent was not just a signature on a form, but a thorough understanding of how the research would be used, the procedures for disclosure, what happens to the data after the 
study is completed, and the ability of participants to freely withdraw (and know that their data would be expunged) at any time upon their request. My impression is that the study also permits a certain amount of mentoring of the participants themselves that will help the generational transfer of knowledge that will occur over the coming years.

\section{Integrating the Literature, Theoretical Frameworks, and the Interviews}

The final phase of the research design involves the integration of the interview results with the literature review and the theoretical frameworks. This comprises three aspects:

1. The purpose of the research is to gain insight into how young people who care about the environment interpret environmentalism. The data for such discernment was obtained through interviews with young people in the form of their personal stories and descriptions. However, a study to determine the emergence of a new form of environmentalism would suggest that the starting point for such an exploration is to contrast it with an existing form that has evolved over time. I chose to do this by synthesizing the contemporary literature on environmentalism and the environmental movement, and using this as the basis for contrasting the primary themes that emerged through the participant research.

In Chapter One, I addressed a validity issue inherent in my approach, in that while I have created a profile for a younger generation, I have not done the same for an older generation of environmentalists. Instead, I contrast the phenomenological experience of the participants against what the literature says about those who came before them, together with my personal experience in this field. 
As noted, I am representative of the older group. I can draw on my experience over four decades. I interact with others of my generation who are involved in environmental issues. My subjective experience is extensive, and much of it is professionally reflected. But to defend against the limitation that my views are subjective, I verified my views against what the literature of my contemporaries says. I also tested broad themes in informal conversations with colleagues. Such data were not available to yield an understanding of the new generation of environmentalists, and that required a much more intensive and specific approach.

What is strikingly obvious is how diverse modern environmentalism is, making a contrast with the participants' views a challenge. Nevertheless, the research results in Chapter Five show a degree of focus and new thinking, and a de-emphasis on some traditional characteristics, together with new ideas about tactics that give an indication of how environmentalism might evolve in the future.

2. The second aspect involves the use of theoretical frameworks. As noted in Chapter Three, I chose generational theory and social movement theory to help me understand what was emerging through the research. I used generational theory as I felt that environmentalism and the environmental movement could be interpreted as a generational phenomenon of the baby boom generation, based on the size of the cohort and the conditions of the time. I do not believe you can understand environmentalism without an understanding of the generation that was coming of age when modern environmentalism was formed. I wanted to explore whether generational theory could help me discern if a new interpretation of environmentalism might also have a generational component. Furthermore, generational theory predicts 
that social change occurs through generational replacement. As previously noted, the generation who largely defined modern environmentalism (i.e., the Baby Boomers) is beginning to retire from professional life. They will lose their power to influence and define environmental thinking in the process. Generational theory would suggest that a new interpretation of environmentalism over the coming decade would be as much about generational replacement and transition, as it is about the new ideas that emerge among a younger group.

In addition, I used social movement theory to help me understand whether a new view of environmentalism might be interpreted as the predictable evolution of movements and organizations over time. In this context, the emerging ideas are viewed as the result of changes that occur as movements and their underlying frameworks adapt to new circumstances and conditions. In Chapter Two, I summarized the themes that characterize modern environmentalism, but also the critiques. Social movement theory would suggest that adaptation and evolution is a product of addressing the criticisms - but also the learning needed for environmentalism to continue as a relevant worldview, and the environmental movement to be a catalyst for action.

3. Finally, a claim that a new interpretation of environmentalism is emerging, based on a purposive sample of only 20 individuals, might be questioned. My counter-argument is that shifts in culture and attitude start with an emergent idea that is shared among a relatively small number of people who are passionately concerned about something. I am not suggesting that the participants I interviewed are the core of this shift - only that they represent those who are part of that change. This pattern is supported by 
diffusion theory, which predicts how new ideas or innovations are spread. Chatman (1986) notes, "In the diffusion process a person becomes aware of an innovation and communicates this awareness to someone else. That person in turn communicates it, and so on as the innovation is spread or diffused" (p. 377). Scully and Creed (2005) likewise argue that the diffusion of new ideas and change occurs through primary agents or actors, who construct persuasive identities and courses of action that are "facilitated by networks of relationships, organizational structures, models of leadership, and technologies of communication" (p. 312). My argument is that the participants in this research are part of a passionate community of young people who are interpreting environmentalism in their own way. 


\section{Chapter Five: Results}

\section{Introduction}

I begin this chapter with a profile of the participants. I describe the characteristics of the group, and contrast them to comparable themes about the Millennial generation noted in Chapter Three. As previously indicated, the participants are not a random sample, but a group of individuals who are deeply interested in environmental issues. I outline some of the group's defining features as they relate to the research.

I then present the results of the interviews, which includes primary themes (i.e., where more than half of the participants represented a common view), illustrative quotes, and longer passages that provide additional depth for key questions. The goal is to offer a description of the participants' beliefs and perceptions as they relate to the primary research questions. I close with a meta-analysis of the participants' views and beliefs, which is the basis for the conclusions in Chapter Six.

\section{Participant Profile}

Table 4 summarizes the 20 participants by age, gender, ethnicity, and education. Fourteen $(70 \%)$ of the participants were female, six $(30 \%)$ were male. Fourteen were of European origin, two were Aboriginal, one was Chinese, and three of mixed ethnicity. All had post-secondary education, 12 had completed or were taking a master's degree, and one individual was completing a $\mathrm{PhD}$. This profile is interesting for several reasons:

1. Gender: The group is primarily female. This is a departure from the leadership profile of the environmental community in the late 1960 s and 1970 s, which was predominantly male (see Chapter Two). An illustration of this change is provided by the class composition of the Fish, Wildlife \& Recreation Program, a two-year 
diploma offered by the British Columbia Institute of Technology. The annual class size of this program has remained between 30 and 35 students since its inception in 1969. In 1976, the year I graduated from the program, there were only two women in the class. In the years 2007 through 2013, the number of females in a class on average exceeded the number of males. ${ }^{2}$ A similar indicator is provided by the staff complement at the David Suzuki Foundation, which as of late 2013 was two-thirds female, one-third male. ${ }^{3}$

2. Ethnicity: The sample is predominantly white. This is consistent with the ethnic identity of those who formed the modern environmental movement in the late $1960 \mathrm{~s}$ and the 1970s noted in Chapter Two.

3. Education: The sample is well educated, with all having some level of post-secondary schooling. This is not simply a factor of the participants being recommended by academics, as non-academic community leaders identified over half of those I interviewed.

4. Children of Baby Boomers: All the participants are children of Baby Boomers (i.e., their parents were born between the years 1946 and 1964). I argued in Chapters Two and Three that the modern environmental movement can be seen as a generational phenomenon of the Baby Boom, so the research might also indicate the intergenerational transfer of knowledge and perspectives (see Chapter Six).

${ }^{2}$ Information obtained from Bob Gunn, Program Head for the Fish, Wildlife \& Recreation Program at the British Columbia Institute of Technology; December 11, 2013. 3 From Catherine Gordon, Director of Human Resources, David Suzuki Foundation. 
Table 4

Participant Profile by Age, Gender, Ethnicity, and Post-Secondary Education

\begin{tabular}{|c|c|c|c|c|}
\hline Identifier & Age & Gender & Ethnicity & Education \\
\hline 1 & 27 & Female & Aboriginal & MA Anthropology (I/P) \\
\hline 2 & 26 & Female & Aboriginal & MA Medieval Literature (I/P) \\
\hline 3 & 29 & Male & European & $\begin{array}{l}\text { MA Environmental Education \& } \\
\text { Communication }(\mathrm{I} / \mathrm{P})\end{array}$ \\
\hline 4 & 23 & Female & European & $\begin{array}{l}\text { Forestry Certificate; Diploma Fish \& } \\
\text { Wildlife; BTech Ecological Restoration }\end{array}$ \\
\hline 5 & 24 & Female & European & Diploma Fish \& Wildlife \\
\hline 6 & 29 & Female & Other & $\begin{array}{l}\text { MSc Fisheries } \\
\text { PhD Environmental Science (I/P) }\end{array}$ \\
\hline 7 & 22 & Female & European & BSc Global Resource Systems \\
\hline 8 & 29 & Male & Other & Certificate - Film Production \\
\hline 9 & 23 & Male & European & $\begin{array}{l}\text { BA Philosophy \& Political Science } \\
\text { MA Journalism (I/P) }\end{array}$ \\
\hline 10 & 26 & Male & European & $\begin{array}{l}\text { BSc Physics \& Engineering } \\
\text { MSc Materials Engineering }\end{array}$ \\
\hline 11 & 29 & Female & European & MA Media Production \\
\hline 12 & 29 & Female & Other & BA Canadian Studies \\
\hline 13 & 24 & Female & European & $\begin{array}{l}\text { BA Communication } \\
\text { MA Environmental Education \& } \\
\text { Communication (I/P) }\end{array}$ \\
\hline 14 & 26 & Female & East Asian & $\begin{array}{l}\text { BA Business Administration } \\
\text { Honours in Sustainability }\end{array}$ \\
\hline 15 & 22 & Female & European & $\begin{array}{l}\text { BA Geography (Environment \& } \\
\text { Sustainability) }\end{array}$ \\
\hline 16 & 28 & Female & European & $\begin{array}{l}\text { BSc Urban Agriculture } \\
\text { MA Religious Leadership for Change }\end{array}$ \\
\hline 17 & 28 & Female & European & MA English Literature (I/P) \\
\hline 18 & 26 & Male & European & BA Business Administration \\
\hline 19 & 24 & Male & European & $\begin{array}{l}\text { BA Political Science } \\
\text { MA Environment \& Development }\end{array}$ \\
\hline 20 & 26 & Female & European & $\begin{array}{l}\text { BASc Engineering Physics } \\
\text { MSc Resource Management (I/P) }\end{array}$ \\
\hline
\end{tabular}

Note. European $=$ White; Other $=$ mixed; $\mathrm{I} / \mathrm{P}=$ in progress. 
5. Class: All the participants were middle class (either self-declared or the distinction emerged through the interviews). This is consistent with the middle-class origins of the modern environmental movement in the late 1960s and the 1970s.

Early in the interviews, I began to notice that the participants talked about areas of environmental interest based on the direction they hoped to go with their careers. Some wanted to work in conservation settings, others in the sustainable technology sector, and another group in the community organizing and social justice fields. These areas of interest bear a similarity to the environmental clusters outlined by Martinez-Alier (2002) noted in Chapter Two. I decided to adapt this typology to differentiate the participants' interests, as shown in Table 5. This was not intended to set up a classification system for the study group - rather, I was curious to know whether the participants might have different views based on their areas of interest. This would further test the strength of the primary themes. I added a category to the profile accordingly (see Table 6).

Table 5

Participant Environmental Clusters, Adapted from Martinez-Alier (2002)

Environmental Cluster

Wilderness \& Conservation

Sustainability \& Technology

Environmental Rights \& Justice

\section{Traits and Focus}

- Preservation of intact ecosystems

- Stewarding the environment

- Ecological restoration

- Sustainability

- Sustainable use of resources

- Belief in (green) technology

- Belief in entrepreneurial solutions

- Local focus

- Social justice (including First Nations rights and title)

- Social change and activism

- Democratic reform 
Based on the participant interview responses and backgrounds, I matched the individuals to one of the environmental clusters identified above. Three of the participants were placed in the Wilderness and Conservation cluster, four in the Sustainability and Technology group, and 13 in the Environmental Rights and Justice category.

Table 6

Participant Profile Adjusted for Environmental Interest

\begin{tabular}{clll}
\hline Participant & Age & Gender & Environmental Interest \\
\hline 1 & 27 & Female & Environmental Rights \& Justice \\
2 & 26 & Female & Environmental Rights \& Justice \\
3 & 29 & Male & Environmental Rights \& Justice \\
4 & 23 & Female & Wilderness \& Conservation \\
5 & 24 & Female & Wilderness \& Conservation \\
6 & 29 & Female & Environmental Rights \& Justice \\
7 & 22 & Female & Environmental Rights \& Justice \\
8 & 29 & Male & Environmental Rights \& Justice \\
9 & 23 & Male & Environmental Rights \& Justice \\
10 & 26 & Male & Sustainability \& Technology \\
11 & 29 & Female & Environmental Rights \& Justice \\
12 & 29 & Female & Environmental Rights \& Justice \\
13 & 24 & Female & Wilderness \& Conservation \\
14 & 26 & Female & Environmental Rights \& Justice \\
15 & 22 & Female & Environmental Rights \& Justice \\
16 & 28 & Female & Environmental Rights \& Justice \\
17 & 28 & Female & Environmental Rights \& Justice \\
18 & 26 & Male & Sustainability \& Technology \\
19 & 24 & Male & Sustainability \& Technology \\
20 & 26 & Female & Sustainability \& Technology \\
\hline
\end{tabular}

Note. The categories of gender and environmental interest are used to assess each primary theme that emerged through the interview results. 
In summary, this group represents a possible snapshot of young environmentalists in British Columbia circa 2012-2013. The profile of the group is primarily female, white, well educated, and middle class. As previously noted, this is not a representative sample of the Millennial generation. This is a group of young people who care deeply about the environment, and were recommended by community and academic leaders who were asked to identify individuals based on that passion. I suggest that the group represents both a continuation of and a shift in who makes up the environmental community. The continuation relates to the group being middle class and primarily white. This is consistent with the origins of the modern environmental movement outlined in Chapter Two. The shift relates to the majority of the participants being female. This is a departure from the early movement leaders, who were primarily male. I suggest that this is an important demographic shift with implications for the future of environmentalism, which I will discuss in Chapter Six. Furthermore, the profile illustrates the evolution of academic programs and environmental professions since the late $1960 \mathrm{~s}$ - as such programs and careers are themselves an outcome of modern environmentalism.

\section{Responses to Interview Questions}

\section{Introduction.}

In Chapter Four, I described the process of phenomenological reduction, and how the participant responses were coded into themes that emerged from each question. Chapter Five outlines the results of this assessment, and provides supportive examples for the primary themes (i.e., where more than half of the participants from the group were represented in a particular thematic node). For several primary themes, I also provide 
longer quotes in order to present more depth. The chapter is structured around the 14 interview questions, and includes the following elements:

1. For each question, I describe all the thematic nodes that emerged.

2. For each of the primary thematic nodes, I summarize what the participants said and provide a sample of representative comments.

3. For each of the primary thematic nodes, I also sort by gender and environmental interest, in order to see if there were variations based on these attributes that might add further depth to my findings.

4. If applicable, I note outlier comments and opinions that contradict the primary themes, as well as possible inferences.

5. I conclude the analysis of each question with a summary of what emerged from the data.

I start with Question 1 "Tell me about your outdoor and nature experiences as a child", in order to supplement the profile of the participants. I then proceed through Questions 3 to 14, and return to Question 2 "How would you describe your generation?" at the end. The observations, together with the findings from the literature review and the theoretical frameworks, form the basis for the conclusions developed in Chapter Six.

Question 1: Tell me about your outdoor and nature experiences as a child.

As noted in Chapter Four, the purpose of this question was to help participants become comfortable with the interview process, as well as to describe their early exposure to the natural world. The results were meant to provide a richer profile of the group than one based simply on age, gender, ethnicity, and education. 


\section{Emerging themes.}

After reviewing the participants' childhood stories, four general themes emerged. These included the impact of where the individual grew up, the kind of play they engaged in as children, the influence of their parents, and in many cases a defining moment for when they became interested in environmental issues.

Growing up in a community.

Half (10) of the participants grew up in small communities or rural areas, three in suburban environments around larger communities, and seven in urban centres such as Vancouver. This is interesting because it does not reflect the typical population profile, in which $81 \%$ of Canadians now live in urban environments (Employment \& Social Development Canada, 2013). Richard Louv (2005) notes that regular access to the natural world influences a child's environmental outlook. The suggestion is that the participants enjoyed easier access to wild spaces by virtue of where they grew up - an observation echoed by Dunlap (2004) when describing how his earlier experiences influenced his later work, "Nature entered my life quite early, for my first memories include exploring what seemed to a three-year-old a wilderness of grass beyond the yard" (p. 7).

\section{Playing outdoors as a child.}

All the participants said they had played outdoors in nature when growing up, but a clear majority (17) said they did so a lot. They described the profound experience of walking in forests, working on farms, and playing along shorelines. Their stories were rich in memories of sights, sounds, and smells (Table 7). 
Table 7

Sample Comments: Playing Outdoors

\section{Participant Comment}

Female, 29 From the time I could walk, I was in the creek mucking around, travelling up and down the creek, going through orchards, our routes were everywhere through orchards, and on clay cliffs. It was the hot clay cliffs in the summer with the smell of sage, just super aromatic and powerful and just the dust kicking up.

Female, 26, I usually had leaves and moss in my hair and I was absolutely soaked and Aboriginal covered in mud and had fish scales and bird feathers and things stuck to everything I was wearing and it was just a really amazing, interactive, magical experience.

Female, 26, I was five. And I remember it was really sunny outside and you have these Chinese images of kind of these sun speckles coming in from the corner and running down into the garden and my grandma was pruning the tomato plants. And then it was just about to be summer and you really just smell the vines of the tomato.

Female, 24 Handling geese and doing a bunch of banding and stuff as a kid, like actually having that being with animals, holding them. I mean, that was what really kind of drew I think an emotional connection to wildlife as well.

Male, 29 So, I spent a lot time, in my early childhood, exploring the property and the surrounding areas, and looking for salamanders under logs, and spending hours on my own just out kind of playing in the forest.

Female, 29 Just growing up there and everything was so pure, the water was so clean, and the shape of the mountains was so calming. There were like those rolling kind of green mountains.

Male, 26 My parents just essentially took me out back and then I would go find things to play in, there were farms back there and horses. The people next door had rabbits and all kinds of things to get my hands on and play with. There were maple taps there so we'd eat a bunch of maple syrup.

Female, 24 I would chase the frogs through the dirt, in the back field, which I later discovered was actually cow poop. And I'd show up at the door ready for dinner covered in it. And I would try to give the pigs hugs and I'd sneak into the pigpen and come back completely covered in dirt.

\section{The outdoor experience.}

Over half the participants indicated their childhood outdoor experiences were unstructured and unsupervised. This involved playing, either alone or with groups of friends, in areas close to where they lived. The remaining participants indicated their time 
outdoors was organized by their parents into more formal recreation activities such as camping, hiking, skiing, or accompanying a parent in their outdoor work (for example, one participant described the experience of travelling with her father, who was a bird biologist with a large conservation organization). Most of the participants drew a link between their outdoor experiences and their subsequent choice of education program and career path.

Table 8

Sample Comments: The Outdoor Experience

\section{Participant Comment}

Female, 24 When we got home from school, we played outside until dinnertime. And then we would go back out until bath time and try and sneak out once we were nice and clean and it was the same thing day after day.

Female, 29 And we would go on camping trips, a lot of fishing, a lot of inter-tidal exploration. And definitely for me, that was the reason why I was interested in marine biology from a young age. So, that was a typical, I would say, family experience in the outdoors.

Female, 22 My nature experience as a child were that all my play, all of my hanging out with friends after school, in school as well, were all spent either in that forest or down in that beach.

Female, 24 Being outdoors wasn't really an option when we were kids. My dad is ... he's a bird biologist and worked for Ducks Unlimited for over 30 years. And so, I mean, his passion for the outdoors and it was just like a kind of osmosis.

Male, 29 And the first hike I ever did with him stands out as being kind of a really enjoyable experience in nature that I had with my father.

Female, 29 I grew up around a lot trees and mountains and it was a huge part of my memories was playing outside and sort of in the more wild spaces. And on weekends, we would go camping and go to Kananaskis cross-country skiing or snowboarding or whatever.

Female, 29 I had a remarkably free-range childhood, had no concept of private property, ranged around the creek in the backyard from like the early ... from the time I could walk.

Female, 28 We went camping a lot and we did family road trips every summer up to Northern B.C. or to visit family on the Prairies. 


\section{Call to action.}

I asked the participants if they could recall a point in their lives when they became interested in environmental work (Table 9). Eight indicated it was in their childhood and closely tied to the influence of their parents, four said it was through activities they experienced at high school, and eight said their calling came through academic courses, or interactions with professors and peer groups while attending university.

Additional observations.

In addition to the primary characteristics noted above, there were two other observations of interest. They add a further dimension to the profile.

First, 12 of the participants talked about growing or harvesting food when they were growing up. This included working in small backyard vegetable gardens, visiting farms and orchards, wild berry picking, and fishing. Growing food crossed all groupings - gender, environmental interest, and community of origin.

In addition, six participants said they were motivated to become involved in environmental work as a result of witnessing environmental destruction. For some, this involved the loss of a forest they had played in as a child, or seeing farmland replaced with tracts of single-family homes. For three it involved the experience of seeing the destruction of coral reefs while diving.

\section{Supplementing the participant profile.}

The participant profile I described earlier in this chapter was of a group that is primarily female, white, well educated, and middle class. To this can be added additional attributes based on early exposure to the natural world and the influence of parents. 
Table 9

Participant Comments: Call to Action

\section{Participant Comment}

Female, 24 I really felt like I had my call to action, it was on a three-week trip to Costa Rica, as part of a Global Perspectives class in high school.

Female, 29 It wasn't until I started my master's that I realized the oceans were in such trouble, then I started to look into solutions and the effects of anthropogenic forces on ocean.

Female, 22 In grade four actually, I founded with a friend of mine, EcoKids, which was a student-led environmental club at my elementary school.

Female, 24 Volunteering at Stream Keepers when I was a kid and doing stream cleanup and seeing all the garbage like I just ... I feel like I understood there was that negative kind of, the negativity that humans were inflicting on the environment. I knew it was there and I knew it was wrong.

Female, 26, In the class my mind really started to open to these ideas of systems and Chinese systems thinking and the different worldviews that people have in terms of working on wicked issues ... wicked problems such as poverty, women's rights, and sustainability.

Male, 29 I came to a bit of a realization about what I wanted to do and got into the Environmental Studies Program at the University of Victoria, which I was really excited about. And when I started taking courses there, I really, for the first time in my young adult life, felt I was doing something that I really believed in, I was really passionate about and felt really good about.

Male, 26 I was the student union president at my university and there were ... I worked really closely with the Earth Club on campus on planning Earth Day events and climate change activist issues and made it a point that you have a sustainability and environment position in our student government structure. So I started that and that's when I started getting more into the governance aspects and policy aspects.

Female, 26 Learning about green buildings was kind of the first ... I mean, I kind of thought, "Oh, that's really interesting, I'd like to pursue that." And so, I did take a class in green building design and did an internship and then just kind of worked in that area and went into really the environmental side of Engineering.

Male, 24 I became aware of the fact [at university] that sustainability is not just an emergent paradigm now but it's one of the most dominant issues.

Female, 27, I did end up shaping my research project in a way that does incorporate Aboriginal community, community values, our history, our culture, our quality of life, and our perception of, and interaction and influence, on our natural environment. And so, I mean, ultimately, those kind of defining moments did continue to shape my focus over the years. 
The group had wide-ranging outdoor experiences when they were children. These were not kids who hung out in malls or watched hours of television, which is counter to the prevailing trend of time children spend with electronic media (Wartella, Vandewater, \& Rideout, 2005). They were encouraged to play outdoors by their parents, and most had access to wild spaces close to where they lived. Although a causal relationship cannot be determined, the suggestion is that early exposure to the natural world has led this group to be more sensitive to environmental issues. The positive influence of parents and early exposure to the natural world is supported by research undertaken by Louise Chawla (2006), who noted:

A succession of studies which have asked other activists or environmental educators what inspired their commitment to the environment have reported similar results (Chawla 1998, Tanner 1998, 1999, Eigner \& Schmuck 1998, cited in Bögeholz 2006). In countries as far flung as England, Germany, Greece, Slovenia, Australia, Canada, El Salvador and South Africa, from half to more than $80 \%$ of the respondents mention childhood experiences of nature as a significant influence. Typically, they mention family members or other role models equally often or second in importance. (p. 61)

Furthermore, the parents of this group (who were all Baby Boomers) were mostly active themselves. In many cases they were role models for outdoor recreation, gardening, or careers in the environment. Some had made a purposeful decision to relocate to smaller communities in order to raise their children in a non-urban environment. Several participants also recalled kitchen table discussions about issues of environmental justice, third world development, and indigenous rights. 


\section{Question 3: What is environmentalism to you?}

\section{Emerging themes.}

When I first reviewed the transcripts for this question, 15 thematic nodes

emerged. After the initial round of coding, I determined that some of the nodes were redundant, and combined them into larger aggregations. For example, I originally created themes for "personal responsibility," "personal awareness," and "passion." After further review, I concluded that the references in these nodes all suggested that environmentalism was deeply personal to the participant, and grouped them under a single theme. The second round of coding resulted in eight thematic nodes (Figure 1).

Figure 1

Themes for "What is environmentalism to you?"

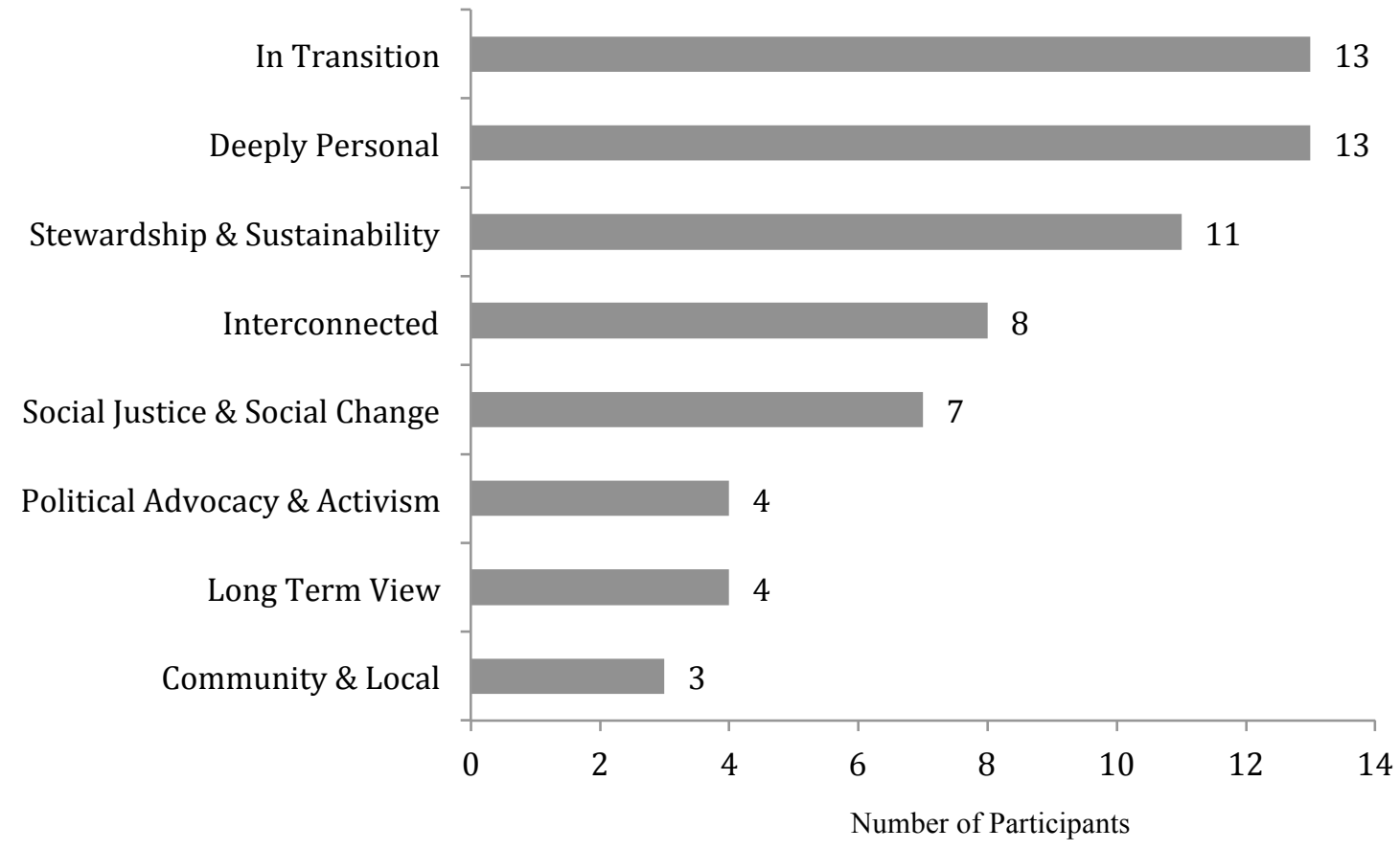

Note. The number in each bar indicates the number of participants in each thematic node. 
The themes that emerged for this question are described as follows:

1. In Transition: Early in the transcript reviews, it became apparent that most of the participants were not so much describing what environmentalism is, but how they felt about it. The two primary themes of "in transition" and "deeply Personal" reflect this observation. In the transition theme, a majority of the participants used language or provided examples indicating environmentalism is continuing to evolve from an earlier form.

2. Deeply Personal: For most of the participants, environmentalism is a way of life. It provides guidance for their actions, and they gave examples of how they integrated aspects of environmentally conscious behaviour into their daily lives.

3. Stewardship \& Sustainability: Beyond the personal expression of environmentalism, just over half of the participants referenced environmental views related to stewardship and sustainability. However, the language they used tended to be broader than traditional concepts of conservation and protection, and included references to ecosystem health, social and economic sustainability, and livelihoods.

4. Interconnected: Eight participants described environmentalism as a connection with the natural world. They noted that humans were dependent on life-giving ecosystems, and need to respect and honour other forms of life.

5. Social Justice \& Social Change: In this theme participants referenced social justice, climate justice, indigenous rights, and fairness. Interestingly, two of the seven individuals were from the Sustainability subgroup, indicating that this is not simply a concern of those aligned with the Justice cluster. 
6. Political Advocacy \& Activism: Four participants thought that environmentalism involves being politically active, or campaigning to influence government policy.

7. Long-Term View: Four participants talked about environmentalism as being strategic, about making the world a better place, and thinking beyond short-term electoral cycles. As one individual put it, "I think it's the growing understanding that we are living in a system that is radically unsustainable and out of balance in many meaningful ways. And it is the impulse to try to restore a sense of balance and to project forward."

8. Community \& Local: Three participants described environmentalism as being inherently place-specific. One of the Aboriginal women spoke about the deep connection between her heritage and the local landscape, while the others talked about protecting the environment in their communities.

\section{Primary themes.}

Three primary themes emerged from the question of "What is environmentalism to you?" - environmentalism is in transition, it is deeply personal, and it incorporates stewardship and sustainability.

\section{Environmentalism is in transition.}

For the transition theme, the participants provided a range of comments suggesting that change has already happened (some used the terms "old environmentalism" and "new environmentalism"), is happening, or needs to happen. Several talked about environmentalism as something practised by their parents' generation, one that may no longer be effective in meeting current and future challenges.

\footnotetext{
${ }^{4}$ Female participant, age 29, Justice subgroup.
} 
Most referenced elements they felt were missing, including social justice, system-level thinking, and sustainability.

Table 10a

Participant Comments: Environmentalism Is in Transition

\section{Participant Sample Comment}

Female, 22 There was a past environmentalism in terms of the movement and how it's moved from very environmental focus ... to more sustainability, social justice kind of thing.

Female, 28 We are forced to speak in the language of science all the time. And my great wish would be that we could open up that conversation and talk more about values.

Female, 28 The word environmentalism more frequently seems small to me ... it doesn't necessarily seem to me like it gets to climate change or that it gets to much of a system change level.

Female, 26, Sometimes I think what we hear and see as environmentalism does not Chinese

Female, 23 involve what I think is a pretty fundamental part of protecting society and the planet, which is social justice.

Male, 23 It seems to go in waves throughout history.

We need to have values that transcend the narrow industrial modes of production that we're looking at now.

Female, 26, I think a lot of what my dad's generation did was very action oriented. It

Aboriginal was finding really immediate solutions to big looming problems and reacting to them ... but it's very different from how we operate now.

Female, 29 It is the impulse to try to restore a sense of balance and to project forward beyond.

Male, 26 Environmentalism historically, is like the liberal environmental movement that grew out of the $60 \mathrm{~s}$ and $70 \mathrm{~s}$... It failed because the governments just systematically had their whole ability to regulate destroyed in the $80 \mathrm{~s}$.

Male, 29 When I think environmentalist, I think mostly we're concerned with protecting nature, not necessarily the complications and intersections that exist between the degradation of the natural world and the suffering of communities experiencing all kinds of oppression.

Male, 24 We have to approach sustainability and environmentalism in a different way.

Female, 27, I would like to see a bit of a shift toward modern environmentalism.

Aboriginal

Female, 26 The area that I work in, that's sustainability, and that's working to do the best we can with what we know and how we can do it!

Note. One comment from each of 13 participants. 
The transition theme suggests that environmentalism as a way of viewing the relationship between humans and the natural world is evolving from a focus on protecting landscapes toward one that increasingly incorporates people. The new focus is expressed through the inclusion of sustainability, social justice, and political activism.

Reviewing the subgroups of gender and environmental interest for this theme, no marked differences from the total group profile were apparent.

Table $10 \mathrm{~b}$

Subgroups: Environmentalism Is in Transition

\begin{tabular}{cccccc}
\hline \multicolumn{2}{c}{ Gender } & & \multicolumn{3}{c}{ Environmental Interest } \\
Female & Male & & Conservation & Sustainability & Justice \\
\cline { 1 - 2 } \cline { 5 - 6 } 9 & 4 & & 1 & 3 & 9 \\
\hline
\end{tabular}

Note. Total group profile ( $n=20): 70 \%$ (14) female, 30\% (6 male); 3 Conservation, 4 Sustainability, 13 Justice.

\section{Participant story of transition.}

I tend to be very cautious in my usage of a term like environmentalism. I think, in the past, the tendency was to want to use very defined ideas as to what environmentalism is. But I think, increasingly, people are understanding that environmentalism is something that's expressed in a cultural language. So, environmentalism means different things to a lot of different people, and I guess, in studying development studies and studying international politics, this is something I've become very aware of. And so, for me, environmentalism, I suppose, would be one dimension of a larger sustainability project ... living and creating livelihoods within, or in a manner that doesn't compromise the 
environment, which, granted, is a fairly vague way of putting it, but I think in

some ways, its very definition is sort of useful for the reasons I say.

(Male participant, age 24, Sustainability subgroup)

Environmentalism is deeply personal.

Table 11a

Participant Comments: Environmentalism Is Deeply Personal

\section{Participant Comment}

Female, 28 To me, environmentalism means, in some way, having a concern about the natural world that is related to the way one conducts themselves in a natural world.

Female, 22 My environmentalism, insofar as seeing it as doing tangible things, that directly reduces my impact on the world, and in fact, maybe improves it.

Female, 26, I have a personal passion and connection with nature and that the work Chinese we're doing is trying to protect those places in some way, shape, or form ... it's a sense that I belong.

Male, 23

It has to be a meaningful part of your life.

Female, 26, Aboriginal

When I think about my personal environmental ethic, I am interested in protecting the places that matter to me because I have a strong intimate connection to them, and because I rely on them, and because my identity is tied to them.

Male, 26 I feel the human relationship with nature really is everything about the human experience to me.

Female, $24 \quad$ Have to be passionate about it, for me it's a way of life.

Female, 26 I'd say environmentalism is having a sense of responsibility for one's self and one's impact on people and the planet, and how one lives their life.

Male, 29 Giving and living in a way that allows for all of these different connections and organisms to be able to continue and to thrive.

Female, 22 My parents ... care very deeply about environmental values and about social values. And so I think I was really just brought up in that framework and brought up in such a way that I was taught that it mattered from a really, really young age.

Female, 29 Environmentalism to me is a way to live. So, it's not a category. It's more just how you interact with everything around you day to day.

Female, 29 It's viewing your relationship, extending your self-interest out ... incorporating the environment in your own self-interests.

Male, $26 \quad$ My moral beliefs are around that shared energy that's in all things. 
This theme aligns with a similar theme that emerged through Question 4 (What would a sustainable life look like for you, and how would you live that way?). In this instance, a primary theme raised by 13 participants was related to being personally aware of their actions and taking personal responsibility for the choices they make.

For these participants, environmentalism is about how they live their lives. They integrate environmentalism into choices they make about small things such as conserving energy or not driving a car, to more substantive choices involving careers and education. Several described it as a way of life or a way to live. Interestingly, eight participants referenced growing their own food as an element of personal responsibility.

When the subgroups were reviewed for gender and environmental interest, the breakdown was the same as the theme of environmentalism is in transition. No marked differences from the total group profile were apparent.

Table $11 b$

Subgroups: Environmentalism Is Deeply Personal

\begin{tabular}{cccccc}
\hline \multicolumn{2}{c}{ Gender } & & \multicolumn{3}{c}{ Environmental Interest } \\
Female & Male & & Conservation & Sustainability & Justice \\
\cline { 1 - 2 } \cline { 5 - 6 } 9 & 4 & & 1 & 3 & 9 \\
\hline
\end{tabular}

Note. Total group profile ( $n=20): 70 \%$ (14) female, 30\% (6 male); 3 Conservation, 4 Sustainability, 13 Justice.

In sum, most participants conceived environmentalism as being built on a strong foundation of personal awareness and responsibility. They used "I" language to describe this personal connection ("I feel," "I belong," "I understand," "I do care"). This sense that environmentalism is personal was even stronger in Question 4 "What does a sustainable life look like for you?" and suggests that environmentalism for this group is more a 
practice than it is a critique of the excesses of the modern world. A comment that best summarizes this theme is "There's no part of my life where I don't feel it's part of me."5 Environmentalism is stewardship and sustainability.

Table 12a

Participant Comments: Environmentalism Is about Stewardship and Sustainability

\section{Participant Comment}

Female, $22 \quad$ Now it's moving to more sustainability, social justice kind of thing. It's more holistic.

Female, 28 It's a goal or movement of protecting natural ecosystems.

Female, 23 Advocating for respect of nature, in the broadest sense.

Male, 23

To have a sustainable economy going forward, we need to sort of reincorporate the environment in the way that we look at our economic system.

Female, 26, When I think about my personal environmental ethic, I am interested in Aboriginal protecting the places that matter to me because I have a strong intimate connection to them.

Female, 26 To be totally honest, environmentalism to me is conservation.

Aboriginal

Female, 24, Humans and nature, it is really interconnected. And so, environmentalism is kind of taking that stewardship, protecting the environment.

Female, 22 So to me, environmentalism really is kind of bringing together social and environmental sustainability in such a way that we can move forward as a society without damaging the world that we live on.

Male, 29 My sense of what environmentalism has come to mean is valuing nature and the natural world, ecological systems and the need to protect them.

Male, 24 For me, environmentalism, I suppose, would be one dimension of a larger sustainability project. Living and creating livelihoods within, or in a manner that doesn't compromise, the environment.

Female, 27, I feel like, at this point, that term goes hand-in-hand with the concept of Aboriginal sustainability and stewardship. And so, environmentalism I suppose is any approach to interacting and understanding the environment, and ... as a steward.

Note. One comment from each of 11 participants.

${ }^{5}$ Female participant, age 26, Aboriginal, Justice subgroup. 
This theme blends elements of stewardship that focus on conservation and protection of landscapes, with the more contemporary concept of sustainability. In Chapter Four I indicated my preference for the description of sustainability coined by John Robinson (2004): "sustainability focuses attention where it should be placed, on the ability of humans to continue to live within environmental constraints" (p. 370). I combined stewardship and sustainability into a single thematic node because both encompass aspects of actively managing the human environmental footprint in more benign ways. Furthermore, several of the 11 participants represented in this theme explicitly spoke about stewardship and sustainability as part of a single, holistic approach to environmentalism.

When the subgroups were reviewed for gender and environmental interest, no marked differences from the total group profile are apparent.

Table $12 \mathrm{~b}$

Subgroups: Environmentalism Is about Stewardship and Sustainability

\begin{tabular}{cccccc}
\hline \multicolumn{2}{c}{ Gender } & & \multicolumn{2}{c}{ Environmental Interest } & \\
Female & Male & & Conservation & Sustainability & Justice \\
\cline { 1 - 2 } \cline { 5 - 6 } 8 & 3 & & 2 & 2 & 7 \\
\hline
\end{tabular}

Note. Total group profile ( $n=20): 70 \%$ (14) female, 30\% (6 male); 3 Conservation, 4 Sustainability, 13 Justice.

This theme suggests continuity with an older form of environmentalism centred on preservation and protection of natural landscapes. Combined with the more recent concept of sustainability based on reducing the human footprint on the natural world, the suggestion is that people should be more conscious of their dealings with the environment. 


\section{Summary of question three.}

The responses to the question of what environmentalism currently means to the participants indicate it is something they try to practise in their daily lives. It guides their choices and decisions. It is important to them that their personal actions mirror their concept of environmentalism.

Second, the participants think that environmentalism is currently undergoing transition and change. They feel it is evolving to include a broader perspective on the human relationship with nature.

Finally, environmentalism increasingly involves elements of sustainability, social justice, political activism, and a holistic view of the economy and the environment. How the participants apply environmentalism in their daily lives is more fully explored in the next question, "What does a sustainable life look like for you?"

Question 4: What does a sustainable life look like for you? How would you

\section{live that way?}

\section{Emerging themes.}

After two series of coding, five themes emerged for this question. The primary theme of "personal awareness and personal responsibility" was referenced by 16 participants ( $80 \%$ of the group). The remaining themes are shown in Figure 2. 
Figure 2

Themes for "What does a sustainable life look like to you?"

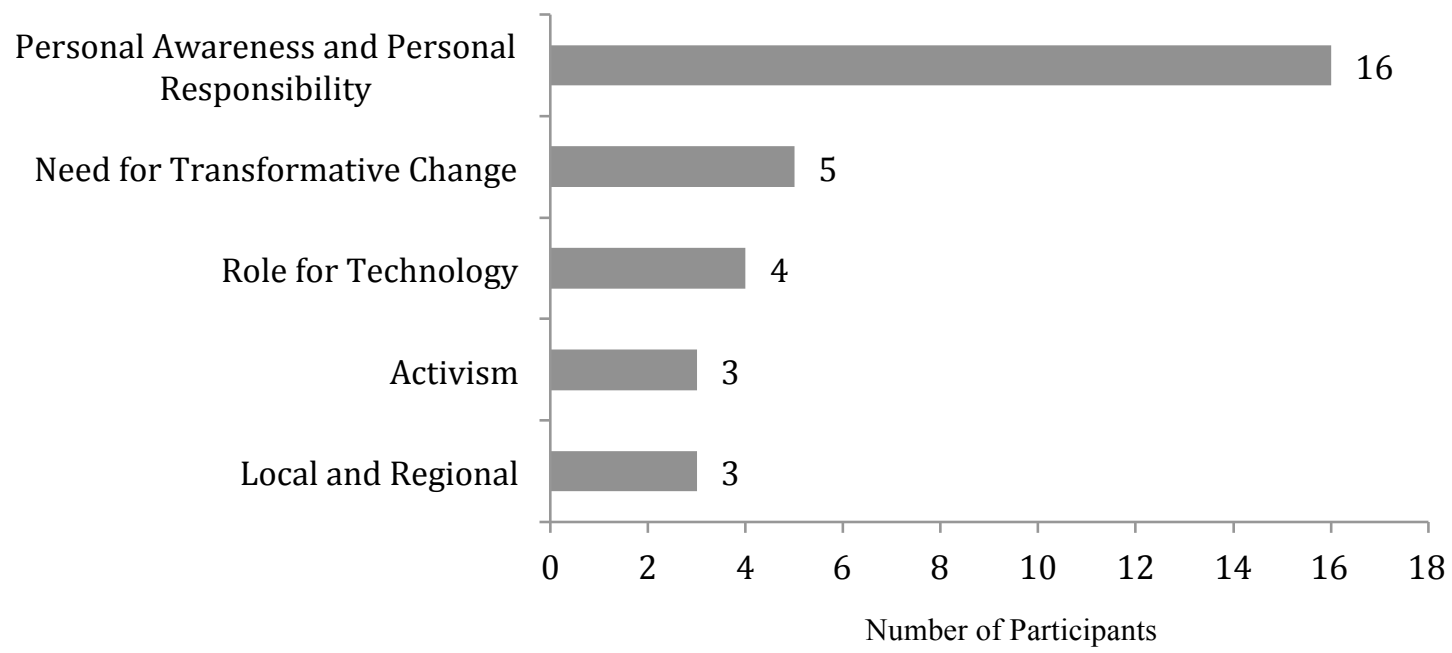

Note. The number in each bar indicates the number of participants in each thematic node.

The themes that emerged can be summarized as follows:

1. Personal Awareness and Personal Responsibility: Most of the participants indicated that living a sustainable life includes being personally aware of, and taking responsibility for, their own actions. This reference to sustainability being a personal attribute echoes the "deeply personal" theme from Question 3, in which many of the participants noted that environmentalism guides the way they live their lives.

2. Need for Transformative Change: Five participants argued that transformative change of our political and economic systems is required. In particular, a number of individuals noted that the economy should transition to a no-growth or steady-state form.

3. Role for Technology: In this theme, participants acknowledged that a sustainable life would involve the development of appropriate technologies. They referenced a range 
of "green" initiatives, including public transit, communications, energy generation, home design, and agriculture.

4. Activism: Three participants indicated that living a sustainable life is the foundation for organizing and enabling people to achieve social change in their communities.

5. Local and Regional: Three participants felt that sustainability was inherently local. They spoke about being part of a community of like-minded people. One individual described a sustainable life as "driven by deep connections with each other.",6

\section{Primary theme - personal awareness and personal responsibility.}

A single primary theme emerged for this question, in which the participants indicated that living a sustainable life involves being personally aware of and taking responsibility for their actions. The language used was generally positive, with individuals noting that the outcome of such a life would be "rich," "abundant," "healthy," "high quality," and "personally sustaining." There were also several references to selfreliance and taking measures to reduce a person's ecological footprint.

In addition, the personal dimension of living a sustainable life involves connections with family and friends. For this group, sustainability includes people as well as the environment - they are interconnected. This is illustrated by a comment from one woman who said she tried to live a sustainable life "Not because it's a wild place or it's an environmental value, but just our community as a whole, to do everything you can to make it, and us, strong and self-reliant."7

\footnotetext{
${ }^{6}$ Female participant, age 29, Justice subgroup.

${ }^{7}$ Female participant, age 26, Aboriginal, Justice subgroup.
} 
Table 13a

Participant Comments: Sustainability Is Personal Awareness and Personal Responsibility

\section{Participant Comment}

Female, 26, Where I use my time outside of work to grow stuff with my mom and Chinese have dinners that we make from scratch that are healthy.

Female, 26, It's really important personally for me to model my values, and I value Aboriginal sustainability.

Male, 26

A sustainable life would be one where I would have a very high quality of life ... working on issues that I really care about in engaging and rewarding ways.

Female, 26 A sustainable life includes setting up the way that I live and work to be in line with my values ... a kind of integrity based on the best I know.

Male, 26 My input would not unduly harm or irrevocably harm the environment or other humans.

Male, 29 I try to consume only what I need, so I really try to use less energy, to ride my bicycle.

Female, $24 \quad$ Doing things that are really good for the environment.

Female, 22 When I first came to university, I saw sustainability really as reducing your impact on the world around you to the furthest extent you could.

Female, 29 You would not have a big impact on the planet.

Male, 29 It involves ... more typical stuff about how we would get our own energy and self-sufficiency.

Male, 24 It would be educating myself as to what sort of behaviours have what impact and trying to live my lifestyle accordingly.

Female, 29 Small examples like recycling or eating local food or trying to have a discourse with our leaders to keep a sustainable engagement.

Female, 27, Personally, I drive my car as little as possible ... I'm conscious of any Aboriginal kind of household products. And in my day-to-day life, those are the things I do.

Note. One comment from each of 13 participants.

When the subgroup was reviewed for gender, no noticeable difference from the total group profile was apparent. The subgroup for environmental interest is slightly under-represented by participants from the Justice cluster (all the participants from the other two interest clusters were included in this theme). Nevertheless, the responses 
indicate the majority believes that sustainability involves taking personal responsibility for their behaviours.

Table $13 b$

Subgroups: Sustainability Is Personal Awareness and Personal Responsibility

\begin{tabular}{cccccc}
\hline \multicolumn{2}{c}{ Gender } & & \multicolumn{3}{c}{ Environmental Interest } \\
Female & Male & & Conservation & Sustainability & Justice \\
\cline { 1 - 2 } \cline { 5 - 6 } 11 & 5 & & 3 & 4 & 9 \\
\hline
\end{tabular}

Note. Total group profile ( $n=20$ ): $70 \%$ (14) female, 30\% (6 male); 3 Conservation, 4 Sustainability, 13 Justice.

Participant story of personal awareness and personal responsibility.

One where I'm living close to my family, my parents, and my extended family, which includes my aunts and uncles. Yeah, one where I'm living close with my immediate family and my extended family, which are like my aunts, uncles, and cousins. And where I use that time outside of work to grow stuff with my mom and have dinners that we make from scratch that are healthy, that are not filled with pesticides from God-knows-where. Where I have time to appreciate the art of life, whether that is through calligraphy or playing music or singing. Where I can be in nature, I can climb, I have time for climbing and hiking and just sitting in the front yard and reading a book.

And during my work hours that I could ... All that stuff I just described, would be kind of my recharge for kind of doing the hard work of social change, as a fulltime gig, as a job. And where I'm biking and walking, and I don't always feel like I'm in a rush and that I don't wake up and roll over and check my email. But instead I wake up and sit and appreciate life for 10 minutes in the morning. I think, for me, the epitome of all that is, like, having a sense of patience and 
calmness, so that I can be an empathetic person, and really hear people when they're talking to me, versus just hearing what I think they're saying, which is mostly my voice. To me, I think that is a sustainable life, 'cause I think too many times we're in these situations where we're always rushed and crunched and we're not really listening to people's problems, which is I think part of why it's hard to find really effective solutions for environmentalism or social change. So that would be great.

(Female participant, age 26, Justice subgroup)

\section{Outliers.}

Two participants described a perspective at odds with the rest of the group, in which they raised a concern about the emphasis on personal accountability. One noted, "This emphasis on personal responsibility, or you can just buy your way into environmentalism by buying organic food or like buying a Prius ... that's not enough." This was echoed by a second participant who said, "I see living a sustainable life more as the outputs that you put into your community than actually being really individualistic about the actions you take." ${ }^{, 9}$ These comments suggest that collective actions at a larger scale are also necessary to address environmental challenges. However, the two participants indicated they had incorporated aspects of sustainability into their daily lives at other points in their interviews, suggesting that they have already integrated a certain responsibility at a personal level.

\footnotetext{
${ }^{8}$ Male participant, age 23, Justice subgroup.

${ }^{9}$ Female participant, age 22, Justice subgroup.
} 


\section{Summary of question four.}

When asked "What is environmentalism to you?" in Question 3, a theme that it was "deeply personal" emerged. Similarly in Question 4, the majority of the participants indicated that living a sustainable life involved being personally aware and responsible for their actions. The responses to these two questions suggest that environmentalism and sustainability are integrated into the lives of this group, and involve challenges that an individual deals with on a day-to-day basis. This indicates a connection to their personal beliefs and values, which is discussed further in the next two questions.

\section{Question 5: What beliefs, values, or experiences motivate and shape your} choice to live a sustainable life?

\section{Emerging themes.}

\section{Figure 3}

Themes for "What beliefs, values, or experiences motivate and shape your choice to live a sustainable life?”

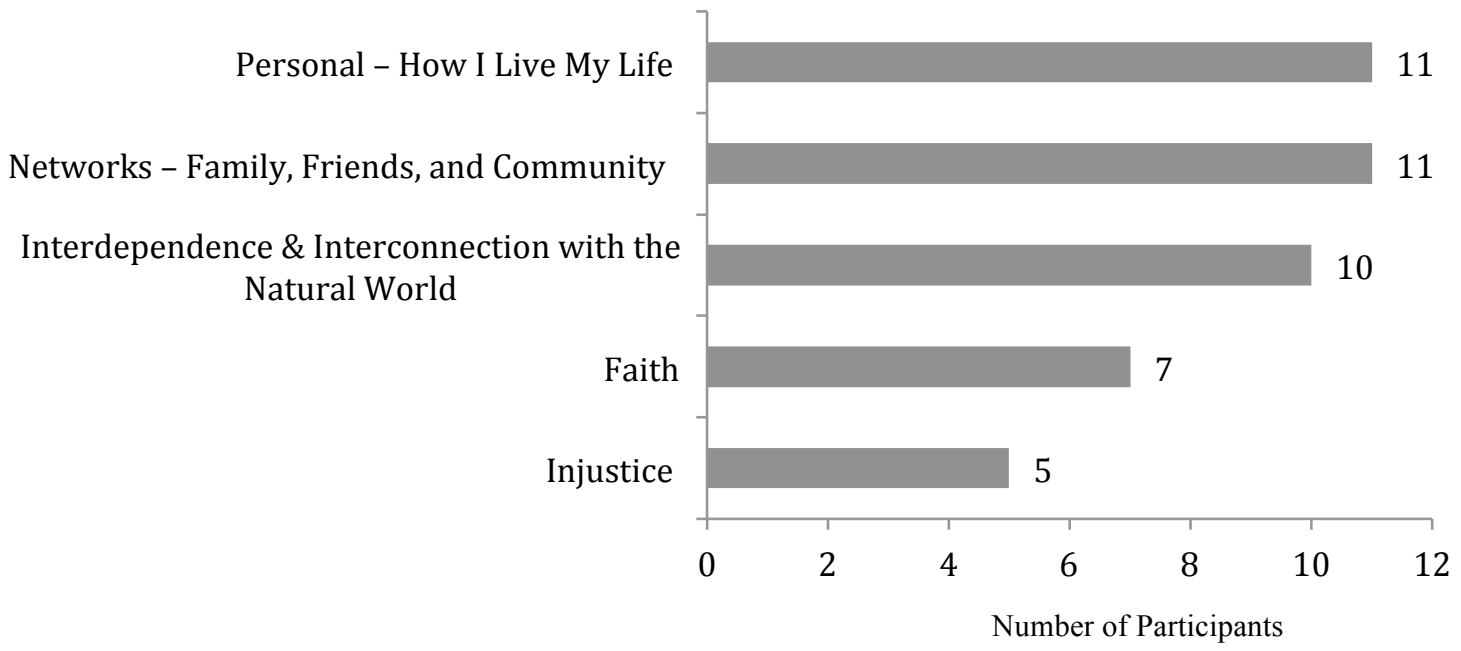

Note. The number in each bar indicates the number of participants in each thematic node. 
This question generated a wide range of comments. As a result, I chose to initially group the responses into both themes and subthemes. I used the subthemes to help me code the participants' views at an early stage in the analysis, and then aggregated them into higher-level thematic nodes. After two series of coding and editing, five themes emerged as shown in Figure 3. The themes are summarized as follows:

1. Personal - How I Live My Life: Eleven participants indicated their motivation for living a sustainable life was based on personal qualities and experiences. These include being self-aware, spending time in nature, doing the best one can, creativity, and being optimistic.

2. Networks - Family, Friends, and Community: In this theme, individuals spoke about a deep connection to family and their local community. For many, their parents remain a source of support and inspiration for their education and work. The theme of networks also includes a belief in the value of diversity.

3. Interdependence and Interconnection with the Natural World: Ten participants indicated their motivation for living a sustainable life was based on a belief that humans and nature are interconnected. This includes a conviction that science can promote a deeper understanding of the natural world, as well as the value of stewardship. This is not the same as spending time in nature noted in "Personal How I Live My Life" above, which is about the sense of well-being that comes from being outside. 
4. Faith: Seven participants drew on their religious faith and beliefs as a motivation.

5. Injustice: Five participants said they were motivated to reduce suffering, address inequality, and speak up when necessary. The comments indicated a values-based approach to living a sustainable life based on compassion and empathy.

\section{Primary themes.}

Three primary themes emerged from the question of "What beliefs, values, or experiences motivate and shape your choice to live a sustainable life?": personal - how I live my life; networks - family, friends, and community; and interdependence and interconnection with the natural world.

Personal - how I live my life.

This theme explores the personal values and beliefs underpinning the decision to align a participant's actions with their views on environmentalism. The responses indicated that a powerful motivation to live a sustainable life was spending time in nature. Several participants talked about the beauty and spiritual benefits they received from being outdoors.

Other comments included making a conscious shift in a person's life to reduce their environmental footprint, about being more creative and optimistic in how they make decisions, and the value of integrity in their actions. The remarks in "how I live my life" suggest that the motivation for choices about how they live their lives is more emotional than it is calculated or objective. 
Table 14a

Participant Comments: Personal - How I Live My Life

\section{Participant Comment}

Female, 22

The best thing for human health, mentally, socially, and spiritually, is to live a way that's more connected to nature.

Female, $28 \quad$ I guess there's a sort of love there in the way that you would love another person; like with the natural world, it's like a tenderness and a gentleness and a gratefulness.

Female, 23

The value of nature, just to enjoy the beauty and to have it around you.

Male, 24

What's happening more and more, and maybe I'm not there yet, is that people are trying to craft a narrative of environmentalism which is more positive.

Female, 26 I undergo a very constant and conscious process of self-reflection and

Aboriginal self-assessment in my work and in my personal life to make sure that I'm measuring myself against the standard that I have.

Male, 29 There's a belief for me in the real, innate goodness that exists in people.

Female, 26

Wanting to live in a way that is meaningful and surrounded by community. I think, in general, we all kind of try to do the best we can.

Female, $24 \quad$ I think I have morals. Maybe that's kind of a weird response, but ... Who decides that I have the right to take more than my share, is kind of how I look at it, like in terms of living sustainably.

Female, 27, I value my home and my natural environment.

Aboriginal

Note. One comment from each of 9 participants.

When the subgroups were reviewed for gender and environmental interest, no marked differences from the total group profile are apparent.

Table $14 \mathrm{~b}$

Subgroups: How I Live My Life

\begin{tabular}{cccccc}
\hline \multicolumn{2}{c}{ Gender } & & \multicolumn{2}{c}{ Environmental Interest } & \\
Female & Male & & Conservation & Sustainability & Justice \\
\cline { 1 - 2 } \cline { 5 - 6 } 8 & 3 & & 2 & 2 & 7 \\
\hline
\end{tabular}

Note. Total group profile ( $n=20): 70 \%$ (14) female, 30\% (6 male); 3 Conservation, 4 Sustainability, 13 Justice. 
Networks - family, friends, and community.

In this theme participants indicated their motivation to live a sustainable life was grounded in close networks of family and friends.

Table $15 \mathrm{a}$

Participant Comments: Networks - Family, Friends, and Community

\section{Participant Comment}

Female, $26 \quad$ I have a very diverse set of friends and people that I interact with and try to understand their views and opinions ... I think that better informs me.

Female, 28 I believe families have a role to play in the way that children see the world and children understand nature.

Female, 22 Right now, I have a community which I feel very deeply connected with ... it's so nourishing to me.

Female, 23 I have this really good surrounding of friends and family who all think, and it's not all the same, but we have this stronger regard for nature.

Male, 24

We draw a lot of inspiration from our surroundings, so what our friends and colleagues and co-workers and families, how they're acting makes a big impact, has a big impact on how we act.

Female, 22 I think one of the biggest things is the community piece ... I don't think we can have sustainability without healthy communities.

Female, 26 That sense of continuity is really important to me. I know the story that Aboriginal my name comes from, I know the exact place and the landscape it comes from, and I know what it means, and for me it's important that I model that connection continuity.

Female, 26, It also makes me have a stronger appreciation and love for what is already Chinese around for my family and form my health, and for all the amazing people in my life.

Female, 29 It's going back to my family upbringing, the people who raised me, my surroundings, and my experiences that I had.

Female, 24 I think maybe it's the way I grew up, like my grandparents, my dad grew up living off the land.

Female, 27, I have more of connection to this place than others.

Aboriginal

Note. One comment from each of 11 participants.

Many spoke about their parents as role models, using language such as "loving family" or "family values." Other participants indicated they drew their motivation from 
small groups of like-minded friends. These networks tend to reinforce an individual's choices and activities.

The theme of networks also includes a deep connection to a community. Participants talked about a sense of rootedness to a location, healthy communities, and cultural heritage. Both Aboriginal participants spoke passionately about the connection to their community, noting the continuity with past generations and the close ties to a particular place.

When the subgroup of environmental interest was reviewed, no marked differences from the total group profile were apparent. However, males are significantly under-represented for this theme. This might suggest that women place more value on networks of family and friends than do men, although male comments from other themes in this question indicated no differences based on gender.

Table $15 b$

Subgroups: Family, Friends, and Community

\begin{tabular}{cccccc}
\hline \multicolumn{2}{c}{ Gender } & & \multicolumn{3}{c}{ Environmental Interest } \\
Female & Male & & Conservation & Sustainability & Justice \\
\cline { 1 - 2 } \cline { 5 - 6 } 10 & 1 & & 2 & 2 & 7 \\
\hline
\end{tabular}

Note. Total group profile $(n=20): 70 \%$ (14) female, 30\% (6 male); 3 Conservation, 4 Sustainability, 13 Justice.

\section{Interdependence and interconnection with the natural world.}

Unlike the comments in the previous two themes from Question 5 - which were based on personal values, experiences, and relationships - the theme of interdependence and interconnection is based on an understanding of ecological systems. The participants indicated their motivation to living a sustainable life is grounded in the conviction that the impact humans have on the environment can have negative consequences in their own 
lives. This theme aligns with much of the thinking that was expressed early in the formation of modern environmentalism outlined in Chapter Two.

Table 16a

Participant Comments: Interdependence and Interconnection with the Natural World

\section{Participant Comment}

Female, 28

I would say both a religious belief and a scientific understanding of our interdependence and interconnectedness, and of our species dependence ... on a healthy planet.

Female, 29

An understanding of the interdependence of all things. A big part of my philosophy is a fundamental belief in the equality of people and our interdependence at a very, very deep level.

Male, 26

My moral beliefs are around that shared energy that's in all things.

Male, 29

Systemic perspective of the interconnections and the web of life. I feel like that understanding of interdependence is a really strong guiding principle in my value system.

Female, 26 I think there is a huge amount of integrity in the ecosystems around me,

Aboriginal and a huge amount of opportunity to continue interacting with those places in a similar way, with similar values, to how my ancestors did.

Female, $24 \quad$ My belief is that I want all things to have life, and a healthy life, and so I do what I can so that's possible.

Female, 29 My alignment happens emotionally is when I feel that and I see it in nature, but then I don't see it in the systems and structures that humans build. So, trying to reconcile that drives my work.

Female, 29 You have the science saying that we are having an impact on our planet ... but then you have a social dimension, which is not fair.

Male, 24 I think just the increasing consciousness as to the sort of problems that we currently face.

Note. One comment from each of 9 participants.

When the subgroups were reviewed for gender and environmental interest, no marked differences from the total group profile were apparent. 
Table $16 \mathrm{~b}$

Subgroups: Interdependence and Interconnection with the Natural World

\begin{tabular}{cccccc}
\hline \multicolumn{2}{c}{ Gender } & & \multicolumn{3}{c}{ Environmental Interest } \\
Female & Male & & Conservation & Sustainability & Justice \\
\cline { 1 - 2 } \cline { 5 - 6 } 6 & 4 & & 3 & 6 \\
\hline
\end{tabular}

Note. Total group profile ( $n=20): 70 \%$ (14) female, 30\% (6 male); 3 Conservation, 4 Sustainability, 13 Justice.

\section{Summary of question five.}

The question of what motivates a participant to live a more sustainable life aligns closely with the comments about what environmentalism and sustainability mean. It is foremost a personal quality, in which participants indicated the need to align their actions with their beliefs. For many of the group, this behaviour is something engendered in their childhoods by family members who also had strong environmental convictions - and is reinforced by networks of friends who share similar viewpoints.

Together with a belief that humans are part of a web of ecological systems, it is possible to see that environmentalism and sustainability are deeply integrated into the thinking and actions of the participants. The next question explores the barriers to achieving these goals.

\section{Question 6: What stands in the way of you doing so?}

\section{Emerging themes.}

Four themes and 20 subthemes emerged from the first round of coding. Further editing and grouping resulted in the two primary themes shown in Figure 4. The first involved comments about societal norms and systems creating barriers to a participant's efforts to live a sustainable life. The second theme was more intrinsic to the individual, involving issues of resources, time, worry, and stress. 
Figure 4

Themes for "What stands in the way of you living a sustainable life?"

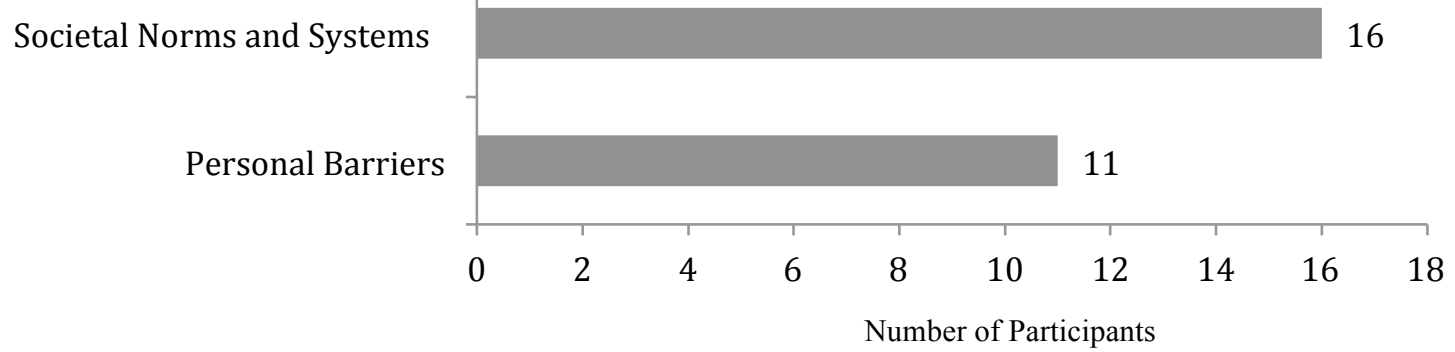

Note. The number in each bar indicates the number of participants in each thematic node.

Societal norms and systems.

A majority of the participants (16) indicated that the biggest barrier to achieving a sustainable life was societal norms and systems. These include consumerism, status quo conformity, unsustainable practices, and a sense of alienation from the democratic process.

Many noted that the current economic system essentially forces them to make choices that make it difficult to reduce their environmental footprint. There were suggestions that a sustainable life should be more convenient than the current situation, otherwise very few people will alter their behaviours. Participants were also concerned that the narrative of a sustainable lifestyle is often one of sacrifice from the status quo, which does not inspire change.

Others identified the structure of our urban environments as a barrier. Comments in this area referenced issues of transportation, and a lack of access to green spaces and places to grow food. 
Table 17a

Participant Comments: Societal Norms and Systems

\section{Participant Comment}

Female, 24 To be completely sustainable, it really is tricky and I wrestle with this often. Because there are things that I feel you just can't get away from.

Female, 28 It's almost like our intention as individuals and even our own ambitions is stifled by the tremendous weight of commercial society.

Male, 26

By over-consuming and by buying and by having these things, it makes it possible to engage in that world. And I think that it's a constructive social pressure.

Male, 23

They don't think they can effect change by knocking on doors or doing civil disobedience or demonstration because they think that the cards are sort of stacked against them.

Female, 26 That commercialized connection to place was very short-lived for lots of Aboriginal complicated reasons and we are having to find new ways to be in the landscape and interact with it and sustain ourselves there.

Female, 29 My experiences caused me to be on my present path and other people, maybe, are not. We likely come from different backgrounds and different experiences, so perhaps, they're not having the same experience that I did, could be the reason they're not environmentalists.

Female, 24

You can't blame them for not wanting to fight for it, because they don't even know what it is. And so, I guess, my fear is that there's not going to be anybody to carry on after I'm gone, because they're not going to understand what's missing.

Female, 26, I think too many times we're in these situations where we're always Chinese rushed and crunched and we're not really listening to people's problems, which is I think part of why it's hard to find really effective solutions for environmental or social change.

Female, 28 A political and economic system that discourages and often ... doesn't make it possible, or that doesn't make it easy or economically viable.

Female, 29 The systems that we live in are a major impediment.

Male, 29

Neo-liberal capitalist culture that we live within demands a certain way of living.

Female, 27, The status quo, it's what we've become accustomed to.

Aboriginal

I think that's due to economic and societal systems that don't place maintaining a sustainable environment and ecological health high.

Male, 24 I think that people have habituated behaviours that become comfortable for them and I think it's very hard to break these kinds of things.

Note. One comment from each of 14 participants. 
Several participants were concerned about the democratic process. One individual noted that when people talk about voter apathy among youth, "they miss the fact that there is a ton of disengagement and clear seeing in peoples' withdrawal in disgust from the system." 10 The barrier for those who raised issues about democracy largely involves impediments to becoming involved - the inability to influence policies, structures that disenfranchise younger people, and hierarchical decision-making processes.

When the subgroups were reviewed for gender and environmental interest, no marked differences from the total group profile were apparent.

Table $17 \mathrm{~b}$

Subgroups: Societal Norms and Systems

\begin{tabular}{cccccc}
\hline \multicolumn{2}{c}{ Gender } & & \multicolumn{3}{c}{ Environmental Interest } \\
Female & Male & & Conservation & Sustainability & Justice \\
\cline { 1 - 2 } \cline { 5 - 6 } 11 & 5 & & 2 & 4 & 9 \\
\hline
\end{tabular}

Note. Total group profile ( $n=20): 70 \%$ (14) female, 30\% (6 male); 3 Conservation, 4 Sustainability, 13 Justice.

Personal barriers.

Just over half of the participants talked about personal barriers that are common to almost any individual. These involve finding meaningful work, making enough money, and having enough time to achieve the things they want to do. However, a number of comments suggested the participants had high expectations for making a difference in what they do - and this creates stress that they are not doing enough, or might fail. The combination of trying to achieve a work-life balance, succeeding in their environmental

10 Female participant, age 29, Justice subgroup. 
or social change work, and having enough resources to get by is a barrier in that it generates a high level of anxiety and worry for many of the participants.

Table $18 \mathrm{a}$

Participant Comments: Personal Barriers

\begin{tabular}{|c|c|}
\hline Participant & Comment \\
\hline Female, 22 & $\begin{array}{l}\text { First of all, really trying to decide where I can make the biggest } \\
\text { difference ... and then recognizing the reality of "I need to pay bills and } \\
\text { pay my rent and get by." }\end{array}$ \\
\hline $\begin{array}{l}\text { Female, 26, } \\
\text { Chinese }\end{array}$ & $\begin{array}{l}\text { If I don't do it right, if I don't do it perfect, if I don't work on it as hard } \\
\text { as I can, then I'm not fulfilling my role as whatever, an environmentalist } \\
\text { or social change maker. }\end{array}$ \\
\hline Male, 26 & $\begin{array}{l}\text { I think for my generation, having three or four different sources of } \\
\text { income will be key. Because finding that one job that you work in for } 40 \\
\text { hours a week is becoming harder and harder. }\end{array}$ \\
\hline Male, 29 & $\begin{array}{l}\text { There are tensions, and there is a personal kind of anxiety and while I } \\
\text { feel very passionately about everything I've said in this interview, I } \\
\text { don't necessarily ... I don't live by it every day. }\end{array}$ \\
\hline $\begin{array}{l}\text { Female, } 26 \\
\text { Aboriginal }\end{array}$ & $\begin{array}{l}\text { You can't ask people to make huge choices and changes without some } \\
\text { reassurance that it's a safe and valuable thing to do. And that requires a } \\
\text { lot of work. }\end{array}$ \\
\hline Female, 22 & $\begin{array}{l}\text { A big stick in the mud for what I want to do is money, the treadmill of } \\
\text { society requires me to just make money so I can sustain myself. }\end{array}$ \\
\hline Male, 29 & $\begin{array}{l}\text { Resources. The idea of actually owning land is something that is not a } \\
\text { real consideration for me, so that's why I say this is a dream. }\end{array}$ \\
\hline Female, 24 & $\begin{array}{l}\text { I guess, it's people's greed, people want money, people want to be } \\
\text { able to eat strawberries all year around. But we've kind of ... We just } \\
\text { shifted our line of thinking away from what makes sense, what's } \\
\text { moral, what's right, to what we want. }\end{array}$ \\
\hline Male, 23 & $\begin{array}{l}\text { Everything does. I mean, paying rent, paying tuition does, have to keep } \\
\text { up my grades does. Just trying to be a successful person. }\end{array}$ \\
\hline Female, 23 & Right now, probably funds or time. Time is a big one. \\
\hline Male, 26 & $\begin{array}{l}\text { There's only do much I can hold at equal weight at one time and move } \\
\text { through the world. }\end{array}$ \\
\hline
\end{tabular}

Note. One comment from each of 11 participants.

When the subgroups were reviewed for environmental interest, no marked difference from the total group profile was apparent. However, the number of males who 
spoke about personal barriers was higher than the ratio for the entire sample - but not by an amount marked enough to draw a conclusion.

Table $18 \mathrm{~b}$

Subgroups: Personal Barriers

\begin{tabular}{cccccc}
\hline \multicolumn{2}{c}{ Gender } & & \multicolumn{3}{c}{ Environmental Interest } \\
Female & Male & & Conservation & Sustainability & Justice \\
\cline { 1 - 2 } \cline { 5 - 6 } 6 & 5 & & 2 & 2 & 7 \\
\hline
\end{tabular}

Note. Total group profile ( $n=20): 70 \%$ (14) female, 30\% (6 male); 3 Conservation, 4 Sustainability, 13 Justice.

\section{Summary of question six.}

Despite their passion for what they do, and that they are all well-educated middleclass adults, none of the participants suggest that living a sustainable life is easy. There was a clear indication that there are multiple systemic barriers inherent in our economic systems and the design of our communities. Furthermore, there is a feeling that the foundational system by which change occurs, the democratic process, does not work well for this group. Many feel alienated from the current political process, with some suggestions that it does not encourage participation. The perception is not that it is broken, but that it needs reform.

Questions 3, 4, 5, and 6 form the category of a participant's environmental beliefs and motivations. Together with Question 1 on the experiences of the participants growing up, the backgrounds and environmental perspectives of the group next lead to comments about the state of the environment and the effectiveness of the environmental movement. 


\section{Question 7: How do you perceive the current health or state of the}

\section{environment?}

\section{Emerging themes.}

Four themes emerged for this question, as shown in Figure 5. Most participants felt that the general health of the global environment was poor and getting worse. The remaining themes included a sense that environmental conditions are better at the local level, that vulnerable people and communities disproportionately feel the impact of a worsening environment, and that our economic systems contribute to environmental degradation.

Figure 5

Themes for "How do you perceive the current health or state of the environment?"

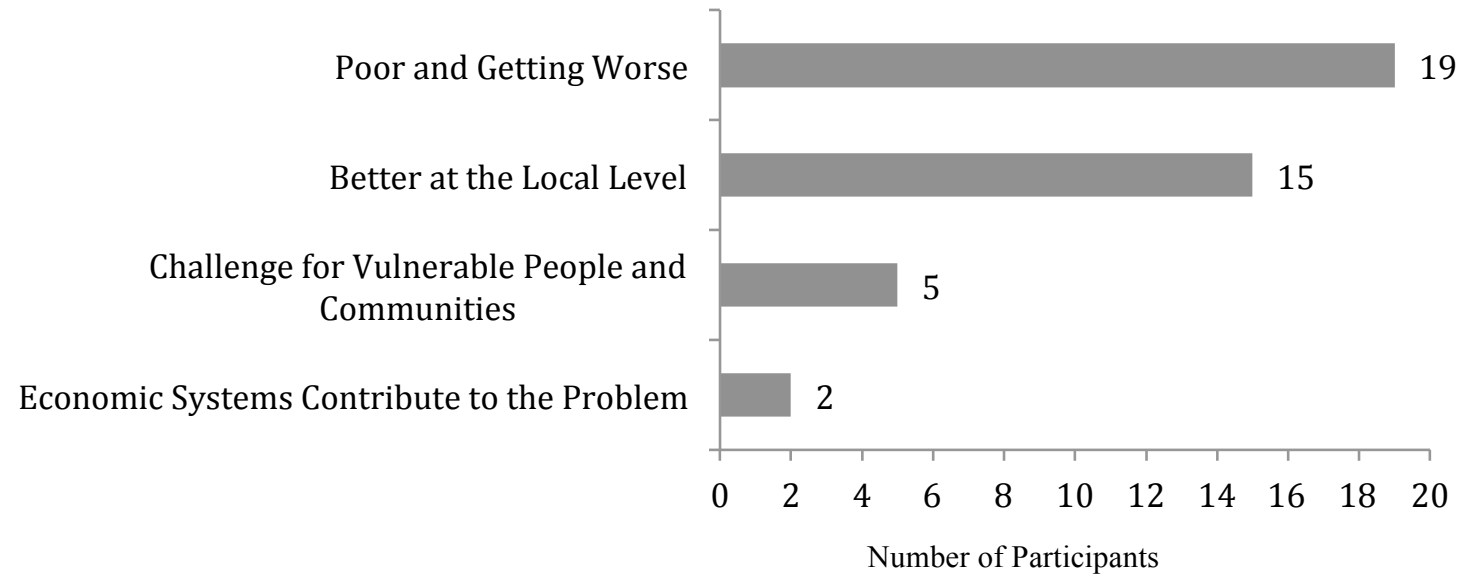

Note. The number in each bar indicates the number of participants in each thematic node.

The themes that emerged can be summarized as follows:

1. Poor and Getting Worse: Nineteen participants said the health of the environment was deteriorating at the global scale. They used language such as "grave," "serious," and "dismal" when describing their perception. 
2. Better at the Local Level: While a clear majority of the participants felt that environmental health was poor at the global scale, 15 also said things were better at the local or regional scale. They referenced sustainability initiatives in their community, or noted that the area in which they lived was still pristine and unaffected by human development.

3. A Challenge for Vulnerable Peoples and Communities: Five participants, all of whom thought conditions were poor at the global level, indicated that deteriorating environmental health was disproportionately impacting vulnerable peoples and communities. These included impacts on indigenous peoples (in Canada and around the world), lower income populations, and in developing nations that lack the resources to address environmental challenges. For example, one participant noted, "I can only imagine where it's like, in places that are even poorer and just don't have the positive influence and the education available to them to learn, that it's bad ... or that it's not good."11

4. Economic Systems Contribute to the Problem: Two participants made a strong argument that deteriorating environmental health was linked to economic systems built on growth and consumption. These individuals were particularly concerned that existing systems often force people to make decisions that have the effect of causing further environmental degradation, or that environmental health is not valued in the same way that money or development are valued.

${ }^{11}$ Female participant, age 24, Conservation subgroup. 


\section{Primary themes.}

Two primary themes emerged from the question "How do you perceive the current health or state of the environment?": that it is poor and getting worse, and that things are better at the local level.

Poor and getting worse.

All but one of the participants indicated that the state of the global environment was bad. The remaining individual was focused on the immediate region where she lived and worked, and was optimistic about the ability of natural systems to recover from environmental changes.

Similar to Question 1 ("Tell me about your outdoor and nature experiences as a child"), the participants used emotive language when describing the state of the environment, although this time it was a negative expression. The responses came quickly, without much reflection, and the terms used were similar (e.g., "dire," "dismal," "grave," "shitty").

Several individuals said that poor environment health had an impact on them personally. One said it caused a knot in her stomach, another that she was terrified. Most of the participants referenced examples of worsening environmental conditions. The majority cited climate change as the leading cause of declining environmental health. There were also references to consumption, the loss of biodiversity, freshwater shortages, and deforestation. 
Table 19

Participant Comments: Environmental Health Is Poor and Getting Worse

\section{Participant Comment}

Male, 29

The state of the global environment doesn't seem very rosy. Like it seems to be getting significantly worse every year.

Female, 22

I think things are getting pretty shitty, and increasingly so.

Female, 28

Globally, the environmental crisis is very grave. I feel like it's very, very serious and that it's getting more serious all the time.

Male, 29

I do think the state of the environment is very poor.

Female, 28

Poor and getting worse.

Female, 23

It's becoming more obvious how much damage we're causing.

Male, 23

I think the current state is absolutely dismal. Our climate has warmed at a faster rate than most scientists expected ... so things aren't good.

Female, 29

So global, I think things are incredibly dire. I am terrified by the reality of climate change.

Male, 26

Realistically things could move very quickly, things could become more protracted.

Female, 26 Not especially great, we're not heading in a great direction.

Female, 27, Globally, I don't feel optimistic. I think there are some huge, huge Aboriginal environmental threats that people are facing right now.

Note. One comment from each of 11 participants.

Better at the local level.

While virtually all the participants said that the state of environment at the global level was poor and getting worse, a surprising number (15) said that things were better if not improving - at the community or regional scale.

In this theme, participants generally spoke to three different aspects of the environment being better locally. Overall, many said there was something about the health of the region that was unique. 
Table 20a

Participant Comments: Environmental Health Is Better at the Local Level

\section{Participant Comment}

Female, 28 We're lucky in Vancouver that, locally, it can easily feel like we're addressing issues and it's getting better.

Female, 23 Pacific North West seems like a pretty different ... Like we have different views.

Female, 26, I think there is a huge amount of integrity in the ecosystems around me.

Aboriginal

Female, 29

Locally, there is actually more happening around environment than there ever has been before, at least where I live.

Male, 26

We get the benefit of a really robust ecological system that has a lot of resiliency. And we've done a good job of protecting what's left.

Female, 24 I actually think that here we've making a little bit more progress.

Male, 24 I'm pretty inspired, I guess, by what's happening regionally.

Female, 29 I think, for us right now, regionally, we're doing okay.

Female, 22

The water is clean. The air is clean. Compared to many other parts of the world, I think we're in a good state.

Female, 27, Locally, I think that we're doing very ... quite well. Aboriginal

Note. One comment from each of 10 participants.

One participant referenced that "it seems like where we hug this coast and we love it so much and we love our forests"12 to describe a special affinity to the area. If the participant lived in a large city like Vancouver, they referenced sustainability initiatives such as public transit, bike lanes, urban food gardens, and green roofs. If they lived in rural or First Nations communities, they spoke about vibrant, intact ecosystems and ongoing stewardship initiatives to protect them.

When the subgroups were reviewed for gender and environmental interest, no marked differences from the overall group profile were apparent.

12 Female participant, age 23, Conservation subgroup. 
Table 20b

Subgroups: Environmental Health Is Better at the Local Level

\begin{tabular}{cccccc}
\hline \multicolumn{2}{c}{ Gender } & & \multicolumn{2}{c}{ Environmental Interest } & \\
Female & Male & & Conservation & Sustainability & Justice \\
\cline { 1 - 2 } \cline { 5 - 6 } 12 & 3 & & 2 & 3 & 10 \\
\hline
\end{tabular}

Note. Total group profile ( $n=20): 70 \%$ (14) female, 30\% (6 male); 3 Conservation, 4 Sustainability, 13 Justice.

\section{Outlier.}

One participant who thought environmental conditions were better at the local level stressed that this was not necessarily a good thing. Her position was that this tends to isolate us from the challenge that things are getter worse at the global scale. She raised the concern that the appearance that things are good can lead to a lack of urgency to deal with emerging large-scale environmental issues such as climate change.

\section{Summary of question seven.}

For this group, there was an overwhelming perception that global environmental conditions were deteriorating. The participants based this view on a variety of indicators, the predominant one being the rate and impact of climate change. As noted in the profile section of Chapter Four, at least half of the individuals have advanced post-secondary education in fields related to environmental studies, and several have worked and travelled internationally in areas impacted by climate change. Therefore, their belief that conditions are bad is not an uninformed one.

However, the concurrent view that things are better at the local level links to previous themes about taking personal responsibility for the choices they make. In such instances the individual can exercise more control. They can get involved and see the 
impact, be it recycling and using public transit, or working with groups focused on regional environmental issues. The result would be more awareness of local conditions.

It is apparent that these individuals feel deeply about the environment, and are passionate about what they are doing. The emotional response to the question about the health of the environment is the subject of the next question.

\section{Question 8: How do you feel about this?}

Question 8 is a follow-up from the preceding one, "How do you perceive the current health or state of the environment?" The participants were therefore expressing an emotional response to how they had previously described current environmental conditions. As all but one of the group previously indicated that conditions were bad and getting worse, the expectation was that the reaction would be primarily negative. Interestingly, this was not the case.

I noted in Chapter Four that this question was designed to provoke a frank, emotive response. I also indicated my caution that the interviews might cause unintended impacts on the participants. This question did, in fact, initially lead to visible reactions. Most paused before answering, a number lowered their heads and looked distressed, three cried. In all instances, I gave the individuals time to think and speak, and attempted to move them back to a reflective mode. It helped that the major theme that eventually emerged for this question was one of turning the emotion of distress into one of motivation to effect change.

\section{Emerging themes.}

Five themes emerged for this question, as shown in Figure 6. The predominant theme was one of motivation and opportunity. The other themes included the 
aforementioned sadness and despair, accepting the current state of the environment for what it is, anger, and a sense of being overwhelmed by the perception that environmental conditions are deteriorating.

Figure 6

Themes for "How do you feel about this?"

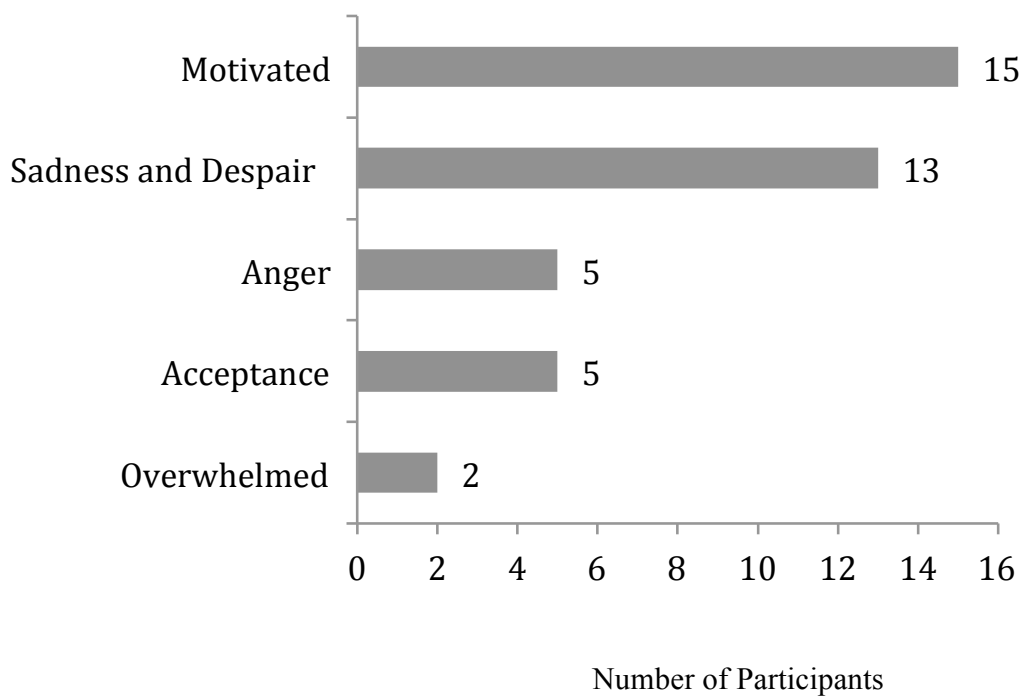

Note. The number in each bar indicates the number of participants in each thematic node.

The themes that emerged can be summarized as follows:

1. Motivating: Fifteen participants indicated their feelings of sadness and despair were a motivation for their work, as well as for how they live their personal lives. Several indicated this motivation included seeking out opportunities to apply their beliefs.

2. Sadness and Despair: The initial response to the question for 13 participants was to express that they were saddened and distressed by the perception that global environmental conditions were deteriorating. They used words like "despondent," “despair," "upsetting," and "terrible." 
3. Anger: Five individuals said they were angry or mad that environmental conditions might be worsening. Frustration about not being able to change things was part of this theme.

4. Acceptance: Five participants noted that they had to accept things for what they are, and not dwell on the negative. This is different from being motivated to do more, although some participants were included in both themes. A few referenced the stages of grief process, in which a person moves from shock, through anger and despair, to acceptance. As one individual noted, "You just have to learn to accept it."13

5. Overwhelmed: Two participants said they felt overwhelmed with the scale and complexity of the challenges. One indicated she just wanted to run away from the problem, but subsequently said that was not in her character.

\section{Primary themes.}

Two primary themes emerged from the question "How do you feel about this?": a sense of being motivated to grapple with environmental challenges; and feelings of sadness and despair about the perception that conditions are bad or getting worse.

\section{Motivation and opportunity.}

The strongest theme was one of turning despair into motivation and opportunity. Participants moved quite quickly from an expression of anxiety, sadness, and anger about how they perceive global environmental conditions, to a sense that these feelings encourage them to work harder to make a change.

13 Male Participant, age 26, Sustainability subgroup. 
Table 21a

Participant Comments: Motivation and Opportunity

\section{Participant Comment}

Female, 28

Female, 23

I have a way to turn those types of feelings into motivation.

Male, 26

It motivates me.

Female, 28

I feel some hopelessness in there, but also fired up.

\section{Female, 28}

Using the phrase "emotional alchemy" to describe a lot of things but partly the transition that's needed in recognizing despair at how bad things are and are getting, and using that to propel forward.

Female, 26, Aboriginal I owe it to the places that make me feel exuberant and full of awe to do

Male, 29 everything I can to be a hopeful spokesperson for them.

Male, 29 I think I get faith from that and that that's the only way to, yeah, work

Female, 29 through the sadness and the fear.

Male, 24

$$
\text { I find it personally very motivating. }
$$

I try my best not to be altogether too depressed by that, 'cause I think that maybe it's forcing us to re-evaluate how we approach these kinds of issues.

Female, 26, Through recognizing all the things that I do really appreciate and love, I Chinese can go to acceptance and say, "Okay. Well, what can I do about it?" Male, $26 \quad$ You can use that grief to just continually be motivating.

Note. One comment from each of 10 participants.

Several participants talked about the how their negative perception of environmental conditions pushed them to seek out opportunities to undertake meaningful work. One talked about how this encourages her to collaborate in her community on initiatives that can address current environmental challenges. Another said he was inspired to work on sustainability efforts at the local level.

When the subgroups were reviewed for gender and environmental interest, no marked differences from the overall group profile were apparent. 
Table $21 b$

Subgroups: Motivation and Opportunity

\begin{tabular}{cccccc}
\hline \multicolumn{2}{c}{ Gender } & & \multicolumn{2}{c}{ Environmental Interest } \\
Female & Male & & Conservation & Sustainability & Justice \\
\cline { 1 - 2 } \cline { 4 - 6 } 11 & 4 & & 3 & 9 \\
\hline
\end{tabular}

Note. Total group profile ( $n=20): 70 \%$ (14) female, 30\% (6 male); 3 Conservation, 4 Sustainability, 13 Justice.

\section{Sadness and despair.}

As previously noted, the initial reaction to this question was one of marked sadness and distress. This was apparent in the physical reactions of some of the participants to the question, as well in the words they used. One individual paused and asked me, "I don't know if you've had many people crying in your interviews." 14

Table 22a

Participant Comments: Sadness and Despair

\begin{tabular}{ll}
\hline Participant & Comment \\
\hline Female, 28 & It makes me feel despondent. \\
Female, 23 & I feel bad about it a lot of the time. \\
Female, 26, & It makes me really sad. \\
Chinese & \\
Female, 23 & It's pretty upsetting. \\
Female, 29 & It feels terrible. \\
Male, 26 & On the whole, shitty. \\
Male, 29 & Just simply sadness. \\
Female, 29 & I think it's devastating. \\
Female, 27, & I do think we're kind of in a dismal time. \\
Aboriginal & \\
Female, 29 & It really affected me. \\
\hline
\end{tabular}
Note. One comment from each of 10 participants.

${ }^{14}$ Female, age 29, Justice subgroup. 
In acknowledging their sadness, several participants also spoke about the need to integrate emotions into the broader discussion on environmental degradation. Their point was that dispassionate conversations about the environment do not allow those impacted to fully express the consequences of such degradation on their families and communities.

When the subgroups were reviewed for gender and environmental interest, no marked differences from the overall group profile were apparent.

Table $22 b$

Subgroups: Sadness and Despair

\begin{tabular}{cccccc}
\hline \multicolumn{2}{c}{ Gender } & & \multicolumn{3}{c}{ Environmental Interest } \\
Female & Male & & Conservation & Sustainability & Justice \\
\cline { 1 - 2 } \cline { 5 - 6 } 10 & 3 & & 2 & 3 & 8 \\
\hline
\end{tabular}

Note. Total group profile ( $n=20): 70 \%$ (14) female, 30\% (6 male); 3 Conservation, 4 Sustainability, 13 Justice.

\section{Summary of question eight.}

It was apparent from the responses to this question that the participants care deeply about the environment. They visibly showed their distress when asked how they felt about the perception that environmental conditions were deteriorating. They expressed these feelings through language that indicated sadness, anger, or a sense of being overwhelmed. This question elicited more emotional responses than any other during the interview.

On the other hand, there was also a clear indication that these emotions do not paralyze participants' ability to do something about the problems they see. There was a powerful sense that they use their negative feelings as a motivation to take action - either through their work, in their academic studies, or in their day-to-day lives. In fact, many of 
them have already made a difference through the formation of grassroots organizations or activist campaigns in their communities.

\section{Question 9: Could the current environmental challenges have been avoided?}

As noted in Chapter Four, the purpose of this question was to determine whether the participants would make a link between their perception of environmental conditions, and historical developments or technical inventions. Because I am conducting research on the generational dimension of environmentalism, I also wanted to explore whether participants ascribed blame to previous generations. The issue of blame was not a predetermined question, as I was looking for whether a theme might emerge through the participant comments.

\section{Emerging themes.}

Unlike previous questions, this one was designed to elicit more of a "yes or no" response. The themes that emerged were a weak yes, we could have avoided this - and a stronger no, we do not place blame.

Figure 7

Themes for "Do you think current environmental challenges could have been avoided?"

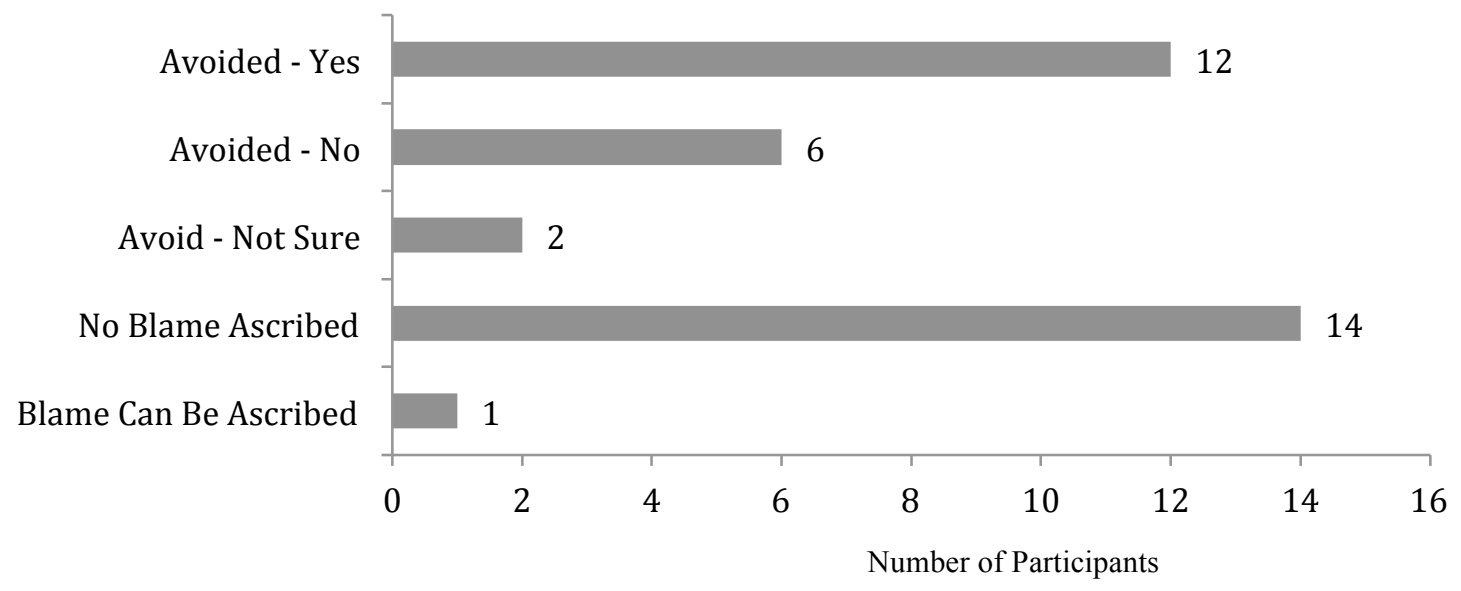

Note. The number in each bar indicates the number of participants in each thematic node. 


\section{Avoiding environmental challenges.}

Two thirds of the participants said that the current environmental challenges could have been avoided. In most cases, these individuals said the problems were due to a combination of an economic system that does not take the environment into account, and a lack of suitable values.

With respect to the economy, the suggestion was that the system was primarily geared to growth and consumption. Individual comments referenced the unintended consequences of industrial activity, powerful business interests, and a market-based ideology. The reference to values related to the need to create more collaborative communities, poorly informed decision-making processes, an education system that does not teach a more holistic view, and an emphasis on greed and competition.

The one third who said that current environmental challenges could not have been avoided used words such as "inevitable" to suggest it was human nature to develop the way we did.

When the subgroup was reviewed for gender, the proportion of males was slightly higher than for the overall group profile. There was no marked difference for environmental interest.

Table 23

Subgroups: Environmental Challenges Could Have Been Avoided

\begin{tabular}{cccccc}
\hline \multicolumn{2}{c}{ Gender } & & \multicolumn{3}{c}{ Environmental Interest } \\
Female & Male & & Conservation & Sustainability & Justice \\
\cline { 1 - 2 } \cline { 5 - 6 } 7 & 5 & & 1 & 2 & 9 \\
\hline
\end{tabular}

Note. Total group profile ( $n=20)$ : 70\% (14) female, 30\% (6 male); 3 Conservation, 4 Sustainability, 13 Justice. 


\section{Ascribing blame.}

As previously noted, the results for this theme were not part of a predetermined question. Instead, I was listening for whether the participants would place blame on previous generations. Fifteen individuals referenced this theme, and all but one said no blame could be ascribed.

Table 24a

Participant Comments: No Blame Can Be Ascribed

\section{Participant Comment}

Female, 22 If I were in the place of all generations before me, I would have chosen exactly the way they would have chosen.

Female, 28 I also am cautious to get into a blame game ... I don't think it's useful.

Female, 26, That kind of energy doesn't make anything better.

Chinese

Male, 23 I don't think people foresaw this.

Female, 26 I don't think that's a productive thing to do.

Female, 26 Getting caught up in conflict over whose fault it is ... isn't useful.

Female, $24 \quad$ I'm not going to blame someone for the unknown.

Female, 29 To cast blame on any group of people, it's not my right, and it's not fair.

Note. One comment from each of 8 participants.

When the subgroup was reviewed for gender, no marked difference from the overall group profile were apparent. The Sustainability subgroup was marginally underrepresented.

Table $24 \mathrm{~b}$

Subgroups: No Blame Can Be Ascribed

\begin{tabular}{cccccc}
\hline \multicolumn{2}{c}{ Gender } & & \multicolumn{3}{c}{ Environmental Interest } \\
Female & Male & & Conservation & Sustainability & Justice \\
\cline { 1 - 2 } \cline { 5 - 6 } 11 & 3 & & 3 & 1 & 10 \\
\hline
\end{tabular}

Note. Total group profile ( $n=20): 70 \%(14)$ female, $30 \%$ (6 male); 3 Conservation, 4 Sustainability, 13 Justice. 


\section{Summary of question nine.}

For this question, most of the participants thought that the current environmental challenges could have been avoided, but that this would have entailed a different economic system - one that places a greater value on the environment. No one suggested how this could have evolved differently, just that the impacts of a modern industrial, consumer economy significantly contribute to environmental problems. A smaller number indicated that it was inevitable that we would be facing these challenges, due to patterns of human behaviour and imperfect knowledge.

With respect to placing blame for the environmental problems we now face, the group overwhelmingly said none could be attributed. They felt that seeking to do so was either misplaced, or ignored the circumstances that existed when the current economic and industrial systems were originally put in place.

\section{Question 10: How would you describe the environmental movement?}

Questions 10 and 11 focus on the environmental movement, which I earlier defined as the manifestation of environmentalism. It is noteworthy that for these questions most of the participants did not distinguish between the movement and its constituent organizations, instead treating them interchangeably.

In my initial coding for this question, I identified 11 thematic nodes. After reviewing the materials further, I aggregated the themes into three final nodes, as shown below in Figure 8. 
Figure 8

Themes for "How would you describe the environmental movement?"

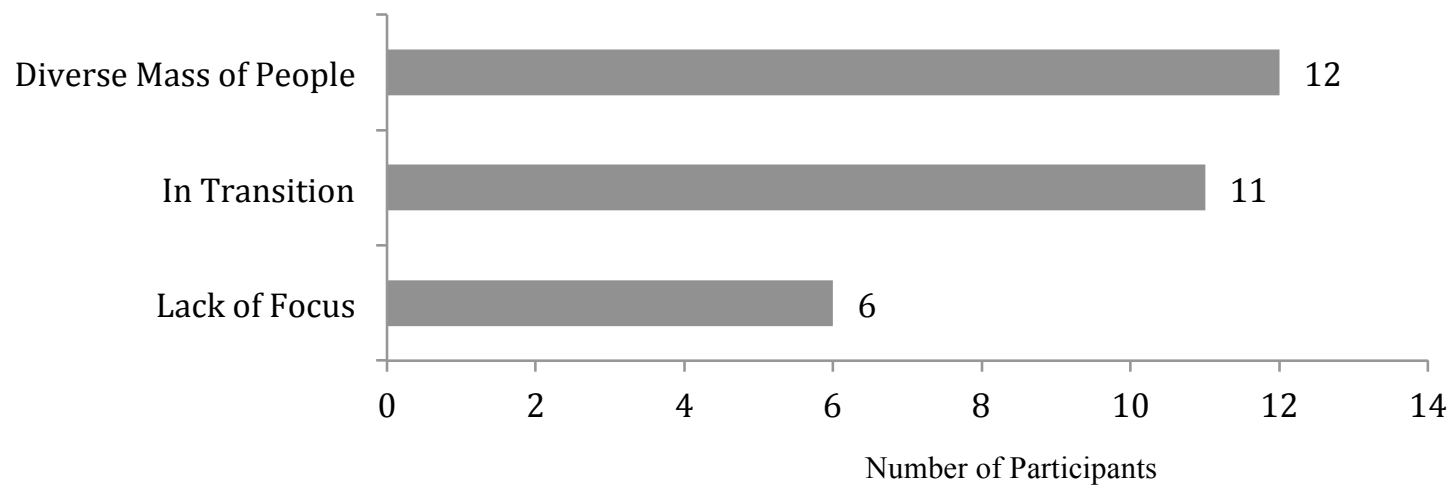

Note. The number in each bar indicates the number of participants in each thematic node.

The three themes that emerged can be summarized as follows:

1. A Diverse Mass of People: Twelve participants spoke about the diversity of the movement, its populist nature, and that it encompasses a broad spectrum of individuals. The comments in this theme were generally positive.

2. The Movement Is in Transition: In this theme, participants noted the movement is currently undergoing change. This was reflected in remarks about the shift from a traditional conservation focus, to one that was more inclusive of social justice issues. In discussing the evolution of the movement, some expressed frustration with large, entrenched environmental organizations who they felt received generous funding with few substantive outcomes to show for their efforts.

3. The Movement Lacks Focus: Six participants were more critical of the movement, using words such as "useless stereotype," "stalled," "irrational," and "off the rails." Many thought it was overly negative in its outlook, and focused on messages of guilt. Others noted the fractured nature of the environmental movement, arguing that the internal tensions were endemic and paralyzing. Two said it had stalled. One 
participant summed up the negative aspect of the movement by noting, "I don't want to be negative. I feel like I want to inspire people and make people hopeful."15

\section{Primary themes.}

Two primary themes emerged from the question "How would you describe the environmental movement?": that it is large and diverse, and that it is currently evolving and changing.

A diverse mass of people.

The strongest theme about the environmental movement was a hopeful, positive description of something that is growing, diverse, and grounded in strong values. Participants felt that the range of opinions and approaches within the movement were a strength, even if this might lead to a lack of a single, unified focus. Several noted that such diversity promotes continuous innovation and experimentation (for example, the sudden emergence of Idle No More in 2012). Others argued that environmentalism was now very much in the mainstream of public consciousness.

The area where the growing numbers and diverse nature of the movement was not viewed as a strength was around questions about whether it was capable of getting at the issue of deeper systemic change. In this instance, the comments were that too broad a spectrum and rapid change might not permit an in-depth analysis of long-term effects - as efforts become too focused on immediate or emerging challenges.

15 Female participant, age 28, Justice subgroup 
Table 25a

Participant Comments: A Diverse Mass of People

\section{Participant Comment}

Female, 22 I think it's important to have that spectrum because it really defines the different possibilities and what's right, what's wrong, what's most effective through kind of a trial and error.

Female, 26, Any group that's made up of people is bound to be the most diverse, Aboriginal wonderful, strange thing it can possibly be.

Female, 24

There are people in all sorts of different sectors that are all trying to work toward the betterment of the environment.

Male, 26 There's this group of concerned citizens ... and they all want to make good decisions around what that means.

Female, 29

I see it as growing, getting more sophisticated, getting more accepted and people realizing that they can't ... they can no longer deny it.

Female, 29 It's exciting, it is grassroots, and it brings you somewhere.

Male, 29

There's a huge spectrum of people in the environmental movement. And the idea of the modern environmental movement I think that's popularly conceived of is a movement as whole, and I think within that movement there is a huge diversity of perspective.

Male, 24

There is no one environmental movement ... environmentalism means a lot of different things for different people.

Female, 27, An environmental movement is a group of people who have maintained Aboriginal a sense of value on the natural environment and they're willing to do and act ... in line with those values.

Male, 26 There's this growing issue, people are starting to realize it a bit more, and I think there's more being offered to people to learn about it.

Note. One comment from each of 10 participants.

Participant story of movement diversity.

I don't know. Any group that's made up of people is bound to be the most diverse, wonderful, strange thing it can possibly be. The environmental movement in the sense of non-First Nations stewards, I guess, it's a group that I've only worked with fairly recently in my life, but I'm not sure I could point to defining characteristics, it varies so wildly. I think the things that I respect among the people that I work with who identify themselves as being part of the 
environmental movement, they have a strong set of values that influence their work often and a huge amount of passion for the work they do, and don't tend to be doing it because it's a great, well-paying, cushy job or anything like that. There's something a lot deeper that's driving them, and that's something that I have to respect. (Female participant, age 26, Aboriginal, Justice subgroup) When the subgroups were reviewed for gender and environmental interest, no marked differences from the overall group profile were apparent.

Table $25 b$

Subgroups: A Diverse Mass of People

\begin{tabular}{cccccc}
\hline \multicolumn{2}{c}{ Gender } & & \multicolumn{3}{c}{ Environmental Interest } \\
Female & Male & & Conservation & Sustainability & Justice \\
\cline { 1 - 2 } \cline { 5 - 6 } & 4 & & 3 & 2 & 7 \\
\hline
\end{tabular}

Note. Total group profile ( $n=20): 70 \%$ (14) female, 30\% (6 male); 3 Conservation, 4 Sustainability, 13 Justice.

\section{The movement is in transition.}

The second major theme was a view that the environmental movement is currently in the middle of profound change and transition. From this perspective, many of the participants talked about the evolution of the movement from a conservation frame, to one that includes political activism, social justice, and democratic reform. Some used the term "modern" to describe the newer form, perhaps not knowing that an earlier generation used similar terminology in the late 1960s and early 1970s to describe the shift away from a conservation focus that existed at that time.

What is perhaps different for the participants who indicated that change is under way is a rejection of what they see as large, bureaucratic, and ineffective environmental organizations. Their reaction is to speak of returning to a grassroots community focus, 
more emphasis on indigenous people, and a strong emphasis on social justice. For these participants, social justice includes an emphasis on indigenous rights, direct democracy, more control over local economies, and solidarity with people in developing nations (particularly those impacted by climate change). As noted in Question 5, they see this occurring in smaller networks of peers, connected by social media.

Table 26a

Participant Comments: The Movement Is in Transition

\section{Participant Comment}

Female, 28 In my mind, the kind of older environmental movement is the sort of Sierra Club type of conservation model. And the stuff that's coming out of 350 [dot org] ... I would call all of that the modern environmental movement.

Female, 26, I think right now, it's very curious, the environmental movement creating Chinese relationships and strategy to engage with new communities and audiences.

Male, 23

It is shifting and people are discovering that this is about environmental values more than anything and doing whatever engineering fix is proposed is not going to be enough.

Female, 29 The relationship we have today is radically different. And I think the environmental movement has not caught up to the moment that we're in.

Male, 26 The way that I think of environmentalism historically, is like the liberal environmental movement that grew out of the sixties and seventies.

Female, 24 There are a lot of older people that seem to be part of it; that are trying to retire and disappear. But then, there's a lot of younger people, like me, that are just sort of coming into some of these positions, that are really passionate about it, and there's a gap there.

Female, 26 I think environmentalism is really a lot broader and includes social activism and other kinds of community-based movements.

Male, 29

I think what's happening is there's sort of this gathering of a lot of diversity within the movement that's trying to do lots of different things, and I see myself as being kind of on the grassroots, local fringes of the environmental movement.

Female, 22 I think it's changing a lot from earlier movements being based on protection, conservation ... modern environmentalism is operating more in kind of political and economic realms and operating in a space where we recognize our needs for the environmental in very basic ways to much more meaningful ways.

Male, 24 It seems to me that there is no one environmental movement ... and environmentalism means a lot of different things for different people. 
When the subgroups were reviewed for gender and environmental interest, no marked difference from the overall group profile were apparent.

Table $26 b$

Subgroups: The Movement Is in Transition

\begin{tabular}{cccccc}
\hline \multicolumn{2}{c}{ Gender } & & \multicolumn{3}{c}{ Environmental Interest } \\
Female & Male & & Conservation & Sustainability & Justice \\
\cline { 1 - 2 } \cline { 5 - 6 } & 4 & & 1 & 3 & 7 \\
\hline
\end{tabular}

Note. Total group profile $(n=20): 70 \%$ (14) female, 30\% (6 male); 3 Conservation, 4 Sustainability, 13 Justice.

\section{Summary of question ten.}

In Chapter Four, I noted that the purpose of this question was to obtain feedback about the nature of the environmental movement in the broader context of contemporary social movements. I wanted to discern whether a younger group of individuals who were not around during the formative period of the environmental movement would recognize that movements grow, mature, and either evolve or fade out. From that perspective, the answers to this question reflect a view that the environmental movement is still evolving, but is changing in response to new issues, a more diverse community of interest, and a recognition that many of the existing movement structures may no longer be as effective as they could be. The strengths, weaknesses, and areas for improvement are covered in more detail in the next question.

\section{Question 11: Is the environmental movement as effective as it could be?}

When one designs interviews, asking if something is as effective as it could be might not be considered a useful question. It invites the answer that things could always be more effective. However, my intent was to allow the conversation to shift to areas of 
the movement's strengths and weaknesses, and a discussion about how to improve its success.

The feedback was diverse, with no single theme generating a response from over half of the participants. I have therefore structured this section as a narrative about the range of all the comments.

\section{Strengths of the environmental movement.}

In the area of strengths, 15 participants talked about where the movement has improved or is succeeding. They commented on the growing diversity within the movement, the maturing of its voice, and access to better scientific information.

Figure 9

Themes for "Strengths of the Environmental Movement"

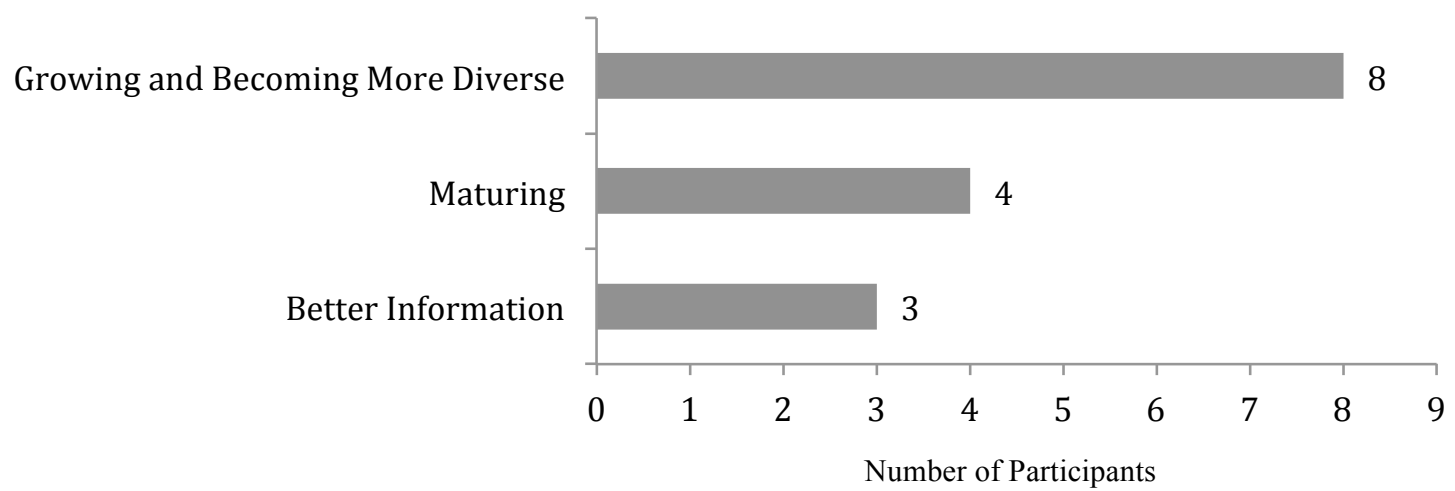

Note. The number in each bar indicates the number of participants in each thematic node.

Eight participants thought that the movement was growing and becoming more diverse. It is unclear on what basis they made this claim, but several noted changes in their own communities where they had seen this happen. In particular, the two Aboriginal women provided examples of how more people were becoming involved with environmental issues related to pipelines, oil tanker traffic, and control over local resources. One noted, in reference to her participation at large public gatherings, "there 
was no one thing that we all identified as having in common ... other than just some basic value, I think, around justice."16

Four participants thought the strength of the movement was related to its maturing. These individuals referenced the emergence of more creativity, humour, a focus on changing people's behaviours, and better communication of key messages. One thought that the next generation of environmentalists is going to be stronger because the base of environmental awareness is much deeper, due in large part to the successes of the environmental movement over the last half century.

Participants felt that the range of opinions and approaches within the movement was a strength, even if this might result in the lack of unified focus. Several noted such diversity promotes continuous innovation and experimentation. This allows campaigns and communications to be based on sound reasoning instead of empty rhetoric.

\section{Weaknesses of the environmental movement.}

Fifteen participants talked about the movement's weaknesses, as follows:

Figure 10

Themes for "Weaknesses of the Environmental Movement"

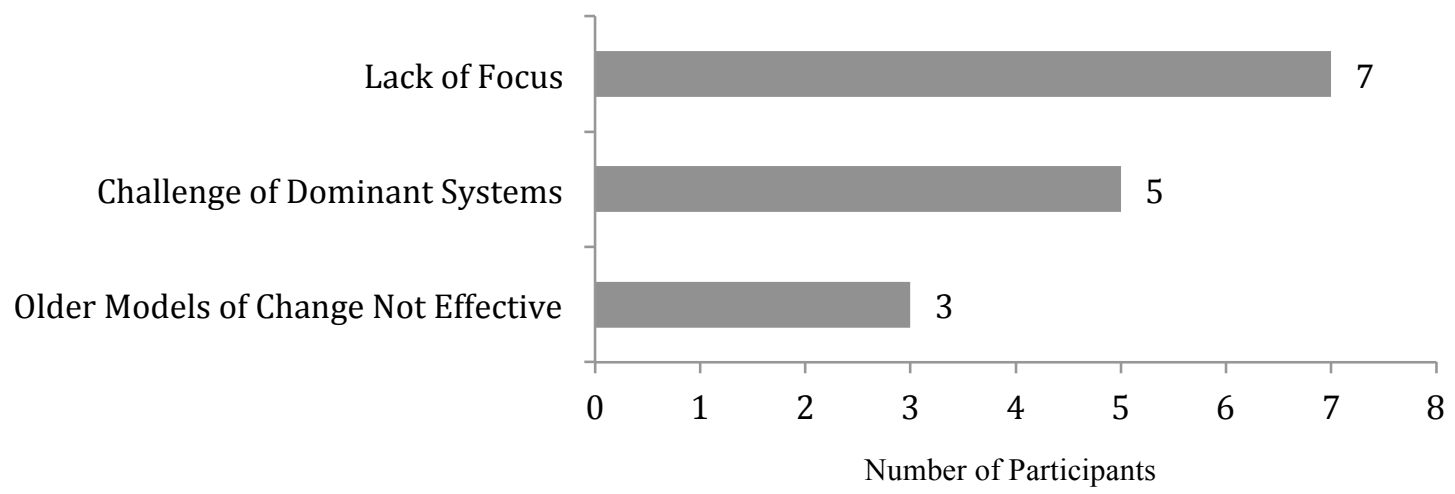

Note. The number in each bar indicates the number of participants in each thematic node.

16 Female participant, age 26, Aboriginal, Justice subgroup. 
Seven participants indicated the environmental movement lacks a focus, or perhaps is irrelevant to many who are just trying to earn a living and manage their lives. The comments about lack of focus are curious because one of the primary themes that emerged from Question 10 was that the range of opinions and approaches within the movement was actually a strength. In Question 11, the remarks were about dispersing efforts over too many issues, not having a collective message, and confusion about the goals of the movement. Two individuals said that the danger of being too widespread is that the general public might lose interest. One noted, "It's almost so widespread that it's becoming shallow and it's almost a little bit washed out in a way.",17

The challenge of dominant systems theme covered several aspects. The first was the failure of the environmental movement to address pressing issues through the lens of the current economic system. Several participants indicated there was a need to talk more about green jobs, sustainable economies, and technical solutions in a language that businesses and governments understand. One argued that if the goal was to shift the economy, then it was critical to portray what the new economy would look like. Others were critical of the current political systems, noting the lack of courage, a failure to heed local voices, and what they perceived as the muzzling of scientists in Canada.

The remaining theme that older models of change may no longer be effective addressed topics such as how communications and activism have changed, that many organizations within the movement are trapped in a system of raising adequate resources, and that the capacity to organize people to take action needs to be redefined. As one

17 Female participant, age 22, Justice subgroup 
participant noted, "We need to get a lot more organized ... we're going to have to find other ways of pushing our government to make the changes that we need to see." ${ }^{\prime 18}$

\section{How the environmental movement could become more effective.}

Fourteen participants suggested ways in which the movement could be more effective. These included changing the narrative on environmental issues to be more positive, focusing more efforts at the local and community level, and becoming more inclusive of those who are not currently represented in the movement.

Figure 11

Themes for "How the Environmental Movement Could Become More Effective"

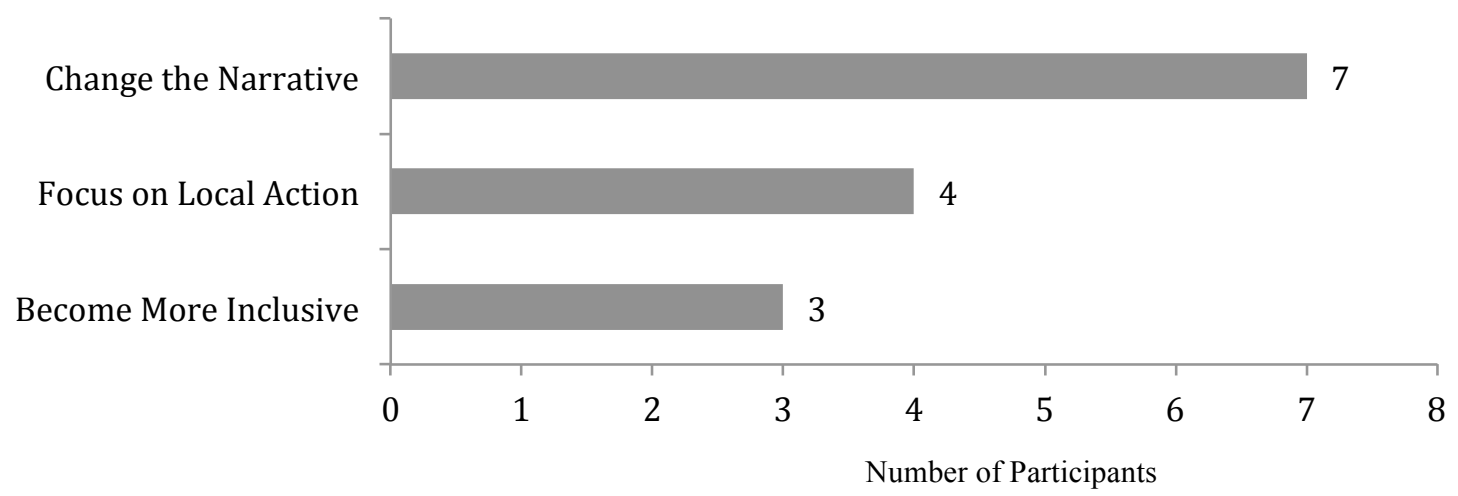

Note. The number in each bar indicates the number of participants in each thematic node.

On the theme of changing the narrative, respondents said the messages from movement organizations should become more positive, that they should convey a sense of happiness and good health, and that spokespeople should be more courageous in speaking out. Several noted how hard it is to motivate people, and that simply providing more information is not the solution. A common comment was about appealing to values, and connecting to individuals at a deeper level.

18 Female participant, Aboriginal, age 27, Justice subgroup. 
The second theme was that the movement could become more effective by focusing efforts at the local level. In this instance, the comments were about integrating interests at the scale of communities, and making a conscious effort to include local groups in the decision-making process.

The final theme was about accelerating the trend to be more diverse, to reach out to different cultural communities and age groups, and to make a special effort for the education of children. One individual suggested more stories be told about how groups and communities in other parts of the world are successfully addressing their own environmental challenges.

\section{Summary of question eleven.}

The focus of Question 11 was on movement effectiveness. The range of comments on strengths, weaknesses, and areas for improvement reinforced one of the primary themes from Question 10 - namely that the environmental movement is currently undergoing change and transition. The strengths were primarily about how the movement is maturing, becoming more diverse, and benefitting from better scientific knowledge. The weaknesses included comments about the danger of losing focus, learning how to address environmental challenges through economic language familiar to business and government, and the notion that older models of change may no longer be effective (particularly with respect to the emergence of new social media systems and networks). The final theme about where improvements can be made addresses the need to change the environmental narrative, to be more relevant to local actions, and to accelerate the shift from a traditionally white composition. 


\section{Question 12: How do you perceive the future of environmentalism?}

Questions 12 through 14 address the future of environmentalism, together with the participants' confidence that the changes they envision will come to pass. The first question, how the participants perceive the future, proved to be a challenge for coding. The responses were diverse and layered - by which I mean the comments displayed complex hierarchies that required considerable analysis to arrive at higher-level themes. In the end, I conducted four iterations of coding before arriving at the final set of nodes (reducing the number from 14 to five). The final themes are shown in Figure 12.

Figure 12

Themes for "How do you perceive the future of environmentalism?"

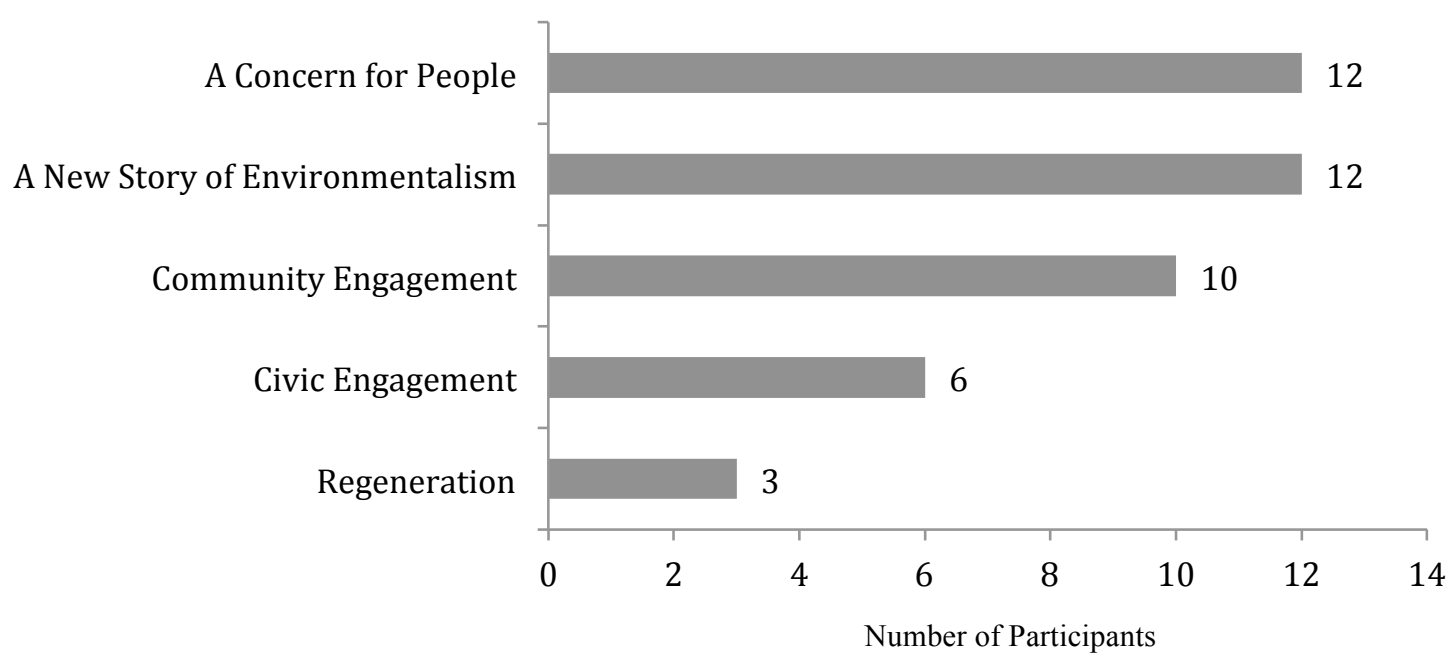

Note. The number in each bar indicates the number of participants in each thematic node.

The themes that emerged can be summarized as follows:

1. A Concern for People: Twelve participants indicated that environmentalism will evolve from a focus on conservation, to one that emphasizes the interdependence of people and nature. This theme includes issues of human rights, social justice, and increasingly something that was referred to as climate justice. 
2. A New Story of Environmentalism: This theme was centred on how the environmental narrative will change to one of hope and solutions for the challenges we face. Many of the participants said this includes an emphasis on meaning-making, the idea that the environment should not be a superficial commitment to living a sustainable life, but a deeper understanding of how humans are embedded in the natural world.

3. Community Engagement: The third theme focuses on actions at the community and local scale. Included in this theme were comments about local capacity building, organizing, diversity, and partnerships.

4. Civic Engagement: While not a primary theme, six participants spoke strongly about the need to engage with and reform the democratic process as it relates to environmental issues. Several individuals felt there had been an erosion of democracy in recent years, and a lack of political resolve to tackle the polarizing subjects of climate change and energy. Comments in this section included developing voter campaigns, working to change political systems, and mobilizing youth to participate in the political process. Leadership and a lack of political will were also part of this theme, with one participant noting that the years ahead must involve "the courage to implement the policies we need to protect our future." 19

5. Regeneration: Three participants described a future that involves what was referred to as regenerative sustainability. This concept moves beyond preventing the deterioration of environmental conditions, to one in which efforts are made to reverse the destruction of ecosystems and restore them to a more resilient and diverse form.

${ }^{19}$ Female participant, age 22, Justice subgroup. 
One participant, who is familiar with the concept, referred to it as "the regeneration of large-scale ecosystems and replicating those projects as many times ... around the world as possible, reversing desertification, sequestering carbon in soils, reforestation." 20

\section{Primary themes.}

Three primary themes emerged from the question "How do you perceive the future of environmentalism?": a concern for people, a new story of environmentalism, and a focus on community engagement.

A concern for people.

In Question 3 "What is environmentalism to you?", a primary theme emerged that it was in transition. In particular, the participants suggested that it was evolving from a focus on protecting landscapes, toward one that incorporates people. The comments in the theme "A Concern for People" echo this earlier portrayal.

The majority of the comments touched on how environmental impacts, particularly those associated with climate change, effect indigenous peoples and marginalized communities. The indication was that environmentalism would increasingly incorporate a justice focus, one that translates into greater awareness of these impacts on people and the actions needed to address them.

A second element of this theme was that environmentalism in the future will stress the interdependence of people and the natural world. This was indicated by comments that decision-making processes should incorporate our knowledge of how changes to the environment can adversely impact human health and security.

${ }^{20}$ Male participant, age 26, Sustainability subgroup. 
Table $27 \mathrm{a}$

Participant Comments: A Concern for People

\section{Participant Comment}

Female, 22 Not to say that the efforts in purely nature-focused initiatives will cease to exist. It's like that will happen - and even more so social justice.

Female, 28 The future of environmentalism is about behaving in the world and a way of making decisions in the world that reflect our knowledge of systems and creatures and people in crisis.

Male, 23 When I see the future of environmentalism, I see more people are going to start to really question the logic of capitalism. And they're going to be starting to see more linkages between themselves, and the global South that are already experiencing the effects of climate change.

Female, 28

My hope is that a kind of environmental, climate justice-focused movement can get to some of that in the way that Occupy briefly did.

Female, 26, I think it will see a bit more diversity from people of different ages, of Chinese different cultural backgrounds, of different class, and that it will work hand-in-hand in more solidarity with art, indigenous issues.

Female, 29 I think the future ... is also more human. I think human at the level that we understand that we share a planet and there's like one family dealing with the enormity of these crises.

Male, 29 Finding ways to welcome people into a compassionate relationship with the diversity of non-human others that we share the planet with, and finding ways that we can coexist in a mutually beneficial way.

Female, 22 My hope is that as we move forward we can see stronger environmental policies and environmentalism within our society in such a way that it's implemented that it does not negatively affect low-income groups, marginalized communities.

Male, 29 I think one of the terms I've been using is the idea of taking actions at the point of system failure. I think taking action at these points of system failure is where the injustice is.

Note. One comment from each of 9 participants.

When the subgroup was reviewed for gender, there was no marked difference from the overall group profile. The environmental interest results were noticeably skewed toward the Justice subgroup. This likely reflects that the majority of the participants were from this subgroup, and as noted in my adaptation of Martinez-Alier (Table 5), their focus in on community and social justice. 
Table $27 b$

Subgroups: A Concern for People

\begin{tabular}{cccccc}
\hline \multicolumn{2}{c}{ Gender } & & \multicolumn{2}{c}{ Environmental Interest } & \\
Female & Male & & Conservation & Sustainability & Justice \\
\cline { 1 - 2 } \cline { 5 - 6 } & 4 & & 0 & 1 & 11 \\
\hline
\end{tabular}

Note. Total group profile ( $n=20): 70 \%$ (14) female, 30\% (6 male); 3 Conservation, 4 Sustainability, 13 Justice.

The implication is that participants from the wilderness and eco-efficiency subgroups, who believe that environmentalism is evolving to a form that increasingly includes people, do not necessarily see this as primarily a justice concern. Their perspective is that emphasizing the human dimension is a reflection of how you engage individuals where they live, together with the stories we collectively tell. A balanced perspective among the subgroups emerges in the next two themes about a new story of environmentalism and a focus on community engagement, where the profile reflects the orientation of the entire group.

Participant story about a concern for people.

I think that, increasingly, people get that a lot of the issues that we face socially and environmentally and, you know, politically and economically are connected, and so I like to think that the future of the environmental movement names and recognizes that for people in a way that I think ... well, that I think and that I hope has more integrity and therefore more resonance in really motivating people to get involved. My sense is that, and this gets into some of those works that I've done around faith communities, that there's a real lack of kind of meaning and purpose in ... for a lot of people in our culture. And that people are looking for something to give their lives meaning and to collectively work toward. And my hope is that a 
kind of environmental, climate justice-focused movement can get to some of that in the way that Occupy briefly did and in a way that a number of these movements have tried to do. That we have a big task ahead of us and that we will need to work on it together, but that, potentially, in the process of working on it together, we can shift some of those pieces and help people find more meaning. And some of that I see in the way that the modern ... these modern environmental groups have been shifting their framing and language to reflect a lot of the effective tone and sort of narrative focus that came out of the Civil Rights Movement and big times of social change. I think that's been done well in some areas and my hope is that that is where we are all headed a bit more.

(Female participant, age 28, Justice subgroup) A new story of environmentalism.

In the second theme, the participants were concerned about how environmentalism is framed. The suggestion was that the story of environmentalism (how it is described and depicted) should shift from one of despair - to one of hope, optimism, and motivation. Several individuals were particularly critical of traditional messages of doom, indicating that such approaches do not motivate people to take sustained action.

Many of the participants commented that the future of environmentalism should emphasize a new narrative, one that pays careful attention to its language, and increasingly be based on stories that individuals can connect to. There were several comments that such a framing would help give meaning to people's lives. It would be an emotional connection instead of one based on objective science. 
Table 28a

Participant Comments: A New Story of Environmentalism

\section{Participant Comment}

Female, 28 I would say the future of environmentalism is about being a way of behaving in the world.

Female, 26, You have to do the lifestyle, the story, and the heart stuff.

Chinese

Male, 26

Trying to tell those stories of regeneration.

Female, 28

Modern environmental groups have been shifting their framing and language to reflect a lot of the effective tone and sort of narrative focus that came out of the Civil Rights Movement and big ... big times of social change.

Female, $24 \quad$ I hope so much that it's positive and that we start to see things improve and we start to engage more people and that some of the doom and gloom that I think a lot of environmentalists see, when they read these articles, changes.

Female, 24 My definition of environmentalism is having children and youth and that younger generation actually outdoors and connecting with nature. Not just hearing about it ... but actually having people go outside and see it.

Female, 26

People will come into a different world and have different views and different needs and meaning, and they'll need to have it be something that resonates with them.

Male, 29 My ideal environmentalism, it's more of an overarching value. And it's not politicized in a way that it's just like another issue, another problem that needs a solution. It's just the true nature of reality that we are connected and interdependent beings.

Female, 22 The future of environmentalism, the one that I would hope for, is a more positive ... it's not about doing less harm, it's about doing good for the environment.

Male, $29 \quad$ There's a story, a compelling story.

Note. One comment from each of 10 participants.

When the subgroups were reviewed for gender and environmental interest, no marked differences from the overall group profile were apparent. 
Table $28 b$

Subgroups: A New Story of Environmentalism

\begin{tabular}{cccccc}
\hline \multicolumn{2}{c}{ Gender } & & \multicolumn{2}{c}{ Environmental Interest } & \\
Female & Male & & Conservation & Sustainability & Justice \\
\cline { 1 - 2 } \cline { 5 - 6 } & 4 & & 2 & 3 & 7 \\
\hline
\end{tabular}

Note. Total group profile ( $n=20$ ): $70 \%$ (14) female, 30\% (6 male); 3 Conservation, 4 Sustainability, 13 Justice.

Participant description of a new story of environmentalism.

I hope so much that it's positive and that we start to see things improve and we start to engage more people and that some of the doom and gloom that I think a lot of environmentalists see, when they read these articles, changes and that maybe we can put a more positive spin, when we're presenting this to the public. So, they want to read it. So, they're not worried they're going to pick up the Metro at the SkyTrain station and read an article about the environment and feel like the world is over. We need to frame the articles in a different way and maybe if we do that, the future won't seem so bleak. So, I mean, to work in this field and to be an environmentalist, on a personal level as well, I have to see it as hopeful because otherwise, I don't know where I would be.

(Female participant, age 24, Conservation subgroup)

Community engagement.

The final primary theme about the future of environmentalism deals with its application at the community, local, or neighbourhood level. 
Table 29a

Participant Comments: Community Engagement

\section{Participant Comment}

Female, 29 I think that female leadership, and leadership of diverse communities and indigenous people, is going to be really critical.

Female, 26, I'm personally recognizing that community building and civic Chinese engagement go hand-in-hand if we really want to fight climate change and protect the environment.

Male, 26 And I think that people will be more connected to a local system ... I think that we will have an increased local-ness to knowing what those impacts are and make choices that are reflective of our moral beliefs.

Female, 28 It would mean as a society ... and as citizens, because I think that's gonna take a lot of collaboration.

Female, 26, It's actually a shift that's happening and strengthening in the youngest Aboriginal generations in my community and going back to past generations right through to the oldest elders in our community who are discovering a new understanding of stewardship.

Female, 29 A way to live is not just how you interact with the Earth, but it's obviously how you interact with your community.

Female, 29 I think it's gonna be this combination ... this local-global combination. People being able to connect to each other more through technology, and therefore being able to build more capacity in their local communities.

Female, 23 I think more opportunities to get involved ... in schools and stuff, I like how they're teaching these garden things.

Note. One comment from each of 8 participants.

This theme is consistent with comments about the local scale that emerged in other questions. For example, the importance of communities showed up in responses to what environmentalism is now, what is a sustainable life, beliefs and values, and the effectiveness of the environmental movement. The indication is that this group has embraced environmentalism in their networks and communities, and are confident that they can effect change at the local scale (in fact, many are already doing so).

When the subgroups were reviewed for gender and environmental interest, no marked differences from the overall group profile were apparent. 
Table $29 b$

Subgroups: Community Engagement

\begin{tabular}{cccccc}
\hline \multicolumn{2}{c}{ Gender } & & \multicolumn{3}{c}{ Environmental Interest } \\
Female & Male & & Conservation & Sustainability & Justice \\
\cline { 1 - 2 } \cline { 5 - 6 } & 2 & & 1 & 2 & 7 \\
\hline
\end{tabular}

Note. Total group profile ( $n=20$ ): $70 \%$ (14) female, 30\% (6 male); 3 Conservation, 4 Sustainability, 13 Justice.

\section{Summary of question twelve.}

All the primary themes for the future of environmentalism indicate that it will increasingly incorporate a human dimension. This manifests through aspects of justice and rights, hopeful stories about the environment, and engaging people at the local scale. Every participant was represented in one of these themes, although those who are already focused on environmental justice tended to emphasize the justice aspect as a core dimension of environmentalism in the future.

However, there is a further aspect to this question that is not reflected in what the participants said, but rather by what they did not say. One of the primary themes that emerged from what environmentalism currently means to this group was that it was deeply personal. None of the individuals noted this as a characteristic in the future. A possible explanation is that the personal dimension of environmentalism will become a foundation from which people act. They would not need to articulate it, as it is assumed that people had already incorporated environmental beliefs and actions into their lives.

Furthermore, the themes of conservation and stewardship did not emerge as a future characteristic. Comments related to this area were instead more about increasing the exposure to the natural world, or acknowledging the interconnection between people and the environment. 


\section{Question 13: Are you pessimistic or optimistic this will occur?}

The purpose of this question was to understand the participants' belief that their vision for the future of environmentalism could be achieved. All but one participant said they were confident the necessary changes would happen.

Table 30

Participant Comments: Are you pessimistic or optimistic this will occur?

\section{Participant Comment}

Female, 23 I like to be optimistic ... 'cause I think that change is coming.

Female, 26, The only thing we are lacking is an understanding among those individuals Aboriginal in my community of how incredibly powerful they are.

Female, 26, When I see youngsters from high school organizing their own stuff ... I Chinese can't be anything but hopeful.

Male, 23 It doesn't matter what your politics are, changes are happening.

Female, 28 It's a battle I choose to fight. I choose to stand among the ranks of people who will be pursuing that.

Female, 26 There's just so much going on, and kind of in every field.

Male, $26 \quad$ I'm optimistic ... because I'm worried that it won't happen.

Female, 29 I am optimistic this is going to happen 'cause I'm seeing it every day.

Female, 26 I'm going to fight my hardest.

Female, 29 So the more people do it, the more people will do that kind of thing.

Note. One comment from each of 10 participants.

In Question 12, I noted that the future of environmentalism for this group

increasingly incorporates people. The primary themes included environmental justice and rights, a deeper engagement at the local level, and a re-telling of the environment story through positive narratives. For Question 13, the participants were overwhelmingly positive that this future vision would occur.

The characteristics of this positive outcome were reflected in several ways. The first was that participants were confident that the changes would happen because they could already see it occurring in their fields of work or study. The second aspect was that 
the changes would happen because the alternative was worse - a continued degradation of environmental conditions. A final characteristic that emerged was a sense that the changes would not come easy, but that they were inspired by the challenge.

\section{Outlier.}

One individual from the Environmental Justice subgroup said his vision for the future of environmentalism would not occur in his lifetime. In describing the future, he was represented in the themes "A Concern for People" and "A New Story of Environmentalism.” His comments were about environmentalism becoming an overarching value that recognizes "ways to welcome people into a compassionate relationship with the diversity of non-human others that we share the planet with." ${ }^{21}$ In arguing the changes will not occur during his life, he indicated that people would not change their behaviours unless confronted by a crisis that shakes them into action.

Nevertheless, he believes such an event will eventually occur, and therefore propel the kinds of outcomes he hoped for.

\section{Summary of question thirteen.}

In contrast to the pronounced negative view that emerged from Question 7 (i.e., the health of the environment is poor and getting worse), the participants were overwhelmingly optimistic that their vision for the future of environmentalism will occur. The theme that this will increasingly include a human dimension represents a continued shift in environmentalism from its roots in the conservation of landscapes to one that explicitly acknowledges the interdependence of people and the natural world.

Furthermore, the emphasis on a positive story of environmentalism is consistent with a

${ }^{21}$ Male participant, age 29, Justice subgroup. 
deeper understanding of behaviour change, and a belief that environmental

communications are evolving through the use of fresh narrative styles and forms.

\section{Question 14: What would be needed to achieve the future you described?}

After three rounds of coding, five themes emerged for the question of what would be needed to achieve the future the participants envision (see Figure 13).

\section{Figure 13}

Themes for "What would be needed to achieve the future you described?"

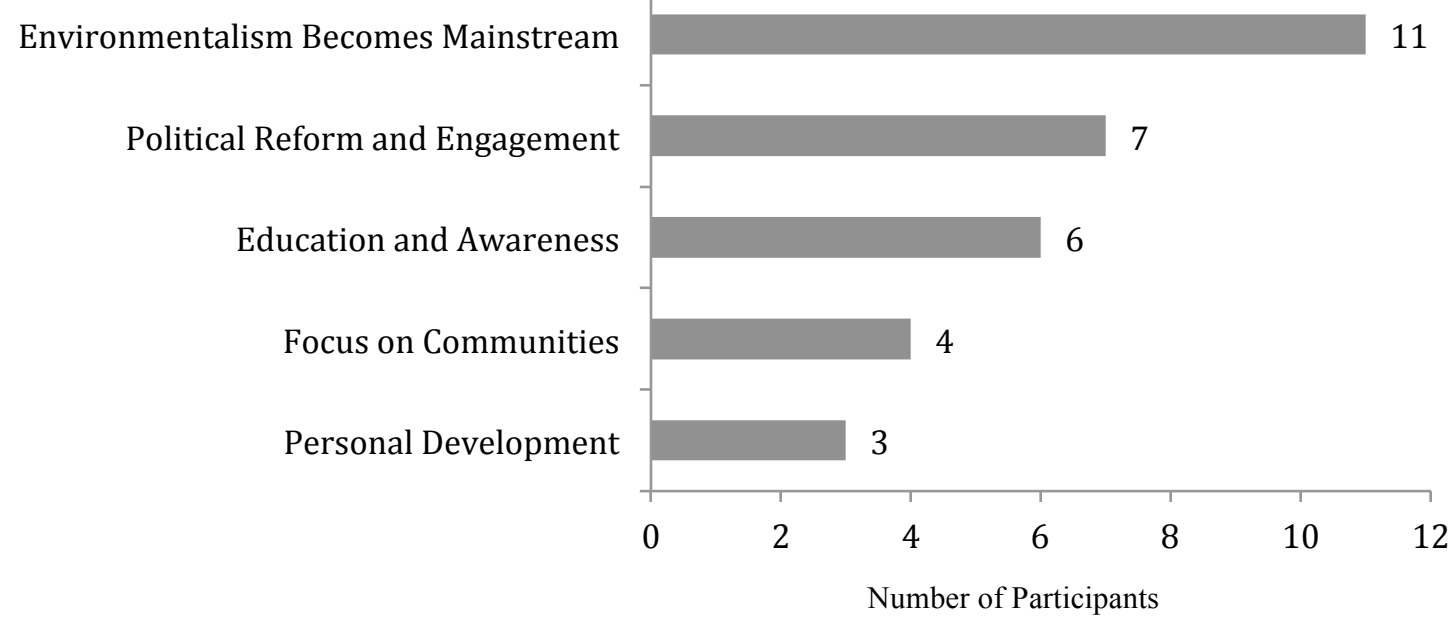

Note. The number in each bar indicates the number of participants in each thematic node.

The themes for "what would be needed to achieve the future you described" (i.e., that environmentalism will increasingly incorporate a human dimension), are as follows.

1. Environmentalism Becomes Mainstream: Eleven participants felt that for environmentalism to evolve to a form that more deeply integrates people, it will need to become an idea more widely adopted by individuals, communities, and governments.

2. Political Reform and Engagement: Seven participants spoke about the needs for the political empowerment of citizens, a political shift, and courageous leadership. A 
number of individuals indicated a larger constituency of people will be needed to demand the environmental changes they believe are necessary. Others thought that reforms to our political systems are required, including references to proportional representation and moving to different models of resource extraction and royalties.

3. Education and Awareness: In this theme, participants suggested the best way to shift environmentalism was through our education systems, or through programs that provide individuals and households with the information they need to achieve greater sustainability in their lives. One said that this would involve "re-tooling business schools around the business of ecological restoration." ${ }^{22}$ A focus on the education system links to the primary theme of environmentalism becoming mainstream, in that several individuals referenced that integrating mandatory environmental programs into the school system would help promote environmentalism in a way that is not currently possible.

4. Focus on Communities: Four participants indicated that stronger, tight-knit, sustainable communities will be needed in order for change to occur. This would involve capacity building at the local level, developing local economies and jobs based on ecological regeneration, and creating connections between individuals. For one participant, a focus on communities was central to his vision. He spoke passionately that such communities would be deeply connected to the physical place in which they were located, would take a long view back into ancestral history - as well as forward in time - and would be both diverse and resilient. His belief in communities as the building blocks for a shift in environmentalism was based on the

22 Male participant, age 26, Sustainability subgroup. 
idea that "the more of those weak, smaller communities that form, the more ripple effects they have into the larger community, and then also the stronger connection these little communities build with one another.,"23

5. Personal Development: When reviewing the responses for this question, I noted that three individuals felt that they could not achieve the future of environmentalism they envision without changes in their own lives. One thought she would need to rebalance how she allots her time to these issues, another felt that she was not ready for the hard work, and one felt she could not move forward until her community stopped thinking of her as "a naïve, young upstart with crazy ideas that can't be substantiated with experience. ${ }^{, 24}$ While this is a minor theme, such comments are a reminder that any cause or calling still involves individuals who are dealing with personal challenges of time, health, and recognition.

\section{Primary theme - environmentalism becomes mainstream.}

A single primary theme emerged for this question, which was that for environmentalism to evolve as the participants envision, it needs to be more widely held among the population. In elaborating on this theme, I should point out that none of the participants actually used the word "mainstream." Instead, the comments reflected that their understanding of environmentalism, articulated by individuals throughout the interviews, should be more deeply embedded in our systems, practices, communications, beliefs, and values.

23 Male participant, age 29, Justice subgroup.

24 Female participant, age 26, Aboriginal, Justice subgroup. 
Table 31a

Participant Comments: Environmentalism Becomes Mainstream

\section{Participant Comment}

Female, $28 \quad$ I don't think that scientific information on its own can carry the weight of social transformation ... we need to envision and advertise a better world.

Male, 26 Basically working with people so that they would know what to do and then be able to support and maintain a healthy lifestyle doing it.

Female, 22

I think people really need to have the courage to believe that our economic system does not need to be at the forefront of every decision.

Female, $28 \quad$ That means that we are doing more together and supporting one another more effectively.

Female, 26, All I can do in my work and in my life is make sure that I'm doing Aboriginal everything I can to create the conditions for that growth to happen.

Female, 24 A lot of these issues are so interconnected and that maybe that's what needs to happen, is we stop looking at it as segregated areas.

Female, 29 Hopefully, the generations after us and the people around now will understand that we can't make those types of decisions in the future that would impact us. Hopefully ... we'd be wiser.

Male, $24 \quad$ It would require a fairly fundamental alteration of our consciousness.

Female, 28 We need to envision a better world to show people what is worth working toward and why.

Female, 23 Interactions and working with people who are different than ourselves, and finding points of commonality.

Note. One comment from each of 9 participants.

When the subgroups were reviewed for gender and environmental interest, no marked differences from the overall group profile were apparent.

Table $31 b$

Subgroups: Environmentalism Becomes Mainstream

\begin{tabular}{cccccc}
\hline \multicolumn{2}{c}{ Gender } & & \multicolumn{2}{c}{ Environmental Interest } \\
Female & Male & & Conservation & Sustainability & Justice \\
\cline { 1 - 2 } \cline { 5 - 6 } 9 & 2 & & 2 & 3 & 6 \\
\hline
\end{tabular}

Note. Total group profile ( $n=20)$ : 70\% (14) female, 30\% (6 male); 3 Conservation, 4 Sustainability, 13 Justice. 


\section{Summary of question fourteen.}

The intent of questions 12 through 14 was to explore whether participants think environmentalism is changing, and how it might continue to do so in the future. The final question of "What would be needed to achieve the future you described?" resulted in comments suggesting that the critical determinant of this change would be that environmentalism as an idea, value, or belief system is more widely held in the population. The primary theme referenced by the participants relates to the idea that environmentalism must become embedded in systems and practices, although minor themes about education and political changes are equally supportive of this change.

What emerges through this final question is that the participants believe the changes they envision will occur over time, rather than abruptly. They acknowledge this will require hard work, but also that it can be done through actions at the local scale, and through new forms of communication and networking. They also do not underestimate the need for political engagement and reform. It was clear that this group is overwhelmingly positive that these shifts will occur.

\section{Question 2: How would you describe your generation?}

I argued earlier that the emergence of modern environmentalism in the late 1960s and 1970s could be viewed as a generational phenomenon. I based this claim on the unique circumstances of the time, the sheer size of the Baby Boom generation that was then entering adulthood, and the growing awareness of the harmful consequences of industrial processes. Over the ensuing four decades, the environmental perspective has altered the way people view their interaction with the natural world. However, in that time there have also been significant changes in technology, resource consumption, and 
global population numbers. In the early twenty-first century, Canada and the United States are witnessing the emergence of a generational cohort as large as the Baby Boomers, in the form of the Millennials, but the formative circumstances under which modern environmentalism appeared in the late 1960s no longer exist.

The purpose of my research is to gain insight into how young people who care about the environment are interpreting environmentalism. Question 2 explored whether the participants identified with a particular generation, and how they described it. The comments in this section, together with the literature review and the references to generational theory in Chapter Three, are intended to help answer the question of whether changes to the way environmentalism is perceived can be considered a generational phenomenon. Eight themes emerged (Figure 14).

Figure 14

Themes for "How would you describe your generation?"

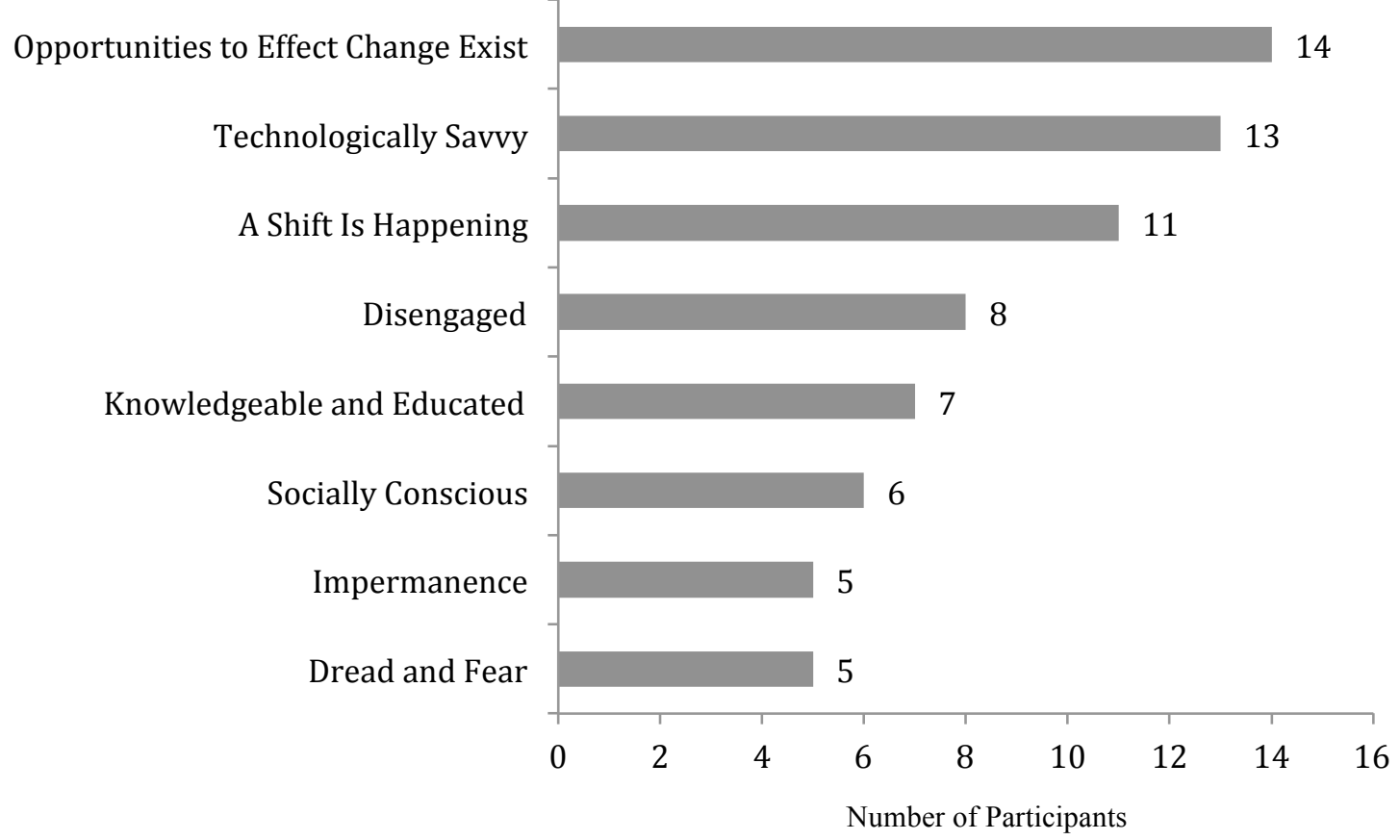

Note. The number in each bar indicates the number of participants in each thematic node. 
At the start, it is important to note that most of the participants acknowledged there is considerable diversity within their age cohort. They indicated that their generational experience would likely not be the same as that of young people from different backgrounds and upbringings.

Furthermore, none of the participants stated they were part of Generation Y or the Millennial generation. If pressed, some of them indicated that was a label put on their age group. The descriptions the group provided more likely referenced an age (in their twenties), a contrast with their parents' generation (the Baby Boomers), or a particular time (an age of digital technology and communications).

The themes that emerged for this question are as follows:

1. Opportunities to Effect Change Exist: Fourteen participants felt that their generation lived in a unique time and place - where opportunities for leadership, youth-driven solutions, and the possibility to effect change exist. Individuals used language such as hopefulness, optimistic, excited, and self-empowered to describe themselves, their friends, and their networks.

2. Technologically Savvy: Not surprisingly, a majority of the participants indicated that what was unique about their generation was access to technology. Primarily this involved communications (cell phones and social media), but a number referenced the ability to obtain information through the internet. The combination of these factors meant that participants felt they were networked in a way no previous generation could imagine.

3. A Shift Is Happening: Eleven participants suggested that their generation was growing up in the midst of a shift in how people view the world. Individuals 
referenced a post-globalization age, a global perspective on climate change impacts, a stronger sense of awareness and engagement among Aboriginal youth, and changes in jobs and careers in a post-financial crisis era.

4. Disengaged: While not a primary theme, eight participants argued that not all young adults in their age cohort were motivated to be active and engaged. Comments reflected the disconnection that communications technology can create, coping with student debt, the challenge of finding full-time work, a lack of urgency to deal with difficult issues, and a sense that things are not right. An example of this is from an individual who noted the disparity between being well off, and yet being aware of the problems that exist: "We are very comfortably living and so one of the strange patterns that I've noticed in my friends, is that we all know the same thing ... we want to do good things and we want to be part of that movement, and then at some point we turn to the same kind of pattern that our parents had." 25

5. Knowledgeable and Educated: In this theme, participants argued they had more access to information than their parents, were more aware of different cultures and diversity, had unprecedented opportunities to travel, and were likely more conscious of the impact of their actions. A number also said that the volume of information could be overwhelming at times.

6. Socially Conscious: Six participants felt that their generation was more politically aware and engaged than their parents. They believe that they can make a difference in the world, based on a broader knowledge of problems, solutions, and interdisciplinary thinking.

${ }^{25}$ Female participant, age 29, Justice subgroup. 
7. Impermanence: A number of participants commented that, unlike their parents, there is no well-defined career path laid out for them. They noted that stable jobs and workplace identity are changing rapidly. There were several comments about a growing bitterness over the higher education experience not leading to fulfilling careers.

8. Dread and Fear: Five participants also said there was a certain amount of existential dread and fear that typifies their generation. Climate change in particular was referenced, with one individual noting it is the equivalent of what nuclear war was for their parents' generation. Feelings of being overwhelmed were also part of this theme, together with scepticism that our institutions can address future challenges.

\section{Primary themes.}

Opportunities to effect change exist.

In describing their generation, the highest participant response theme was that current circumstances offered a range of opportunities for the cohort in their twenties to effect change. The changes indicated were primarily environmental in nature, climate change in particular, which is expected from participants who were selected for their environmental passion.

Participants in this theme were optimistic and hopeful that their generation could provide leadership toward making an impact. There were references to the number of individuals in their age cohort, and the strong sense of possibility that they share. One individual likened it to "a latent power that's kind of just waiting for the right opportunity or moment to be collectively expressed."26

${ }^{26}$ Male participant, age 29, Justice subgroup. 
Table $32 \mathrm{a}$

Participant Comments: Opportunities to Effect Change Exist

\section{Participant Comment}

Female, $28 \quad$ I'm moved by this tremendous hopefulness and gratitude for this place and time and the people around me.

Female, 26, The good news is that the more youth-driven solutions we can come up Chinese with, regardless of whatever community you're from, the more we'll be able to bring us back and give us that sense of purpose and balance.

Male, 23 I think where we are environmentally is very encouraging.

Female, 29 I'm incredibly optimistic in terms of the interventions that I think can be staged and are being staged in Canada.

Female, 26, Young people are a lot more unified around a strong sense of possibility. Aboriginal

Male, 26

I think it's a really interesting time to be alive and to face those challenges and really define them for myself, define them for my peers.

Female, 26 I would say it's a group that feels fairly self-empowered and like they have the opportunity to pursue and view whatever they want.

Male, 26 My cohort of individuals, each individual has potential and is amazing and is capable and can make change.

Female, 22 During my working life, we will have to tackle climate change. I see that is a big opportunity ... something that can be empowering and hopefully bring my generation together.

Male, 29 I definitely think of it as positive. I see it is a huge power in sheer numbers in the future that is theirs to inherit in terms of age.

Female, $29 \quad$ A lot of opportunity and options.

Note. One comment from each of 11 participants.

When the subgroup was reviewed for gender, no marked differences from the overall group profile were apparent. However, no participants from the Conservation subgroup were represented in the environmental interest profile. Furthermore, within the question of describing their generation, the Conservation subgroup predominantly placed their cohort in the themes of "technologically savvy" and "knowledgeable and educated." On the other hand, they were proportionately represented in the other categories about environmentalism, a sustainable life, and the environmental movement. The suggestion is that in their fields of work and study they do not consider themselves to be change 
agents, even as they place tremendous value on natural systems and the interdependence of people and nature.

Table $32 b$

Subgroups: Opportunities to Effect Change Exist

\begin{tabular}{cccccc}
\hline \multicolumn{2}{c}{ Gender } & & \multicolumn{3}{c}{ Environmental Interest } \\
Female & Male & & Conservation & Sustainability & Justice \\
\cline { 1 - 2 } \cline { 5 - 6 } 9 & 5 & & 0 & 4 & 10 \\
\hline
\end{tabular}

Note. Total group profile ( $n=20)$ : 70\% (14) female, 30\% (6 male); 3 Conservation, 4 Sustainability, 13 Justice.

Participant story of the opportunity to effect change.

I feel that it's a very positive thing. I'm very excited about that despite all of the really bleak potential outcomes you can imagine. I think it's a really interesting time to be alive and to face those challenges and really define them for myself, define them for my peers and also just see how it all plays out. It's very fascinating because we've never been at a point like this in human history in terms of this scale of the global human enterprise and how it's going to have to change either consciously or unconsciously very quickly over the next few decades.

It's really this generation that's coming of age now that I'm a part of, that are maybe in their early thirties or late twenties, who really did get to know it before all of the major climate impacts and energy depletion impacts started just hitting the system really hard and so we kind of got to see how it used to be and now we're seeing how it's changing.

I would think that in 10 more years, we're gonna look back at this moment and see just how much it changed. Now the illusion that business as usual is still 
holding on, it's still somewhat possible, that people can imagine that and it's reinforced because we were educated in that system that perpetuates the idea that it is possible, but on a broader term there's more and more cracks that are forming in that whole story that are showing themselves and a lot of people are experiencing it head on. (Male participant, 26, Sustainability subgroup) Technologically savvy.

Predictably, the participants noted the strong impact of technology in their daily lives. The technology that most impacts them is communications. They are comfortable with social media, they network with like-minded individuals regardless of intervening distances, and they access information as needed through the internet. They also acknowledge that much of this technology is about personal identity and expression.

Table 33a

Participant Comments: Technologically Savvy

\section{Participant Comment}

Female, 22 I was born into a world with technology ... the age of digital communications.

Female, 26, I'm on email, I'm on Instagram, I'm on Facebook, I'm on Twitter.

Chinese

Male, 23

What sort of typifies my generation, it probably has to do with the way that communications technologies, particularly Facebook, Twitter, cell phones, really have defined the way we communicate with our peers.

Female, 29 We're just a lot more networked.

Female, 27, Technologically, that's a huge change that I have seen from what my Aboriginal parents' generation would have been.

Male, 26 Our generation ... is the first adopter of digital technology.

Female, 24 My generation is a little bit more well-versed in technology.

Female, $26 \quad$ I think the thing that stands out is the technology.

Male, 24 We have unprecedented access to communication, media communication, different technologies.

Female, 29 We have more of a global culture, like a global mind, because of technology and the internet. 
Note. One comment from each of 10 participants.

However, several noted a darker side to technology, in that a dependence on this medium can detract from a sense of what is most important in their lives. One noted that "the whole kind of chatting non-stop, I don't know if I necessarily agree with that.",27

When the subgroups were reviewed for gender and environmental interest, no marked differences from the overall group profile were apparent.

Table $33 b$

Subgroups: Technologically Savvy

\begin{tabular}{cccccc}
\hline \multicolumn{2}{c}{ Gender } & & \multicolumn{2}{c}{ Environmental Interest } & \\
Female & Male & & Conservation & Sustainability & Justice \\
\cline { 1 - 2 } \cline { 5 - 6 } 9 & 4 & & 3 & 2 & 8 \\
\hline
\end{tabular}

Note. Total group profile $(n=20): 70 \%(14)$ female, 30\% (6 male); 3 Conservation, 4 Sustainability, 13 Justice.

Participant story about technology.

Our generation, I would say, is the first adopter of digital technology. We were there right before the advent of computers and the internet. So it's not part of our DNA, but we're close enough to it that we're definitely hybridized and become a part of that. So we make our friends and connect with our friends through internet sources and through digital technology as the noughts do, but we also remember a time when that wasn't necessarily the case. And we had to call people on pay phones to get them to pick you up, or when you showed up somewhere you had to show up on time because there was no way of communicating that to somebody. (Male participant, age 26, Sustainability subgroup)

27 Female participant, age 24, Conservation subgroup. 
A shift is happening.

In this theme, participants described their generation as one that is in the middle of enormous shifts in knowledge, awareness, and an understanding of the actions to take.

Table 34a

Participant Comments: A Shift Is Happening

\section{Participant Comment}

Female, $28 \quad$ I feel there is a definite shift happening in the way that my generation sees the world.

Female, 26, I have watched some incredible shifts happen in young people in my Aboriginal community, particularly in the last 10 years.

Male, 23 People in my generation more and more are thinking internationally in terms of climate justice.

Female, 23 I think there's a shift going on ... a shift in awareness.

Female, 29 I actually think that there's a clear path forward to getting some pretty deep change accomplished in Canada.

Male, 26 I would think that in 10 more years, we're gonna look back at this moment and see just how much it changed.

Female, 29 Certain older ideas just no longer make sense.

Female, 27, That's something my generation has to be very aware of and hopefully, Aboriginal we are going to be able to mitigate.

Female, 26, The interesting thing about our generation is that it's one that is constantly Chinese being reflected, described, and changed.

Note. One comment from each of 9 participants.

It was apparent that this group felt excited about the initiatives and changes they were seeing around them. As was noted in the other questions, the participants had integrated environmental values and behaviours in their daily lives, and many were determined to effect change in their communities. Their observation that a shift was happening was in effect reinforcing their actions.

When the subgroups were reviewed for gender and environmental interest, no marked differences from the overall group profile were apparent. 
Table $34 b$

Subgroups: A Shift Is Happening

\begin{tabular}{cccccc}
\hline \multicolumn{2}{c}{ Gender } & & \multicolumn{3}{c}{ Environmental Interest } \\
Female & Male & & Conservation & Sustainability & Justice \\
\cline { 1 - 2 } \cline { 5 - 6 } 7 & 4 & & 1 & 2 & 8 \\
\hline
\end{tabular}

Note. Total group profile ( $\mathrm{n}=20)$ : 70\% (14) female, 30\% (6 male); 3 Conservation, 4 Sustainability, 13 Justice.

\section{Participant story of a shift happening.}

I actually do think that there is a tremendous generational shift occurring right now with young people having this concern that is very unique to them. So for young people who came of age and came into adulthood right when climate change was being realized as a global environmental crisis, I think that that plays a really large role in how we understand ourselves in the world, even how we understand things like wealth and prosperity and sustainability in our future, I think, is all very much impacted by that.

(Female participant, age 28, Justice subgroup)

\section{Summary of question two.}

The question of "How would you describe your generation" was intentionally open-ended. I wanted to see if the participants felt solidarity with similarly aged individuals, and how they themselves characterized their cohort. The comments suggest that the participants do feel their age group is unique, particularly those involved in environmental issues - one based on awareness of the issues, the availability of technology, networks of like-minded friends, and a determination to resolve the 
challenges they face. The identification of a unique generational identity among this age cohort was also noted in broader studies undertaken by Pew Research $(2010,2014)$.

Interestingly, the participants' characterization of uniqueness does not include a label. They did not refer to themselves as Generation Y, or Millennials (although some acknowledged these categorizations existed when probed in the interviews). Many did, however, describe their parents as Baby Boomers. In so doing, they contrasted themselves primarily through the use of technology and changes in job stability.

When summarizing the generational description articulated by the research participants, I am careful not to extend it to the entire cohort of individuals in their twenties. However, among the group who are deeply concerned about environmental issues, several factors are apparent. The first is the group's use of technology particularly communications. The individuals use this technology to network, organize, and learn. The ability to mobilize and effect action through social media is a defining characteristic of this group.

The participants were also excited by the opportunity to address current environmental challenges. Many were already doing so as part of smaller, local initiatives (some of which the participants had designed themselves). This positive perspective reflects the outlook noted in Question 13, in which the participants were overwhelmingly confident that their vision for the future of environmentalism would occur. As noted earlier, optimism is a core attribute of this group. 


\section{Meta-Analysis: A Convergence of Views}

The following section summarizes the 29 primary themes that emerged from the questions, to arrive at a portrait of the participants' views and beliefs. This summary contributes to the findings in Chapter Six.

In analyzing the responses to each question, I also sorted the themes by gender and environmental interest. I was curious to see if there might be differences based on these attributes. In Chapter Two, I noted that interpretations of environmentalism based on gender representation and area of environmental interest have historically resulted in disagreements and criticisms within the environmental community. However, the research indicates that the primary themes were generally consistent across the attributes of gender and environmental interest, suggesting the views might be broadly held.

1. Participant Background: The group is very educated, mostly white, mostly women, and middle class. The participants were active in the outdoors growing up, and regularly spent time in natural settings. Their experiences in nature were positive and inspiring. The participants also spoke of a deep connection to their families. They indicated their parents were supportive and involved in their upbringing, as well as in later choices about careers and academic studies. This is a shift from what the literature says about young adults involved in the formation of the environmental movement in the late 1960s (noted in Chapters Two and Three), which was often characterized as rebellious. The findings are also consistent with Bibby's 2009 research about Canadian Millennials, in which he noted the positive influence of parents, and "contrary to stereotypes, most teens say they actually find mom and dad enjoyable to have around" (p. 151). 
2. Networks: The participants spoke about being embedded in networks of friends, and linked by social media. Networks emerged as a primary theme about what experiences shape an individual's choice to lead a sustainable life, and in the role of technology as a defining characteristic of their generation. Networks of friends are also a strong generational theme that emerged in research from Bibby (2009), and the Pew Research Center (2010, 2014).

3. Generational Perspective: In describing their generation, the participants were overwhelmingly optimistic about the possibility to effect change, and that the future of environmentalism they envision will come to pass. They believe a shift is under way with respect to how people see the natural world, and they are hopeful and excited about the sense of possibility that exists to address the current environmental challenges. They view technology (primarily social media and the internet) as a means to network, organize, learn, and mobilize for action. The participants believe they live in a unique time. The degree of optimism among the participants is reflected in research about the Millennial generation. Bibby (2009) found that "one of the remarkable characteristics of Canadian young people ... is that they seem to have something along the lines of that 'hope chip' imbedded" (p. 194). This is also supported by the Pew Research Center (2014), which notes that in the American context "the relative optimism of today's young adults stands in contrast to the views of the Boomers when they were about the same age as Millennials are now" (p. 5).

4. Environmentalism: The participants define environmentalism as deeply personal and in transition. The deeply personal perspective is conceived as a way of life, and a guide for individual actions and decisions. This constitutes a worldview as defined in 
Chapter Two. The participants feel that environmentalism is changing from an historic focus on wilderness preservation and conservation, to one that increasingly incorporates people. The new focus integrates elements of social justice, systems thinking, sustainability, and political activism. A strong theme emerged concerning the interdependence and interconnection between human society and the natural world, an overarching view that continues to characterize modern environmentalism. Participants believe it is a holistic approach that integrates stewardship, sustainability, and responsibility.

5. Personal Responsibility: The theme of personal responsibility is echoed in the questions about living a sustainable life, and the underlying beliefs and values that inform a person's actions. Participants conceive sustainability as a practice, and that it involves being accountable for their actions and reducing their environmental footprint. This emphasis on the personal was an attribute formed in childhood, and one that has been reinforced over time by networks of friends who share a similar view.

6. Local Focus: The participants have a strong connection to their communities and regions. They spoke passionately about undertaking local actions and creating healthy communities. This was particularly apparent among the young Aboriginal women. Furthermore, the group indicated that environmental conditions were better at the local level than at the global, and that they were actively involved in their communities to effect and support environmental initiatives.

7. Barriers: The group acknowledged there were multiple barriers to achieving the vision of environmentalism they desire. These include personal challenges such as 
finding work, making money, having enough time, and experiencing anxiety about the future. Participants also spoke about broader systemic barriers, including an economy based on growth and consumption, the design of our cities, and a democratic process that needs reform. They admit that living a sustainable life is not easy.

8. Health of the Environment: The group was openly concerned about the current state of the environment. Top of mind was the impact of climate change, but they also acknowledged issues such as loss of biodiversity and deforestation. While the participants were distressed about environmental degradation, they use this emotion to motivate them to work harder at achieving the changes they believe are needed. Motivation to effect change was a stronger emotion than feelings of despair. Participants also think the current challenges could have been avoided, but acknowledge this would have required decisions that would have been difficult to take. They did not place blame on the generation(s) that came before them for the current state of the environment.

9. Environmental Movement: References to the environmental movement were similar to descriptions about environmentalism. The participants believe the movement is in transition to one that increasingly focuses on sustainability and justice issues. The group was often critical of large environmental organizations, indicating they could not see positive results commensurate with their level of resources. They felt that the movement and its constituent organizations should focus on grassroots organizing and local community actions, promoting more control over local economies, and operating in smaller networks of peers connected by social media. The group also 
believes the environmental movement is widespread and diverse, and is growing and evolving instead of entering a phase of demobilization and irrelevance.

10. Future of Environmentalism: With respect to the future of environmentalism, the participants believe it will continue to evolve to one that focuses on people integrating issues of human rights, the interdependence of people and nature, and something many referred to as climate justice. They also spoke about the need to tell a new story of environmentalism, one that emphasizes hope, optimism, solutions, meaning-making, and a deeper understanding of how humans are embedded in the natural world. Participants want to shed the stereotype that environmentalists are prophets of doom. Finally, the group indicated that the future would involve a greater commitment to local actions, including community engagement, local capacity building, organizing, and partnerships. 


\section{Chapter Six - Conclusions}

A central tenet of modern humanistic scholarship is that everything we humans do - our speech, our work, our play, our social life, our ideas of ourselves and the natural world - exists in a context that is historically, geographically, and culturally particular, and cannot be understood apart from that context. (Cronon, 1996, p. 35)

I begin this chapter with a quote from environmental historian William Cronon. Cronon believes that environmentalism is inherently specific to a time and place. I concur, and acknowledge that my research is also specific to the time, place, and context in which it was undertaken. However, I also believe that environmentalism as a worldview, and the environmental movement as the manifestation of environmentalism, is continuing to evolve in response to new circumstances and challenges. Furthermore, understanding the views of younger environmentalists is key to understanding the changes that are occurring.

\section{Answering the Research Questions}

The purpose of my research is to gain insight into how young people who care about the environment interpret environmentalism, and to apply the findings to the field in which I work. To achieve this purpose, the research focuses on four questions.

How are young people who care about the environment interpreting

\section{environmentalism?}

I conclude that a younger generation of environmentalists is not rejecting outright the themes of contemporary environmentalism described in Chapter Two. Instead, they are changing the focus to include new emphases, and adopting new strategies and tactics. 
First and foremost, the participants conceive modern environmentalism as deeply personal. It was described as a way of life, and a guide for a person's actions and decisions. This view emerged through their portrayal of environmentalism, but also in how they described living a sustainable life, and how they apply their underlying values and beliefs. Taking personal responsibility for one's actions emerged as a recurring theme throughout the research. In Chapter Two, I quoted a young woman who rejects the label of environmentalist while arguing she undertakes a life consistent with strong environmental values. She echoes the comments of the participants when she says, "protecting the environment is not something out there and far away, but something right here that needs to be intelligently incorporated into our day-to-day" (Larson, 2014, p. 2).

Second, the participants believe that environmentalism is evolving from a traditional focus on wilderness preservation and conservation, to one that emphasizes people. This emphasis on people is more holistic than the form of environmental justice that emerged in the 1990s (see Chapter Two), and entails a wide range of thinking and actions - from how communities are designed, to environmental rights and democracy, to initiatives to educate and mobilize people. Furthermore, when the participants did describe wilderness and conservation, it included a commitment to sustainability and stewardship. Stewardship now involves not just the protection of wild spaces, but also the regeneration and restoration of degraded environments.

Third, there was evidence of disenchantment with global initiatives led by big, unaccountable organizations, toward a focus on increased localism. The participants talked about local actions, community engagement, capacity building, grassroots organizing, and partnerships. To be fair, this is not necessarily a new suggestion. The 
history of environmentalism shows repeated efforts to return to the original grassroots character of the late 1960 s and early 1970s. What is different is that the new focus links smaller, adaptive organizations - to a commitment to mobilizing individuals. It uses social media as a means to network, learn, and organize. Furthermore, over half of the participants are already doing this - and have demonstrated results to show it works.

Fourth, the participants are optimistic. They believe they can help effect the necessary changes. They assert that the future of environmentalism they conceive will come to pass, and that evidence of environmental degradation is a motivation to try harder. A question arises as to whether the research methodology and participant selection process was biased toward individuals who are hopeful and positive. I contend that for the group to have demonstrated their distress about the current state of the environment, to have shown the capacity for critical thinking on a wide range of issues concerning the effectiveness of the environmental movement, to realistically portray the barriers they believe are hindering genuine sustainability - and still be hopeful about the future - suggests this is not blind optimism.

\section{Does this interpretation differ from modern, mainstream environmentalism?}

In Chapter Five, I concluded that the research participants conceived

environmentalism as deeply personal; a holistic approach that integrates stewardship, sustainability, and responsibility; and in transition to an increasing emphasis on people. I also noted that the participants are focused on local actions, community organizing, and creating networks of committed individuals and organizations. A strong theme emerged that the environmental narrative must shift from one based on a negative discourse - to one that is hopeful, positive, and focused on solutions. 
In Chapter Two, I argued the modern environmentalism has accommodated new outlooks, rather than reject them. I noted that it balances different viewpoints based on conservation, green technologies, and environmental justice. I described the presence of large, well-funded environmental organizations focused on research, policy development, lobbying, and public activism. I also singled out a criticism that the historical narrative of environmentalism is based on one of loss, and is framed in negative or apocalyptic language and images.

In comparing these two views, the major differences concern the focus on local actions, a commitment to engage and mobilize people instead of focusing on policy development and lobbying, and creating a new narrative of environmentalism that is positive and solutions oriented. Furthermore, the historic disagreements between the various environmental interests (wilderness preservation, technological solutions, environmental justice) are less apparent among the younger generation of environmentalists. They do suggest there is a transition away from an historical focus on conservation - but epistemological arguments about which viewpoint is better were not apparent in this group.

Curiously, the participants' interpretations reflect not just what is different in a positivist sense, but what is missing. There are several aspects to this observation:

1. Population: As noted in Chapter Two, a critical issue identified in the formative years of the modern environmental movement was population growth. Paul Ehrlich in particular was an early strident proponent of the view that overpopulation would lead to excessive consumption, scarcity and famine (Sabin, 2013). He was an influential figure, and helped to formulate a view that became mainstream at the time. Sabin 
(2013) notes, "with the world population growing from 2.5 billion people in 1950 to 3.35 billion in 1965 , many commentators questioned whether the planet could sustain the growing number of people" (p. 23). The research participants, on the other hand, live in a world where the population is approaching seven and a quarter billion - yet overpopulation was not a dominant theme that emerged in the interviews. A possible explanation is the previously noted shifting baseline syndrome; in which individuals takes as their reference point the conditions that existed when they grew up. Global population has almost doubled since the late 1960s, but the participants seem detached from the issue.

2. Technology: I noted in Chapter Two that modern environmentalism can be seen as a critique of the modern industrial societies. The research participants, on the other hand, seem indifferent to technology. They have embraced those aspects that deal with communications and social media, and many believe that renewable energy systems, public transit, and green building design are important for the future.

3. Role of Government: A third element concerns the role of government. In the formative years of modern environmentalism, a focus on public policy and regulation was a key element of the environmental agenda. With the Millennials, the belief that government can solve the challenges is not as clear. The Pew Research Center (2014) report on the Millennials refers to this as "unmoored from institutions" (p. 1). The participants were relatively silent on the role of government. 


\section{How do the personal beliefs, values, and experiences of the research} participants contribute to their understanding of environmentalism?

The participants spoke passionately about their positive experiences growing up. They enjoyed regular access to the natural world, their parents supported and encouraged their early interests in environmental issues, and the school system - from primary grade to university - reinforced their commitment to the environment. The participants are confident about what they are doing, which is further demonstrated through their optimism and the fact that many are already active in local initiatives and smaller organizations.

The underlying values and beliefs of the participants are essential to understanding how the participants conceive environmentalism. The challenge will be whether they can maintain that commitment and energy into the future.

\section{Does this suggest a generational shift in thinking, and what are the}

\section{implications for the future of environmentalism?}

An important lesson from this research is the finding that environmentalism is deeply personal. This implies that early environmental education and awareness work. The group who participated in this research, who come from different backgrounds and environmental interests, start from the position that everyday actions should mirror a person's convictions. Five decades of embedding environmental actions, from recycling, to conserving water and electricity, to taking public transit, have meant that this cohort of young adults starts from a position of greater personal responsibility. This is a positive example of shifting the baseline. The implication is that environmentalism in the future should continue to emphasize childhood environmental education, creating opportunities 
for children to have meaningful outdoor experiences, and embedding environmental programs in households and communities.

A second implication concerns a new narrative of environmentalism. As noted in Chapter Two, modern environmentalism has been criticized for its use of negative language and images. I quoted Barry's (2004) observation that such a frame does not motivate people to change. A primary theme that emerged through the research was that there needs to be a new story of environmentalism, one that emphasizes hope and solutions for the challenges we face. The participants stressed that such a narrative should pay careful attention to language, and increasingly be based on stories that individuals can connect to.

An increased focus on local activities and organizing emerged through the research, which has implications for the future. This echoes much of the literature. Hawken (2007) writes that a broader movement would involve "coherent, organic, selforganized congregations involving tens of millions of people dedicated to change" (p. 4). He believes this might already exist; I argue that it is a key characteristic of the participants in this research. Nevertheless, the efforts at the local level must build up to larger stories and actions that effect the national and global scale.

Finally, the implication for the future is not just about what will change, but the implications if change does not happen. Social movement theory contends that failure to evolve can lead to demobilization and stasis. Armstrong (2005) argues that those who benefit from an established position or a strategy that once worked, often continue to use traditional tactics beyond the point where they are no longer effective. The implication is 
that the inability of environmentalism to change could lead to it becoming a marginal and irrelevant worldview.

\section{Continuity and Change}

\section{Continuity.}

In Chapter Two, I described modern environmentalism as heterogeneous and diverse, incorporating viewpoints that focus on wilderness conservation, green technologies, and environmental justice. I noted that environmentalists span the range from moderates seeking incremental change, to activists pushing for transformative change. The common denominator has been, and continues to be, a worldview that humans are a part of, and dependent on, the natural world.

This depiction of environmentalism is also apparent among the research participants, and from this perspective their conception of environmentalism initially looks like the historical characterization noted above. However, what has changed is an increasing emphasis on people that is linked to a concurrent disenchantment with governments and large organizations, a focus on local activities and community organizing, and that the starting point from which young environmentalists begin their thinking and actions is different from previous generations. From this perspective, the participants appear to be concentrated on individual and communal agency, rather than relying on the regulation, policy, and state investment that have characterized previous decades. This is a positive development, as one of the critiques noted in Chapter Two is that modern environmentalism is fragmented and lacking a unifying vision.

The portrait of those involved in the environmental community similarly demonstrates continuity with its past. In the Western world, it remains predominantly 
well educated and middle class. This should not be a surprise. Environmental thinking is reflective of an understanding of the disciplines of ecology, systems thinking, human behaviour, and history. The iteration of education, income, and environmental awareness is evident in the literature outlined in Chapter Two. Abramson and Inglehart (1995) in particular note that education is strongly related to socioeconomic values, and that economic security is an important determinant to how an individual develops during their formative years. Nordhaus and Shellenberger (2007) take the economic argument further, strongly arguing that modern environmentalism is a product of prosperity and affluence (pp. 35-37).

\section{What has changed?}

While there is continuity with the past, the context in which modern environmentalism exists has changed. First and foremost, the nature of the environmental challenges has grown. Global problems of climate change, species loss, ocean acidification, deforestation, and toxic waste have become more complex, and less amenable to traditional policy and engineering solutions.

Since the emergence of modern environmentalism in the late 1960s and early 1970s, there have also been technological changes. These include the emergence of the personal computer, the internet, and new social media. Communications and learning have changed as a result. Furthermore, new technologies have made it easier to extract and process natural resources - energy, minerals, timber, and food. These technologies have not necessarily been environmentally benign. At the same time, the global population increased from approximately 3.7 billion in 1970, to just over 7 billion in 2013 (Geohive, 2014). This places added strain on resource consumption and the 
ecological systems on which life depends. A younger generation is interpreting environmentalism from a different foundation than existed five decades ago.

At the scale of those involved in the environmental movement, there is evidence that the gender balance is shifting from one that was predominantly male in the early years, to one where women are increasingly involved. It is difficult to estimate the current proportion, but in Chapter Five I provided examples from the education and non-profit sectors that show women now make up more than half of those who are pursuing environmental studies and careers. The implication of this shift is beyond the scope of this research, but implies that the environmental community is becoming more inclusive and representative of the general population - at least with respect to gender.

A significant development over the past half century has been the progressive institutionalization of the environmental movement. The number of organizations has grown since the early 1970s. In Canada, there are over 100 organizations listed in the Directory of Environmental Organizations and Environmental Government Agencies in Canada (2014). This list does not include smaller groups in communities across the country. The presence of such organizations has brought structure, resources, expertise, and power to the environmental movement. However, as noted in Chapter Three, the institutionalization of a social movement often leads to its normalization into society, and the negation of the original grassroots, activist character (Eder, 1988). A number of the participants voiced a concern that large, bureaucratic environmental organizations are not as effective as they could be - and that in the process they divert resources away from the smaller, more adaptive and innovative groups. 
A further change, in the Canadian context, is the emerging presence of Aboriginal people in environmental issues. This manifests through issues concerning traditional rights and title, resource extraction, and social justice. Furthermore, the growing and vocal Aboriginal youth dimension (e.g., the Idle No More movement) shows similarities to the pattern of social movement development in the late 1960s noted in Chapter Three.

Finally, the concept of shifting baseline syndrome outlined in Chapter Four has repercussions for the future of environmentalism. According to this view, individuals take as their reference point the conditions that existed during their formative years. The implication is that individuals without a memory of pre-existing conditions will normalize the present state as their frame of reference. Applying the syndrome to environmentalism suggests that the outcomes of phenomenon such as climate change, population growth, modified landscapes, and species loss will be viewed as the new baseline, and that efforts to mitigate or return to an earlier state will not be as important as adapting to the conditions that currently exist. Generational theory also predicts that social change occurs through generational replacement - so not only will a younger population take as their reference the conditions that exist for them now, but the memory of a pre-existing state will vanish.

\section{Inter-Generational Themes}

In assessing the research data, I can discern five themes that characterize the younger environmentalists I studied. These can be contrasted against a traditional view of environmentalism, as shown in Table 35. 
- Organic and emergent: The younger environmentalists are less inclined to look to master plans and top-down solutions, because their view of social change is much more organic and emergent.

- Community: They are fiercely local, placing more importance on face-to-face interactions as opposed to faceless interactions among citizens. They focus on community rather than nations - and their international focus tends to be based on relations among civil society members rather than relations among states.

- Individual: They are individual in that they have huge confidence that they themselves can make a difference, as opposed to a traditional focus on collective solutions.

- Networked: They are resistant to, and uncomfortable with, hierarchical structures where authority flows from an office, and information is tightly controlled. They prefer networked relationships that are relatively permeable, flat, and where information is widely shared.

- Private: The younger group is comfortable with linking entrepreneurship and profit with social goals, as opposed to the public focus of past environmentalists.

Table 35

Summary of Themes - Younger vs. Older Environmentalists

\begin{tabular}{ll}
\hline New & Old \\
\hline Organic & Mechanical \\
Community and global & State and global \\
Individual & Collective \\
Network & Hierarchy \\
Private & Public \\
\hline
\end{tabular}




\section{Conclusions}

In closing, the research suggests that among a population of committed young environmentalists in British Columba, environmentalism is changing. There remains strong continuity with the past, but the research suggests a new emphasis on people, localism, and a focus on community organizing grounded in social media. The participants are mistrustful of government and established environmental organizations, and this shows in the actions and careers of this group. Two of the participants have begun innovative local urban gardening programs, one has launched a successful organization focused on minimizing waste in the procurement of seafood in her cultural community, eight are involved in smaller non-profit organizations that are focused on organizing and communications, two are prominent activists who combine drama and passion in their work, three are continuing advanced academic programs that will allow them to apply their thinking when they graduate, and the two Aboriginal women are active in their communities and promoting a powerful First Nations narrative.

The literature on social movement theory states that when a grievance or injustice persists, the movement must reframe the issue and adapt to the new circumstances in order to continue. I believe this is occurring as a new generation enters and changes the movement. The research participants illustrate this shift. They bring new energy, a hopeful narrative approach to environmentalism, together with an emphasis on local actions and community organizing. Further, due to the networks in which the participants are connected, it is plausible to imagine the thinking depicted by the participants is representative across a broader geography than British Columbia. 
I also conclude that the changes occurring within the environmental community have a generational dimension. This is based on research that suggests that Millennials believe their generation has a unique identity (Pew Research Center, 2010, 2014), as well as the findings that suggest new emphases, strategies, and tactics. Furthermore, generational theory predicts that the strongly held views of the Baby Boomers that have dominated much of modern environmentalism will become less influential as young adults replace the older generation. The implication is that new interpretations will assume a stronger presence within the environmental community over time.

In Chapter Two, I summarized a number of visions for the future of environmentalism suggested by writers and theorists. These include a focus on local and grassroots organizing; an increasing emphasis on people; a deepening spiritual perspective; and creating a hopeful vision for the future. These ideas in many ways reflect the views of the participants.

In closing their review of environmentalism since 1945, Haq and Paul (2012) conclude with a section titled "A New Age of Environmental Localism." They argue that: A new form of environmentalism is required for a new age of global challenges, one that addresses the impact that global food and energy insecurity and climate change will have on local communities. The environmental movement has the potential to evolve through a network of grassroots groups that contribute to national and international campaigns using social media and Internet technology (p. 99).

This view reflects the interpretations, beliefs, values, and vision of the young adults who participated in this research - and is one they are already putting into action. 
The solutions the participants are pursuing are not government and state-based, but personal and localized. They are the next step to rebuilding a civil society that truly integrates sustainability. Whether this translates into the kind of systemic change that will ultimately be needed - time will tell. 


\section{References}

Abramson, P., \& Inglehart, R. (1995). Value change in global perspective. Ann Arbor: University of Michigan Press.

Adam, B. (1996). Re-vision: The centrality of time for an ecological social science perspective. In S. Lash, B. Szerszynski \& B. Wynne (Eds.), Risk, environment \& modernity: Towards a new ecology (pp. 84-103).

London: Sage Publications Ltd.

Aerts, D., Apostel, L., De Moor, B., Hellemans, S., Maex, E., Van Belle, H., \& Van der Veken, J. (1994). World views: From fragmentation to integration. Brussels: VUB Press. Retrieved from http://pespmc1.vub.ac.be/CLEA/reports/WorldviewsBook.html

Ahern, K. (1999). Ten tips for reflexive bracketing. Qualitative Health Research, 9(3), 407-411. doi: 10.1177/104973239900900309

American Psychological Association. (2010). Publication manual of the American Psychological Association (6th ed.). Washington, DC: Author.

Anfara, V., \& Mertz, N. (2006). Theoretical frameworks in qualitative research. Thousand Oaks, CA: Sage Publications.

Armstrong, E. (2005). The crystallization of a field of lesbian/gay organizations in San Francisco, 1969-1973. In G. Davis, D. McAdam, W.R. Scott, \& M. Zald (Eds.), Social movements and organizational theory (pp. 161-187). New York: Cambridge University Press. 
Barry, J. (2004). From environmental politics to the politics of the environment: The pacification and normalization of environmentalism. In M. Wissenburg \& Y. Levy (Eds.), Liberal democracy and environmentalism: The end of environmentalism? (pp. 179-191). London: Routledge.

Barry, J. (2007). Environment and social theory. New York: Routledge.

Bashir, N., Lockwood, P., Chasteen, A., Nadolny, D., \& Noyes, I. (2013). The ironic impact of activists: Negative stereotypes reduce social change influence. European Journal of Social Psychology, 43, 614-623. doi: 10.102/ejsp.1983

Bazeley, P. (2007). Qualitative data analysis with NVivo. London: Sage.

Bibby, R. (2009). The emerging Millennials: How Canada's newest generation is responding to change \& choice. Lethbridge: Project Canada Books.

Bluhdorn, I., \& Welsh, I. (2008). The politics of unsustainability: Eco-politics in the post-ecologist era. London: Routledge.

Bowen, G. (2008). Naturalistic inquiry and the saturation concept: A research note. Qualitative Research, 8(1), 137-152. doi: 10.1177/1468794107085301

Brand, K.W. (1990). Cyclical aspects of new social movements: Waves of cultural criticism and mobilization cycles of new middle-class radicalism. In R. Dalton \& M. Kuechler (Eds.), Challenging the political order: New social and political movements in western democracies (pp. 23-42). New York: Oxford University Press.

Braungart, R. (1984). Historical generations and generation units: A global pattern of youth movements. Journal of Political \& Military Sociology, 12(1), 113-135. 
Brulle, R. (1996). Environmental discourse and social movement organizations:

A historical and rhetorical perspective on the development of U.S. environmental organizations. Sociological Inquiry, 66(1), 58-83.

Buell, F. (2003). From apocalypse to way of life: Environmental crisis in the American century. New York: Routledge.

Caelli, K. (2001). Engaging with phenomenology: Is it more of challenge than it needs to be? Qualitative Health Research, 11(2), 273-281.

doi: $10.1177 / 104973201129118993$

Campbell, J. (2005). Where do we stand: Common mechanisms in organizations and social movements research. In G. Davis, D. McAdam, W.R. Scott, \& M. Zald (Eds.), Social movements and organizational theory (pp. 41-68). New York: Cambridge University Press.

Carson, R. (1962). Silent Spring. New York: Houghton Mifflin.

Chatman, E. (1986). Diffusion theory: A review and test of a conceptual model in information diffusion. Journal of the American Society for Information Science, 37(6), 377-386.

Chawla, L. (2006). Learning to love the natural world enough to protect it. Barn, 2, 57-78. Retrieved from http://www.childrenandnature.org/downloads/Chawla_LearningtoLove.pdf

Clayton, S., \& Opotow, S. (Eds.). (2003). Identity and the natural environment: The psychological significance of nature. Cambridge, Massachusetts: MIT Press. 
Clemens, E. (2005). Two kinds of stuff: The current encounter of social movements and organizations. In G. Davis, D. McAdam, W.R. Scott, \& M. Zald (Eds.), Social movements and organizational theory (pp. 351-365). New York: Cambridge University Press.

Coleman, M. (2012). The sustainability generation: The politics of change and why personal accountability is essential now! New York: SelectBooks.

Cronon, W. (1993). The uses of environmental history. Environmental History Review, 17(3), 1-22. doi: 10.2307/3984602

Cronon, W. (1996). Uncommon ground: Rethinking the human place in nature. New York: W.W. Norton.

Dalton, R., \& Kuechler, M. (Eds.). (1990). Challenging the political order: New social and political movements in western democracies. New York: Oxford University Press.

Dalton, R., Kuechler, M., \& Burklin, W. (1990). The challenge of new social movements. In R. Dalton, \& M. Kuechler (Eds.), Challenging the political order: New social and political movements in western democracies (pp. 3-20). New York: Oxford University Press.

Dan, A., \& Kalof, L. (2008). Essentials of social research. New York: McGraw Hill/Open University Press. Retrieved from http://site.ebrary.com.ezproxy. royalroads.ca/ lib/royalroads/ docDetail.action?docID=10274049

Davidson, J., \& Jacobs, C. (2008). The implications of qualitative research software for doctoral work. Qualitative Research Journal,8(2), 72-80. 
Davis, G., McAdam, D., Scott, W.R., \& Zald, M. (Eds.). (2005). Social movements and organization theory. New York: Cambridge University Press.

Davis, G., \& Zald, M. (2005). Social change theory, and the convergence of Movements and organizations. In G. Davis, D. McAdam, W.R. Scott, \& M. Zald (Eds.), Social movements and organizational theory (pp. 335-350). New York: Cambridge University Press.

DeLuca, K. (2007). A wilderness environmentalism manifesto: Contesting the infinite self-absorption of humans. In R. Sandler \& P. Pezzullo (Eds.). Environmental justice and environmentalism: The social justice challenge to the environmental movement (pp. 27-55). Cambridge, Massachusetts: MIT Press.

Denzin, N. (2007). Grounded theory and the politics of interpretation. In A. Bryant \& K. Charmaz (Eds.), The sage handbook of grounded theory (pp. 454-471). Thousand Oaks: Sage.

Dingler, J. (2005). The discursive nature of nature: Towards a post-modern concept of nature. Journal of Environmental Policy \& Planning, 7(3), 210-225. doi: $10.1080 / 15239080500339679$

Directory of Environmental Organizations and Environmental Government Agencies in Canada. (2014). Canadian Environmental \& Conservation Organizations. Retrieved from http://earthdirectory.net/canada

Duke, D. (Ed.). (2006). Canadian environmental history. Toronto: Canadian Scholars' Press.

Dunaway, F. (2005). Natural visions: The power of images in American environmental reform. Chicago: University of Chicago Press. 
Dunlap, T. (2004). Faith in nature: Environmentalism as religious quest. Seattle: University of Washington Press.

Eder, K. (1988). The social construction of nature. London: Sage.

Eder, K. (1996). The institutionalisation of environmentalism: Ecological discourse and the second transformation of the public sphere. In S. Lash, B. Szerszynski, \& B. Wynne (Eds.), Risk, environment \& modernity: Towards a new ecology (pp. 27-43). London: Sage.

Edmunds, J., \& Turner, B. (2002). Generations, culture and society. Buckingham: Open University Press.

Employment and Social Development Canada. (2013). Canadians in ContextGeographic Distribution. Retrieved from http://www4.hrsdc.gc.ca/.3ndic.1t.4r@-eng.jsp?iid=34

Feldman, L., Nisbet, M., \& Leiserowitz, A. 2010. The climate change generation? Survey analysis of the perceptions and beliefs of young Americans. Retrieved from the Yale University, Project on Climate Change http://environment.yale.edu/climate-communication/files/YouthJan2010.pdf

Fiege, M. (2012). The republic of nature: An environmental history of the United States. Seattle: University of Washington Press.

Forkey, N. (2012). Canadians and the natural environment to the twenty-first century. Toronto: University of Toronto Press.

Foster, K. (2013). Generation, discourse, and social change. New York: Routledge. 
Ganz, M. (2008). What is public narrative? Retrieved December 17, 2013 from http://leadingchangenetwork.com/files/2012/05/What-is-Public-Narrative-Fall2011.pdf

Gare, A. (1995). Postmodernism and the environmental crisis. London: Routledge.

Gatehouse, J. (2013, November 25). The nature of David. Maclean's Magazine, 126(46), $64-68$.

Geertz, C. (1973). Thick description: Toward an interpretive theory of culture. New York: Basic Books.

Generation Squeeze. (2014). Fifteen fast facts about GenSqueeze. Retrieved from http://gensqueeze.ca/wp-content/uploads/2013/02/Fast-Facts-Gensqueeze2013-02-03.pdf

Geohive. (2014). Global population statistics. Retrieved from http://www.geohive.com/earth/his_history3.aspx

Gitlin, T. (2003). Letters to a young activist. New York: Basic Books.

Gladwell, M. (2010, October). Small change: Why the revolution will not be tweeted. The New Yorker, 42-49.

Glover, L. (2006). Postmodern climate change. New York: Routledge.

Gottlieb, R. (1993). Reconstructing environmentalism: Complex movements, diverse roots. Environmental History Review, 17(4), 1-19. doi: 10.2307/3984644

Graeber, D. (2014, Spring). 2011: New York City. Lapham's Quarterly, (VII, 2), 27-31.

Greasley, K., \& Ashworth, P. (2007). The phenomenology of approach to studying: The university student's studies within the lifeworld. British Educational Research Journal, 33(6), 819-843. doi:10.1080/01411920701656977 
Greenberg, M. (2012). What future for occupy wall street? The New York Review of Books, 59(2), 46-48.

Groenewald, T. (2004). A phenomenological research design illustrated. International Journal of Qualitative Methods, 3(1). Article 4. Retrieved April 14, 2011 from http://www.ualberta.ca/ iiqm/backissues/ 3_1/pdf/groenewald.pdf

Guest, G., Bunce, A., \& Johnson, L. (2006). How many interviews are enough?: An experiment with data saturation and variability. Field Methods, 18(1), 59-82. doi: 10.1177/1525822X05279903

Hansen, S. (2012). Cultivating the grassroots: A winning approach for environment and climate funders. Retrieved from National Committee on Responsive Philanthropy website: https://www.ncrp.org

Haq, G., \& Paul, A. (2012). Environmentalism since 1945. London: Routledge.

Harvey, D. (1990). The condition of postmodernity. Malden, USA: Blackwell.

Hawken, P. (2007). Blessed unrest: How the largest movement in the world came into being and why no one saw it coming. New York: Viking.

Hays, S. (1987). Beauty, health, and permanence: Environmental politics in the United States, 1955-1985. Cambridge: Cambridge University Press.

Hazlett, J. (1992). Generational theory and collective autobiography. American Literary History, 4(1), 77-96. Retrieved from http://www.jstor.org/stable/489937 
Hearns, A., \& Deeny, P. (2007). The value of support for aid workers in complex emergencies: A phenomenological study. Disaster Management \& Response, $5(2), 28-35$.

Hesse-Biber, S.N., \& Leavy, P. (2011). The practice of qualitative research: Second edition. Thousand Oaks: Sage.

Hoffman, A., \& Ventresca M. (Eds.). (2002). Organizations, policy and the natural environment: Institutional and strategic perspective. Stanford: Stanford University Press.

Intergovernmental Panel on Climate Change. (2007). Climate change 2007: Synthesis report. (2007). Retrieved from http://www.ipcc.ch/publications_and_data/publications_ipcc_fourth_assessment_rep ort_synthesis_report.htm

Intergovernmental Panel on Climate Change. (2013). Climate change 2013: The physical science basis. Retrieved from http://www.ipcc.ch/report/ar5/wg1/\#.UxztdFwfylI

Jaeger, H. (1985). Generations in history: Reflections on a controversial concept. History and Theory, 24(3), 273-292. doi: 10.2307/2505170

Jamieson, D. (2007). Justice: The heart of environmentalism. In R. Sandler \& P. Pezzullo (Eds.). Environmental justice and environmentalism: The social justice challenge to the environmental movement (pp. 85-101). Cambridge, Massachusetts: MIT Press. 
Jamison, A. (1996). The shaping of the global environmental agenda: The role of nongovernmental organisations. In S. Lash, B. Szerszynski, \& B. Wynne (Eds.), Risk, environment \& modernity: Towards a new ecology (pp. 27-43).

London: Sage Publications Ltd.

Johnson, R.B., Onwuegbuzie, A., \& Turner, L. (2007). Toward a definition of mixed method research. Journal of Mixed Methods Research, 1(2), 112-133. doi: $10.1177 / 1558689806298224$

Johnston, L. (2006). Software and method: Reflections on teaching and using QSR NVivo in doctoral research. International Journal of Social Research Methodology, 9(5), 379-391. doi: 10.1080/13645570600659433

Jones, G. (2009). Youth. Cambridge, UK: Polity Press.

Kaufman, L. (2011, December 17). Environmentalists get down to earth. The New York Times. Retrieved from http://www.nytimes.com

Kempton, W., \& Holland, D. (2003). Identity and sustained environmental practice. In S. Clayton, \& S. Opotow (Eds.), Identity and the natural environment: The psychological significance of nature (pp. 317-341). Cambridge, Massachusetts: MIT Press.

Kingsnorth, P. (2013, January/February). Dark ecology. Orion Magazine. Retrieved from http://www.orgionmagazine.org

Koopmans, R. (2004). Protest in time and space: The evolution of waves of contention. In D. Snow, S. Soule, \& H. Kriesi (Eds.), The Blackwell companion to social movements (pp. 19-46). Malden, MA: Blackwell. 
Korth, L. (2008). Environmental literacy of San Marcos river conservationists (Doctoral dissertation). Retrieved from ProQuest (UMI No. 3428836)

Kraft, M., \& Wuertz, D. (1996). Environmental advocacy in the corridors of government. In J. Cantrill \& C. Oravec (Eds.), The symbolic earth: Discourse and our creation of the environment (pp. 95-122). Lexington: University of Kentucky.

Kuechler, M., \& Dalton, R. (1990). New social movements and the political order: Inducing change for long-term stability. In R. Dalton \& M. Kuechler (Eds.), Challenging the political order: New social and political movements in western democracies (pp. 277-300). New York: Oxford University Press.

Kvale, S., \& Brinkmann, S. (2009). Interviews: Learning the craft of qualitative research interviewing. Thousand Oaks: Sage.

Larson, S. (2014, March 7). No, we're not “environmentalists.” It's more complicated than that. Grist. Retrieved from http://grist.org/article/no-were-notenvironmentalists-its-more-complicated-than-that/\#.UxsxG_LK_oE.twitter

Lemann, N. (2013, April 15). When the earth moved: What happened to the environmental movement? The New Yorker. Retrieved from http://www.newyorker.com

Lincoln, Y., \& Denzin, N. (2008). The eighth and ninth moments - Qualitative research in/and the fractured future. In M. Lee \& G. Blank (Eds.), The sage handbook of online research methods (pp. 1115-1126). London: Sage.

Louv, R. (2005). Last Child in the Woods: Saving Our Children from Nature-Deficit Disorder. New York: Algonquin Books of Chapel Hill. 
Luke, T. (2005). The death of environmentalism or the advent of public ecology?

Organization \& Environment, 18(4), 489-494. doi: 10.1177/1086026605283194

Lyons, S., Duxbury, L., \& Higgins, C. (2007). An empirical assessment of generational differences in work-related values. Psychological Reports 101(2). 339-352.

MacDowell, L. (2012). An environmental history of Canada. Vancouver: UBC Press.

Mannheim, K. (1970). The problem of generations. Psychoanalytic Review, 57(3), $378-405$.

Marias, J. (1970). Generations: A historical method. Alabama: The University of Alabama Press.

Marshall, C., \& Rossman, G.B. (2011). Designing qualitative research: Fifth edition. Thousand Oaks: Sage.

Martinez-Alier, J. (2002). The environmentalism of the poor: A study of ecological conflicts and valuation. Cheltenham, UK: Edward Elgar.

McAdam, D., \& Scott, W.R. (2005). Organizations and movements. In G. Davis, D. McAdam, W.R. Scott, \& M. Zald (Eds.), Social movements and organizational theory (pp. 4-40). New York: Cambridge University Press.

McCarthy, S. (2012, February 10). Ottawa's new anti-terrorism strategy lists eco-extremists as threats. Globe and Mail. Retrieved from http://www.theglobeandmail.com

McKenzie, J. (2002). Environmental politics in Canada: Managing the commons into the twenty-first century. Don Mills, Ontario: Oxford University Press.

McKibben, B. (1995). Hope, human and wild: True stories of living lightly on the earth. Minneapolis: Milkweed. 
Millennium Ecosystem Assessment. (2005. Retrieved from http://www.maweb.org/en/Condition.aspx

Moran, D. (2000). Introduction to phenomenology. London: Routledge.

Moustakas, C. (1990). Heuristic research: Design, methodology, and applications. Newbury Park: Sage.

Moustakas, C. (1994). Phenomenological research methods. Thousand Oaks: Sage.

Nordhaus, T., \& Shellenberger, M. (2007). Break through: From the death of environmentalism to the politics of possibility. Boston: Houghton Mifflin.

Owram, D. (1996). Born at the right time: A history of the baby boom generation. Toronto: University of Toronto Press.

Park, J., Conca, K., \& Finger, M. (Eds.). (2008). The crisis of global environmental governance: Towards a new political economy of sustainability. London: Routledge.

Pauly, D. (1995). Anecdotes and the shifting baseline syndrome of fisheries. Trends in Ecology \& Evolution, 10(10), 430.

Peterson del Mar, D. (2006). Environmentalism. Harlow, UK: Pearson Education. Pew Research Center. (2010). Millennials: Confident. Connected. Open to change. Retrieved from http://www.pewsocialtrends.org/files/2010/10/millennialsconfident-connected-open-to-change.pdf

Pew Research Center. (2014). Millennials in adulthood: Detached from institutions, networked with friends. Retrieved from http://www.pewsocialtrends.org/2014/03/07/millennials-in-adulthood/ 
Pilcher, J. (1994). Mannheim’s sociology of generations: An undervalued legacy.

The British Journal of Sociology, 45(3), 481-495. doi: 10.2307/591659

Rintala, M. (1979). The constitution of silence: Essays on generational themes. Westport Connecticut: Greenwood Press.

Robinson, J. (2004). Squaring the circle? Some thoughts on the idea of sustainable development. Ecological Economics, (48), 369-384.

doi: 10.1016/jecolecon.2003.10.017

Rome, A. (2003). Give earth a chance: The environmental movement and the sixties. The Journal of American History, 90(2), 525-554.

Rome, A. (2013). The genius of Earth Day: How a 1970 teach-in unexpectedly made the first green generation. New York: Hill and Wang.

Rootes, C. (2004). Environmental movements. In D. Snow, S. Soule, \& H. Kriesi (Eds.), The Blackwell companion to social movements (pp. 608-640). Malden: Blackwell Publishing.

Royal Roads University. (2014). Doctor of Social Sciences. Retrieved from http://www.royalroads.ca/prospective-students/doctor-social-sciences

Ryan, G., \& Bernard, H.R. (2003). Techniques to identify themes. Field Methods, 15(1), 85-109. doi: $10.1177 / 1525822 \times 02239569$

Sachsman, D. (1996). The mass media “discover" the environment: Influences on environmental reporting in the first twenty years. In J. Cantrill \& C. Oravec (Eds.), The symbolic earth: Discourse and our creation of the environment (pp. 241-256). Lexington: The University Press of Kentucky. 
Sabin, P. (2013). The bet: Paul Ehrlich, Julian Simon, and our gamble over earth's future. New Haven: Yale University Press.

Sadala, M., \& Adorno, R. (2001). Phenomenology as a method to investigate the experience lived: A perspective from Husserl and Merleau Ponty's thought. Journal of Advanced Nursing, 37(3), 282-293.

Saldana, J. (2013). The coding manual for qualitative researchers. Thousand Oaks: Sage.

Sandler, R., \& Pezzullo, P. (Eds.). (2007). Environmental justice and environmentalism: The social justice challenge to the environmental movement. Cambridge, Massachusetts: MIT Press.

Saratovsky, K., \& Feldmann, D. (2013). Cause for change: The why and how of nonprofit millennial engagement. San Francisco: Jossey-Bass.

Scully, M., \& Creed, W.E.D. (2005). Subverting out stories of subversion. In G. Davis, D. McAdam, W.R. Scott, \& M. Zald (Eds.), Social movements and organization theory (pp. 310-332). New York: Cambridge University.

Schneiberg, M., \& Soule, S. (2005). Institutionalization as a contested, multilevel process: The case of rate regulation in American fire insurance. In G. Davis, D. McAdam, W.R. Scott, \& M. Zald (Eds.), Social movements and organizational theory (pp. 122-160). New York: Cambridge University Press.

Shellenberger, M., \& Nordhaus, T. (2004). The death of environmentalism: Global warming politics in a post-environmental world. Retrieved from http://www.thebreakthrough.org/images/Death_of_Environmentalism.pdf 
Shellenberger, M., \& Nordhaus, T. (2011). Love your monsters: Postenvironmentalism and the anthropocene. Breakthrough Institute. Retrieved from http://thebreakthrough.org/index.php/programs/philosophy/love-yourmonsters-ebook

Shenton, A. (2004). Strategies for ensuring trustworthiness in qualitative research projects. Education for Information, 22(2), 63-75.

Sheppard, C. (1995). The shifting baseline syndrome. Marine Pollution Bulletin, 30(12), $766-767$.

Silverman, D. (2006). Interpreting qualitative data: Third edition. Thousand Oaks: Sage.

Snow, D., Soule, S., \& Kriesi, H. (Eds.). (2004). The Blackwell companion to social movements. Malden, MA: Blackwell.

Sokolowski, R. (2000). Introduction to phenomenology. Cambridge: Cambridge. University Press.

Speth, J.G. (2008). The bridge at the edge of the world: Capitalism, the environment, and crossing from crisis to sustainability. New Haven: Yale University Press.

Staggenborg, S. (2008). Social movements. Don Mills, Ontario: Oxford University Press.

Strang, D., \& Jung, D. (2005). Organizational change as an orchestrated social movement: Recruitment to a corporate quality initiative. In G. Davis, D. McAdam, W.R. Scott, \& M. Zald (Eds.), Social movements and organizational theory (pp. 280-309). New York: Cambridge University Press.

Strauss, W., \& Howe, N. (1991). Generations: The history of America's future, 1584 to 2069. New York: Harper Perennial. 
Talshir, G. (2004). The role of environmentalism: From the Silent Spring to the silent revolution. In M. Wissenburg \& Y. Levy (Eds.), Liberal democracy and environmentalism: The end of environmentalism? (pp. 10-31). London: Routledge.

Taylor, B. (2010). Dark green religion: Nature spirituality and the planetary future. Berkeley: University of California Press.

Tilly, C. (1984). Social movements and national politics. In C. Bright \& S. Harding (Eds.), Statemaking and social movements: Essays in history and theory (pp. 297-317). Ann Arbor: University of Michigan Press.

Tufford, L., \& Newman, P. (2012). Bracketing in qualitative research. Qualitative social work, 11(1), 80-96. doi: 10.1177/1473325010368316

Turner, C. (2007). The geography of hope: A tour of the world we need. Random House Canada.

United Nations Environment Programme. (2012). Measuring progress: Environmental goals \& gaps. Nairobi: UNEP. Retrieved from http://www.unep.org/geo/pdfs/ geo5/Measuring_progress.pdf

City of Vancouver. (2011). Greenest City 2020 Action Plan. Retrieved from http://vancouver.ca/green-vancouver/greenest-city-2020-action-plan.aspx

Wackernagel, M., \& Rees, W. (1996). Our ecological footprint: Reducing human impact on the earth. Gabriola Island, British Columbia: New Society Press.

Wartella, E., Vandewater, E., \& Rideout, V. (2005). Introduction: Electronic media use in the lives of infants, toddlers, and preschoolers. The American Behavioral Scientist, 48(1), 501-504. 
Wells, N.M. (2000). At home with nature: Effects of "greenness" on children's cognitive functioning. Environment and Behavior, 32(6), 775-795.

Wenz, P. (2007). Does environmentalism promote injustice for the poor? In R. Sandler \& P. Pezzullo (Eds.). Environmental justice and environmentalism: The social justice challenge to the environmental movement (pp. 57-83). Cambridge, Massachusetts: MIT Press.

Werbach, A. (2005). Where the environmental movement can and should go from here. Retrieved from http://www.grist.org/article/werbach-reprint

Wessel, D. (2010, April 7). Did “Great Recession" live up to the name? The Wall Street Journal, Retrieved from http://search.proquest.com.ezproxy.royalroads.ca/docview/237984272

Williams, R. (2005). The cultural contexts of collective action: Constraints, opportunities, and the symbolic life of social movements. In D. Snow, S. Soule, \& H. Kriesi (Eds.), The Blackwell companion to social movements (pp. 91-115). Malden, MA: Blackwell.

Wissenburg, M., \& Levy, Y. (2004). Liberal democracy and environmentalism: The end of environmentalism? London: Routledge.

Wohl, R. (1979). The generation of 1914. Cambridge, Massachusetts: Harvard University Press.

Worster, D. (1994). Nature's economy: A history of ecological ideas (2nd ed.). New York: Cambridge University Press.

Worthy, K. (2013). Invisible nature: Healing the destructive divide between people and the environment. Amherst: Prometheus. 
Young, J. (1990). Post environmentalism. London: Belhaven Press.

Zald, M., Morrill, C., \& Rao, H. (2005). The impact of social movement organizations: Environment and responses. In G. Davis, D. McAdam, W.R. Scott, \& M. Zald (Eds.), Social movements and organizational theory (pp. 253-279). New York: Cambridge University Press. 
Appendix A

Source of Participant Recommendations

\begin{tabular}{|c|c|c|c|}
\hline $\begin{array}{c}\text { Recommendation } \\
\text { Source }\end{array}$ & Field or Sector & $\begin{array}{l}\text { Location of } \\
\text { Source }\end{array}$ & $\begin{array}{c}\text { Number } \\
\text { Recommended }\end{array}$ \\
\hline $\begin{array}{l}\text { Academic } \\
\text { (University) }\end{array}$ & Sustainability & Lower Mainland & 2 \\
\hline $\begin{array}{l}\text { Academic } \\
\text { (University) }\end{array}$ & $\begin{array}{l}\text { Environmental } \\
\text { Education }\end{array}$ & $\begin{array}{l}\text { Southern } \\
\text { Vancouver Island }\end{array}$ & 2 \\
\hline $\begin{array}{l}\text { Academic } \\
\text { (University) }\end{array}$ & $\begin{array}{l}\text { Environmental } \\
\text { History }\end{array}$ & Lower Mainland & 3 \\
\hline $\begin{array}{l}\text { Academic } \\
\text { (Technical School) }\end{array}$ & $\begin{array}{l}\text { Resource } \\
\text { Management }\end{array}$ & Lower Mainland & 2 \\
\hline Community Leader & First Nations & North Coast & 1 \\
\hline Community Leader & First Nations & North Coast & 1 \\
\hline Consultant & $\begin{array}{l}\text { ENGO } \\
\text { Development }\end{array}$ & Lower Mainland & 1 \\
\hline $\begin{array}{l}\text { Organization } \\
\text { Leader }\end{array}$ & $\begin{array}{l}\text { Youth and } \\
\text { Nature }\end{array}$ & Lower Mainland & 4 \\
\hline $\begin{array}{l}\text { Organization } \\
\text { Leader }\end{array}$ & $\begin{array}{l}\text { Community } \\
\text { Engagement }\end{array}$ & Okanagan & 4 \\
\hline
\end{tabular}

Note. Academics are from two universities and one technical school; Community Leaders represent individuals with established profiles in their communities; Organizational Leaders are in leadership positions in youth-oriented organizations. ENGO is an environmental non-governmental organization. Location of Source represents areas in British Columbia. 


\section{Appendix $B$}

\section{Interview Guide}

\section{Introduction}

The purpose of these interviews is to understand how you define an environmental perspective, how you try to live a more sustainable life, and what stands in your way of doing so. The questions are designed to reveal your beliefs, values, hopes and fears from a generational perspective. No names will be attributed.

\section{Questions}

\section{Category 1: Background and experiences}

- Question 1: Tell me about your outdoor and nature experiences as a child?

○ Prompt - describe your favourite experience?

○ Prompt - how did you become interested in environmental issues?

\section{Category 2: Generational profile}

- Question 2: How would you describe your generation?

- Prompt for generational identification, how do you describe your generation?

- Prompt for positive descriptions (this is who we are) and negative (this is who we are not)

\section{Category 3: Explore the participant's environmental beliefs and motivations}

- Question 3: What is environmentalism to you?

- Question 4: What would a sustainable life look like for you? How would you live that way? 
- Question 5: What beliefs, values, or experiences motivate and shape your choice to live a sustainable life?

○ Prompt - how do the participants apply these values to their daily lives

- Question 6: What stands in the way of you doing so?

Category 4: How does the participant make sense of current environmental challenges and issues?

- Question 7: How do you perceive the current health or state of the environment?

○ Prompt for local and global perspectives

- Question 8: How do you feel about this?

- Prompt for emotional language

- Question 9: Do you think current environmental challenges could have been avoided?

- Prompt - looking for discussions on possible intergenerational tensions and conflicts

Category 5: How does the participant view the modern environmental movement?

- Question 10: How would you describe the environmental movement?

- Question 11: Is the environmental movement as effective as it could be?

Category 6: How does the participant envision the future of environmentalism?

- Question 12: How do you perceive the future of environmentalism? 
- Question 13: Are you pessimistic or optimistic this will occur?

- Prompt for emotional language

- Question 14: What would be needed to achieve the future you described? 